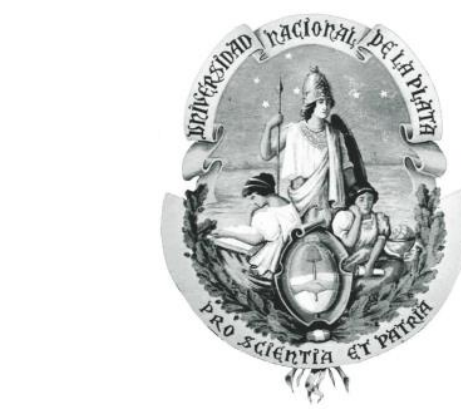

Universidad Nacional de La Plata

Facultad de ciencias médicas

\title{
EL CONSUMO DE TABACO DE LOS MÉDICOS GENERALISTAS, Y SU RELACIÓN CON LA CONSEJERÍA DE CESACIÓN DEL TABAQUISMO EN SUS PACIENTES, ARGENTINA 2011
}

\author{
Ruby Trejo Varón
}

Universidad Nacional De La Plata

Facultad de Ciencias Médicas 
EL CONSUMO DE TABACO DE LOS MÉDICOS GENERALISTAS, Y SU RELACIÓN CON LA CONSEJERÍA DE CESACIÓN DEL TABAQUISMO EN SUS PACIENTES, ARGENTINA 2011

Trabajo de Tesis para optar al título de

- Magister en Salud Pública -

Orientación: Sistemas municipales de salud.

Tesista: Lic, Esp. RUBY TREJO VARÓN

Director: MD, PhD, MPH NOËL CHRISTOPHER BARENGO

Co-Director: MD, MPH, MSc ALICIA ELENA BEATRIZLAWRYNOWICZ

La Plata, 2019 
Facultad de Ciencias Médicas

Universidad Nacional de La Plata

\title{
Autoridades
}

\author{
Decano \\ Prof. Dr. Juan Ángel BASUALDO FARJAT
}

Vicedecano

Prof. Dr. María Alicia MARINI

Secretarías

Secretaria General

Prof. Dra. Adriana MOISO

Secretaría de Asuntos Académicos

Prof. Dr. Mario Pedro SAN MAURO

Secretario de Ciencias Técnicas

Prof. Dra. María Virginia CROCE

Secretaría de Extensión Universitaria

Prof. Dr. Joaquín Ignacio CARA

Secretario en Redes en Salud

Dr. Sebastián Nicolás MURUA

Secretaria Docente Asistencial

Prof. Dra. Mónica Esther FERRERAS 


\section{DEDICADO A:}

Gabriela \& Mariano, mis hijos, los grandes amores de mi vida 


\section{AGRADECIMIENTOS}

Un inmenso agradecimiento para los Doctores Horacio Pracilio y Alicia Lawrynowicz, por su gran apoyo en este proceso académico de la maestría, por su paciencia y orientación en la culminación de la presente tesis.

A mi tutor, esposo, compañero y amor de mi vida, Noël Christopher Barengo, gracias por el soporte, dirección y acompañamiento para lograr finalmente esta tesis.

A mi amiga Lorena Lázaro-Cuesta, gracias por el gran apoyo y acompañamiento durante la fase de la maestría y mi estancia en Mar del Plata.

A la FAMG (Federación Argentina de Médicos Generalistas) y Adrián Alasino, por su infinita colaboración en el desarrollo y obtención de los resultados de mi tesis.

A los médicos que participaron en el diligenciamiento de la encuesta y entrevistas, gracias por la amabilidad y contribución al estudio.

Al Centro INUS por el apoyo otorgado durante el periodo académico. 


\section{TABLA DE CONTENIDO}



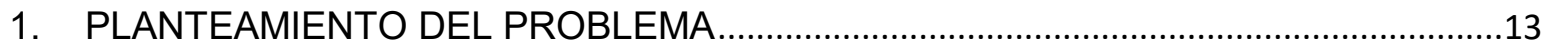

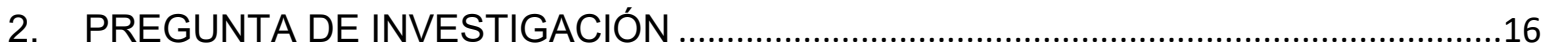

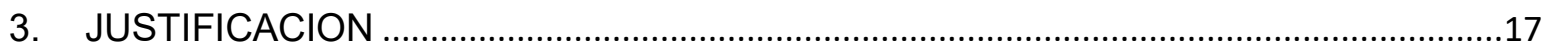

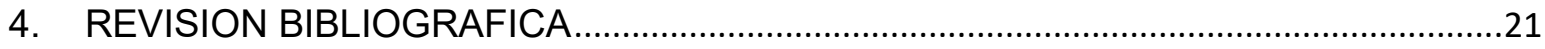

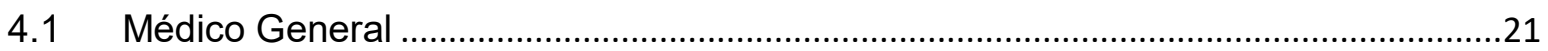

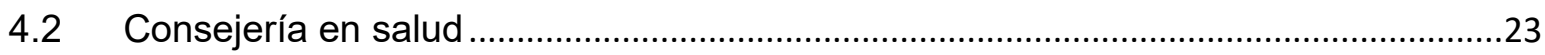

4.2.1 Consejería en cesación de tabaquismo...................................................................24

4.2.2 Etapas o fases de cambio .....................................................................................26

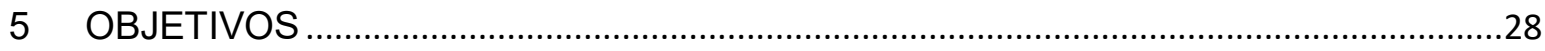

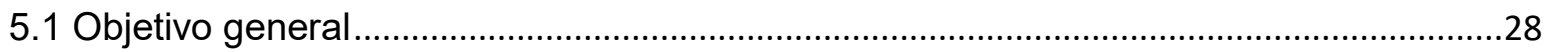

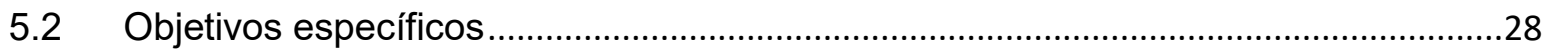

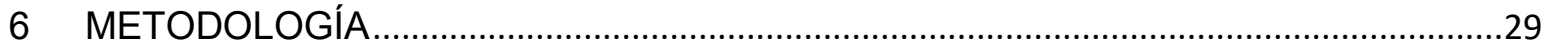

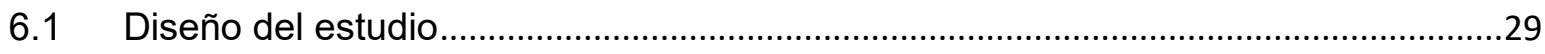

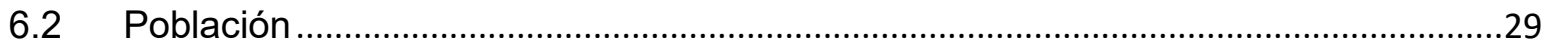

6.3 Muestra y cálculo de la muestra ………………………………………………......29

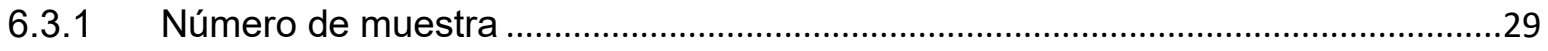

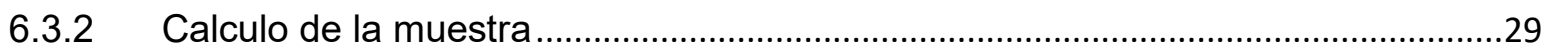

6.4 Criterios de inclusión y exclusión................................................................................30

6.4.1 Criterios de inclusión ...........................................................................................30

6.4.2 Criterios de exclusión .............................................................................................30

6.5 Características de la recolección de datos ...............................................................30

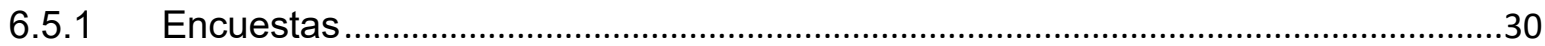

6.5.2 Entrevista - grupo focal....................................................................................

6.6 Instrumentos utilizados para la recolección de la información.......................................31

6.6.1 Definición de variables ......................................................................................3

6.7 Sistematización....................................................................................................

6.8 Tipo de análisis y forma de presentación ...................................................................41 


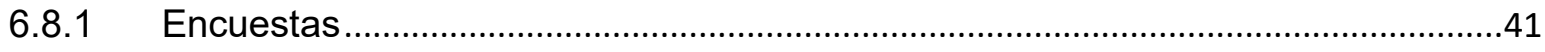

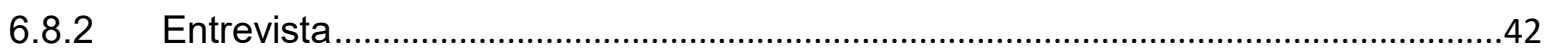

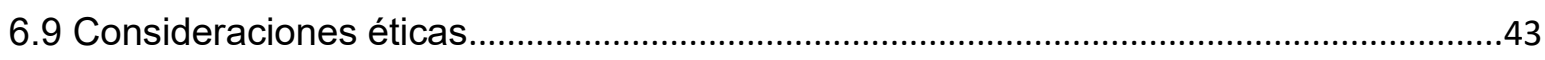



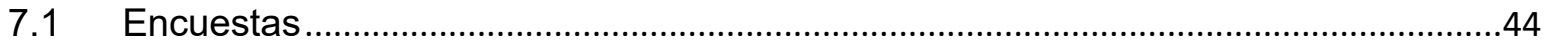

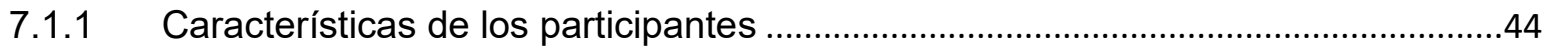

7.1.2 Consejería y prácticas del médico general de la FAMG sobre cesación de

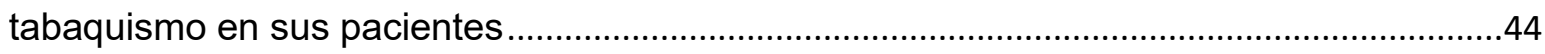

7.1.3 Barreras importantes percibidas por el médico general de la FAMG para dar consejería en cesación de tabaquismo a sus pacientes.

7.1.4 Creencias sobre la consejería de cesación de tabaquismo del médico general de la FAMG a sus pacientes.

7.1.5 Conocimientos sobre los efectos del tabaquismo de los médicos generales de la FAMG. 49

7.1.6 Relación entre el hábito de fumar del médico general de la FAMG y la consejería que realizan.

7.1.7 Relación entre el hábito de fumar del médico general de la FAMG y las creencias sobre la consejería de cesación de tabaquismo a sus pacientes.

Tabla 7. Relación entre el hábito de fumar del médico general de la FAMG y las creencias sobre la consejería de cesación de tabaquismo a sus pacientes. Argentina, 2011............52

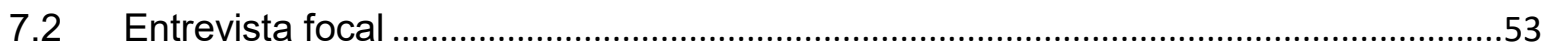

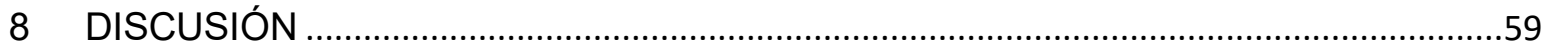

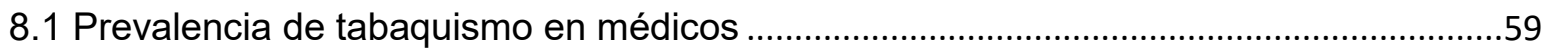

8.2 Consejería y prácticas del médico general de la FAMG sobre cesación de

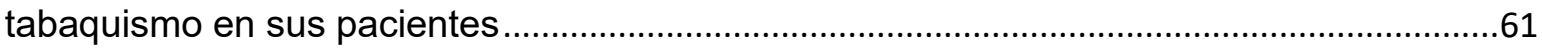

8.3 Barreras importantes percibidas por el MG de la FAMG para dar consejería en cesación de tabaquismo a sus pacientes.

8.4 Creencias sobre la consejería de cesación de tabaquismo del médico general de la FAMG a sus pacientes .65

8.5 Conocimientos sobre los efectos del tabaquismo de los médicos generales de la FAMG 66

8.6 Relación entre el hábito de fumar del médico general de la FAMG y la consejería que realizan. 
8.7 Relación entre el hábito de fumar del médico general de la FAMG y las creencias sobre la consejería de cesación de tabaquismo a sus pacientes ........................................71

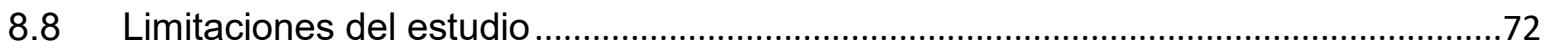

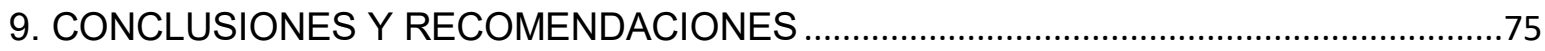

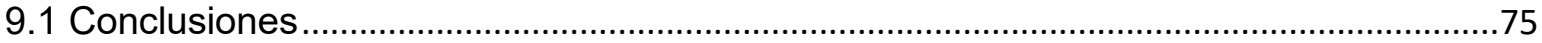

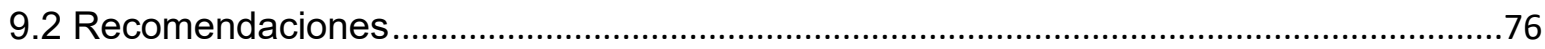

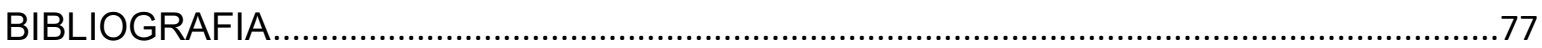




\section{ABREVIATURAS}

ALH: $\quad$ Ambiente Libre de Humo de tabaco.

AP: $\quad$ Atención Primaria

CDC: $\quad$ Centro de Control de Enfermedades de EE. UU.

CMCT: $\quad$ Convenio marco de la Organización Mundial de la Salud para el control del tabaco

CPHA: $\quad$ Asociación Canadiense de Salud Pública

Cultura

EE. UU: Estados Unidos

EMTA: Encuesta Mundial de Tabaquismo en Adultos (en inglés GATS).

EMTJ: $\quad$ Encuesta Mundial de Tabaquismo en Jóvenes (en inglés GYTS)

ENFR: $\quad$ Encuesta Nacional de Factores de Riesgo

ENS: $\quad$ Encuesta Nacional de Salud

ENT: $\quad$ Enfermedades No Trasmisibles

FAMG: $\quad$ Federación Argentina de Médicos Generales

FunPRECAL: Fundación para la prevención de las Enfermedades Crónicas no

GHPS: $\quad$ Global Health Professionals Survey Pilot Study

IBM: International Business Machines

IC Intervalo de Confianza

MG: $\quad$ Médico General

NA: $\quad$ No Aplica

NICE: National Institute for Health and Care Excellence

OMS: $\quad$ Organización Mundial de la salud

OPS: $\quad$ Organización Panamericana de la Salud

OR: $\quad$ Odds Ratio -

PNCT: $\quad$ Programa Nacional de Control del Tabaco

Ref: $\quad$ Grupo de Referencia

S.F: $\quad$ Sin fuente

SPSS: $\quad$ Statistical Package for the Social Sciences

TAMARA: Tabaquismo en médicos de la República Argentina 
Transmisibles en América Latina.

TRN: $\quad$ Terapia de Reemplazo de Nicotina

UNESCO: Organización de las Naciones Unidas para la Educación, la Ciencia y la

UNICEF: Fondo de las Naciones Unidas para la Infancia 


\section{RESUMEN}

INTRODUCCION: Los médicos generales juegan un papel importante en la reducción de la prevalencia del tabaquismo entre la población. Motivar a los fumadores para que dejen de fumar parece ser más complicado y requiere técnicas de asesoramiento especiales. Los médicos tienen la obligación ética de educar a sus pacientes sobre el tabaquismo y no debe dudar en informar sistemáticamente a dejar de fumar.

OBJETIVO: Investigar el consumo de tabaco de los médicos generales de la Federación Argentina de Medicina General (FAMG), y la relación de su consumo de tabaco con la consejería en la cesación del consumo de tabaco en sus pacientes en Argentina en el año 2011.

MATERIALES Y MÉTODOS: Estudio descriptivo, de las características de la consejería y barreras en la prescripción de la cesación del tabaquismo en los médicos generales de la Federación Argentina de Médicos Generales, participantes en el XXVI congreso anual.

Se tuvieron en cuenta dos tipos de muestra para esta investigación: una de tipo probabilística para abordar sobre los elementos en las decisiones y su relación con la propia práctica; la segunda muestra fue de las encuestas de participación que se obtuvieron de los médicos generales participantes en estudios de la FAMG. Para cumplir con los objetivos del trabajo de caracterizar la consejería e identificar las barreras, se aplicó una muestra intencional, en donde los médicos generales participantes presentaron las siguientes características: realizan la consejería en cesación del tabaquismo, contar con la disposición y tiempo para participar de la entrevista de grupo focal.

RESULTADOS Y DISCUSIÓN: Se analizó información de 119 participantes, por sexo los médicos fumadores correspondieron al $25 \%$ de los hombres y el $21 \%$ de las mujeres. El promedio de edad entre los participantes fue de 37 años para hombres y 34 para mujeres. Los médicos generales que fuman tuvieron una probabilidad más alta de aconsejar sobre cesación de tabaquismo en pacientes que se presentan sin enfermedades crónicas relacionadas comparando con los médicos que no fuman (Odds ratio 1.49; 95\% IC 2.2748.60). El hábito de tabaquismo no fue asociado con las creencias. $84 \%$ de las mujeres dan consejería sobre cesación de tabaquismo a pacientes que se presentan sin enfermedades crónicas relacionadas y un $96 \%$ a aquellos que se presentan con enfermedades crónicas. $79 \%$ de los hombres dan consejería sobre cesación de tabaquismo a pacientes que se presentan sin enfermedades crónicas relacionadas y todos a pacientes con enfermedades. Las barreras más frecuentes identificadas por los médicos generales eran la dificultad que los pacientes cambien sus hábitos ( $51 \%$ de las mujeres y $33 \%$ de los hombres) y que los pacientes no están interesados en mejorar sus hábitos (44\% de las médicas y $21 \%$ de los médicos). Un $88 \%$ de las mujeres y un $83 \%$ de los hombres estaban de acuerdo que necesitan entrenamiento en la prevención del tabaquismo. Existe un buen conocimiento sobre los efectos adversos del hábito de fumar en la patogenia de varias enfermedades.

CONCLUSIONES: El papel del médico dentro de la población en general sigue siendo pieza clave para el cambio de hábitos en las comunidades, de ahí que, si los médicos están entrenados y conscientes de los perjuicios que causa el tabaquismo, con su ejemplo en no fumar, se influiría positivamente en los cambios de hábitos. Es importante contar desde la formación académica con la enseñanza de los efectos perjudiciales del tabaquismo. El 
fenómeno del tabaquismo está contribuyendo a una epidemia, donde no solo la persona que realiza el consumo afecta su salud, sino también el entorno que lo rodea.

PALABRAS CLAVE: Médico; prescripción; consejería; tabaquismo; Argentina. 


\section{PLANTEAMIENTO DEL PROBLEMA}

De acuerdo con los Centros para el Control y la Prevención de Enfermedades CDC, el tabaco y su consumo son la principal causa prevenible de cáncer y de muertes por esta enfermedad. Este consumo puede causar no solo cáncer de pulmón, sino también cáncer de boca y garganta, laringe, esófago, estómago, riñón, páncreas, hígado, vejiga, cuello uterino, colon y recto, y un tipo de leucemia. Se estima que todos los años en EE. UU. 660000 personas reciben un diagnóstico de algún cáncer relacionado con el consumo de tabaco y 343000 mueren por esta misma causa [1].

Las cifras estiman que desde 1990 se han evitado más de 1 millón de muertes por cánceres relacionados con el tabaco, en su mayoría debido a programas integrales de control del tabaco, detección temprana del cáncer y las mejoras en el tratamiento contra esta enfermedad [1], por tanto se demuestra que aunando esfuerzos involucrando al estado, sectores como educación y salud, se puede invertir en programas integrales que se dirijan a la población, para que menos personas consuman tabaco y así contribuir a la disminución de este tipo de enfermedades que contribuyen a la carga de enfermedad y muerte. Sin embargo, cerca de 6 millones de defunciones prematuras se producen anualmente a nivel mundial, con desplazamiento de esta epidemia hacia los países de menor desarrollo económico [2].

En Argentina, según la encuesta nacional de tabaquismo en adultos realizada en 2012, la mortalidad asciende a más de 40.000 personas cada año, esto debido a la presencia de enfermedades no transmisibles (ENT), como el cáncer, enfermedades cardiovasculares y respiratorias, adicionalmente aporta a la pérdida de 824.804 años de vida saludables, ajustados a discapacidad [3]. Así mismo los costos de salud asociados directamente al tabaco igualan a lo recaudado por impuestos a los productos del tabaco [4]. Los médicos a menudo se consideran como modelos a seguir, y se espera que muestren responsabilidad respecto al comportamiento en salud. Su papel como ejemplo se ha sugerido que tienen una influencia positiva en el comportamiento de riesgo de la población general.

En la Argentina, para el 2012, se presentó una prevalencia de tabaquismo del $22,3 \%$, mayor en varones $(29,6 \%)$ que en mujeres $(15,7 \%)$. El $73,6 \%$ de los fumadores 
había planeado o estaba pensando en dejar de fumar, y el 48,6\% había hecho un intento el último año [5].

Existen algunos estudios escandinavos que realizaron medición de la prevalencia del tabaquismo, describiendo el comportamiento de los médicos con respecto al hábito de fumar y de la población general en estos países, se demostraron cambios favorables está prevalencia disminuyó entre los médicos de 1951 a 1989 [6]. En Finlandia, entre 1990-2001, demostraron que la prevalencia de tabaquismo entre los médicos de ese país fue relativamente baja y no ha evidenciaron patrones de cambio desde 1995, así mismo concluyeron que la reducción adicional en el hábito de fumar diario y ocasional requiere un enfoque diferente, especialmente ajustado y dirigido por el médico [7]. Se podría pensar que hubo mejor comprensión de los efectos negativos para la salud del hábito de fumar, mejor intercambio de información y las nuevas políticas de salud en materia de control del tabaco en los últimos 10 años, esto tendría que haber tenido un impacto más favorable sobre la conducta de fumar, especialmente entre los médicos bien educados.

Encuestas de tabaquismo entre los médicos, han demostrado ser útiles en destacar la importancia de los médicos como agentes clave en campañas contra el tabaquismo y dejar de fumar $[8,9,10]$. Se ha demostrado que cuando se informa por parte de un médico o se da consejos para dejar de fumar, la proporción de fumadores que logran dejar de fumar aumenta $[9,11,12,13]$. La evidencia reciente indica que el firme, incluso breve asesoramiento, para dejar de fumar puede conducir a un aumento de largo plazo, las tasas de abandono de alrededor de 1-2\% [14,15]. Sin embargo, se informó también que, si un médico no aconseja a un paciente que deje de fumar, este depende del consumo de tabaco de ese médico particular $[11,12,16]$. Existe el riesgo de que el consejo de médicos fumadores se vea afectado por su evaluación individual de las consecuencias para la salud del hábito de fumar, que podría no estar de acuerdo con la evidencia. Esto podría dar lugar a un incorrecto consejo o ningún asesoramiento a los pacientes [17]. Además, no parece haber una relación entre el tabaquismo, el comportamiento de los médicos y de sus conocimientos médicos y actitudes hacia el tabaco [12].

La calidad de vida se extiende como efecto al dejar de fumar [18]. Los médicos deben hacer todo para que sus pacientes fumadores, y aquellos que fuman mucho, estén dispuestos a dejar de hacerlo; en la consulta médica deben de orientar charlas para explicar a cada paciente fumador las medidas para la cesación del hábito, incluyendo las razones médicas y el cambio favorable de su salud futura. Esta breve charla difícilmente tarda más 
de dos minutos [18]. Un asesoramiento más detallado, sólo será necesario si el paciente está listo para dejar el hábito de fumar [19,20].

Motivar a los fumadores que no desean dejar de fumar parece ser más complicado y requiere técnicas de asesoramiento especiales [18]. Los médicos deben tener una obligación ética de educar a sus pacientes sobre el tabaquismo y no deben dudar en aconsejar sistemáticamente a dejar de fumar [14].

Los médicos generales (MGs) juegan un papel importante en la reducción de la prevalencia del tabaquismo entre la población. Sin embargo, el asesoramiento de fumar parece ser afectado por sus conocimientos, habilidades y actitudes con respecto a dejar de fumar [21]. Además, el tabaquismo propio del médico "ha sido quien se interpone para restringir el asesoramiento a sus pacientes para dejar de fumar [22]. Por otra parte, el comportamiento de fumar en los médicos ha demostrado influir en la conducta de fumar de sus pacientes [23]. A pesar de que el consejo de un médico de cabecera para dejar de fumar aumenta significativamente las tasas de abandono entre los pacientes que fuman, fumar no es discutido durante la mayoría de las consultas de rutina con fumadores.

Es importante investigar este tema y sensibilizar al personal médico en la Argentina, en la gran tarea hacia la cesación del tabaquismo y la promoción del no consumo de tabaco, Casi el $80 \%$ de los más de mil millones de fumadores que hay en el mundo viven en países de ingresos bajos o medios, según la Organización Mundial de la Salud OMS, el tabaco mata alrededor de la mitad de los fumadores, cada año mueren alrededor de 7 millones de personas, de las que más de 6 millones son consumidores del producto y alrededor de 890 000 son no fumadores, expuestos al humo de tabaco ajeno [24].

Se espera que los resultados de esta investigación aporten a la academia e instituciones como la FAMG en el fortalecimiento del papel del médico y su gran responsabilidad hacia a la promoción y prevención, consejería de hábitos y estilos de vida saludables; así mismo que sea un insumo para la construcción de políticas saludables. 


\section{PREGUNTA DE INVESTIGACIÓN}

¿Existe una relación entre el consumo de tabaco de los médicos generales y la consejería para la cesación del tabaquismo en sus pacientes en Argentina en el 2011? 


\section{JUSTIFICACION}

El médico es identificado como un actor que trabaja para favorecer los procesos de salud. Su primer título otorgado es de médico con un perfil profesional que lo lleva a desenvolverse en diferentes campos laborales y en diferentes funciones. Una de ellas está dirigida a la atención primaria, donde sus acciones generan un alto grado de compromiso y requieren de una formación adecuada [25].

Tradicionalmente el médico se forma en función a la atención del individuo enfermo. Desde hace varios años este enfoque se ha ampliado para formar médicos en tres aspectos: individuo, familia y comunidad en un todo, llevando a la medicina general y especializada a ver al hombre en forma íntegra. Visto de esta forma este profesional viene a ser el contacto entre la medicina y la comunidad, así como garante del acceso permanente de sus adscritos [26].

Este enfoque integral lleva a la necesidad de crear y formar al especialista en medicina familiar o integral, donde se reconozca dentro del equipo de trabajo con iguales condiciones tanto con los médicos de otras especialidades como los otros profesionales con que interactúa [26].

La Sociedad Española de Medicina Familiar y Comunitaria define esta especialidad como: Una parte de la medicina que tiene su propio campo de conocimiento y metodología; además un marco propio de actuación de la medicina de familia, evoluciona desde la medicina general a establecer un cuerpo doctrinal definido por unos valores profesionales y un perfil de competencia propio, tiene un vasto campo de los conocimientos, buscando integrar de una manera amplia los conocimientos de las distintas ramas de la medicina, además un marco propio de actuación en la atención primaria de salud aplicando lo aprendido en el primer nivel de asistencia (s.f).

Particularmente el médico general en Argentina se considera como un especialista en Medicina General Integral, desempeñándose en la comunidad, asumiendo tareas de promover y proteger la salud, prevenir enfermedades prevalentes, diagnosticar y tratar a los individuos de esa comunidad que se enferma (Federación Argentina de Medicina General, s.f). 
Un especialista de primer nivel de atención, donde sus principios se basan en la integralidad, continuidad, interés y servicio personalizado para el cuidado no solo del individuo sino también de la familia ofreciendo servicios de prevención, diagnóstico, tratamiento o rehabilitación [27]. Igualmente manifiesta que el profesional que se forma en esta especialización entre sus prácticas efectúa la prevención de enfermedades, la promoción de salud, prevención primaria y modificación de los riesgos, estilos de vida y comportamientos no saludables, así mismo el diagnóstico de manejo de enfermedades crónicas no transmisibles que se enmarca en otro nivel de la prevención [27].

EI MG es un profesional especializado en brindar cuidado primordial de la salud de óptima calidad científica y humana, a personas y familias en todas las etapas del ciclo vital individual y familiar, quienes lo consideran su consejero médico de confianza. Asume la responsabilidad por el cuidado continuo, integral, personalizado, accesible y comprometido de todos los problemas de salud y enfermedad que los afectan, resuelve los mismos mediante sus propios servicios, o en base a la consulta oportuna con otros integrantes del equipo interdisciplinario de salud. Trabaja con el equipo de salud en la solución de los problemas de su comunidad y coordina el proceso de atención de las personas bajo su responsabilidad a través de todos los niveles del sistema de salud [28].

El evidenciar a este actor en salud como un agente dentro de la atención primaria, que aporta a la solución de problemáticas de salud pública dentro de un sistema de salud propio de un país, es además identificado como la primera persona a recurrir por parte de la comunidad cuando presenta algún tipo de intervención en salud realzando aún más su importancia.

El accionar del MG por tanto en la atención primaria cumple un papel fundamental en la comunidad ante las diferentes problemáticas en salud existentes, que parten desde la promoción en salud hasta la prevención y particularmente en las ENT, reconocidas a nivel mundial por ser actualmente la principal causa de morbilidad y mortalidad según la OMS [29]. Se plantean que la revolución tecnológica e industrial favorecen al desarrollo de diferentes factores que producen riesgos y elevados costos para la sociedad por la alta mortalidad e invalidez, llevando a que los diferentes países dirijan su accionar en salud, hacia la promoción en salud, buscando constantemente diferentes estrategias para que la población adopte y mantenga hábitos saludables [30].

Por otra parte, se considera que el estilo de vida es la forma más útil para conocer a la persona, donde se involucran los aspectos cognitivos de la conducta. Adicionalmente 
se encuentra que dentro de sus funciones está el organizar y simplificar, construir mitos sobre la autoimagen y la imagen del mundo, además de tener un efecto auto protector en el sujeto [31].

Tomando este concepto de estilo de vida se considera que cada persona genera una identificación y se caracteriza por medio de éste, llegando a afectar su salud por medio de sus diferentes formas de actuar, vivenciar y/o desenvolverse en su entorno. Así mismo será un ideal para los hábitos saludables con miras a disminuir la probabilidad de desencadenar una ENT. La importancia de intervenir con los estilos de vida radica en ser una de las acciones más eficaces para prevenir la enfermedad y la promoción de la salud, haciendo del médico y su práctica esenciales para cumplir con dichos accionares [32].

Para lograr en la población una prevención de las ENT, el accionar del MG dentro de la atención primaria es prioritaria, donde las estrategias para la modificación de hábitos de vida como por ejemplo el consumo de tabaco, ha cobrado gran interés en el papel del personal de salud y especialmente del rol del médico en el estilo de vida sus pacientes [33].

En esta tarea del médico ante las ENT y modificación de hábitos de vida en sus pacientes se identifica la consejería preventiva como el medio para trabajar. La consejería igualmente cobra mayor valor al ser una herramienta de la atención primaria en salud reconocida por la OMS. Dicha herramienta es descrita en inglés como "counseling" (OMS, 1998) y tiene diversas virtudes, mencionando que su quehacer, no es simplemente el hecho de aconsejar, tiene una labor de escucha, de entender a la persona y guiarla para mantener o mejorar su actual estado de salud. Por tanto, se muestra a la consejería con una estructura que requiere ser identificada y reconocida (OMS, 1998).

Aun existiendo estudios en consejería y sus resultados positivos para la salud [34], existen también otros que indican que la recomendación para asesorar de forma rutinaria a todos los fumadores para dejar de fumar ha sido cuestionada, debido a un posible deterioro de la relación médico - paciente [35]. Sin embargo, se ha demostrado que los pacientes se preocupan por su estilo de vida y ven con agrado el correspondiente asesoramiento por personal de salud [36]. En general, la prevalencia de asesoramiento a todos los fumadores para dejar de fumar, identificados en la mayoría de los países todavía está por debajo del $50 \%[37,38,39]$ y, por tanto, es difícil predecir o medir, cómo la implementación de estas recomendaciones podría afectar la relación médico-paciente.

Varios estudios han reportado que el tabaquismo y la actitud hacia el tabaco influye en el entusiasmo de los médicos para dar consejo antitabaco a sus pacientes [40, 41]. Es 
más probable que médicos no fumadores aconsejen a sus pacientes dejar de fumar (86\%) que los médicos que fuman $(70 \%)[3,41]$. 


\section{REVISION BIBLIOGRAFICA}

\subsection{Médico General}

El médico general es identificado como un actor especialista en la atención primaria en salud, así mismo es definido por la Federación Argentina de Médicos Generales (FAMG), "Es un médico especialista de medicina General Integral. Quien forma parte de un grupo interdisciplinario que tiende a tratar al individuo de manera integral y personalizada, teniendo en cuenta su entorno social y sanitario estando capacitado para comprender otras realidades sociales y sanitarias donde deba desempeñarse en el futuro" [Federación Argentina de Médicos Generales, s.f. FAMGV]

La FAMG también manifiesta que en la práctica profesional el MG trabaja en la comunidad asumiendo la tarea de promover y proteger la salud, prevenir las enfermedades prevalentes, diagnosticar y tratar a los individuos de esa comunidad que enferman de forma continua e integral. Entre otras de sus funciones se concibe aplicando estrategias para el primer nivel de atención de la salud, enfatizando en promoción y prevención FAMG, s.f].

Estas acciones en la Atención Primaria en Salud se conciben desde 1978 con la Conferencia Internacional sobre Atención Primaria de Salud de Alma-Ata, organizada por la Organización Mundial de la Salud (OMS), Organización Panamericana de la Salud (OPS)

y El Fondo de Naciones Unidas para la Infancia (UNICEF) quienes la definieron como "La asistencia sanitaria esencial basada en métodos y tecnologías prácticas, científicamente fundadas y socialmente aceptables, puesta al alcance de todos los individuos y familias de la comunidad mediante su plena participación y a un costo que la comunidad y el país puedan soportar, en todas y cada una de la etapas de su desarrollo... Así mismo afirma que una atención debe prestar servicios de promoción y prevención" [42]. Esta definición conlleva a la identificación de diferentes términos a los cuales se pretende tener un acercamiento conceptual con el fin de dimensionar las acciones del médico y relacionarlo finalmente con la consejería en salud.

Se comienza definiendo la promoción de la salud la cual se describe en la carta de Ottawa como "El proceso de capacitar a las personas para que aumenten el control sobre su salud, 
y para que la mejoren. Para alcanzar un estado adecuado del bienestar físico, metal y social". Por su parte el salubrista Henry Sigerst [2001] lo describe como un proceso de educación en salud, donde el personal de salud es responsable, capaz de aconsejar y ayudar a mantener la salud y a su restauración [43].

En cuanto a la prevención se menciona que está dirigida a prevenir la enfermedad y a favorecer la salud. Esta se divide en tres:

1. La prevención primaria definida como el programa de actividades dirigidas a la mejora del bienestar general, además ofrece protección específica en determinadas enfermedades.

2. La prevención secundaria se centra en el diagnóstico precoz, la utilización de servicios de consulta y la rápida intervención.

3. Finalmente, la prevención terciaria se ocupa de la rehabilitación del paciente y potencializar su estado para que no recurra la enfermedad [44].

Así mismo en estos diferentes accionares por parte del médico se busca que un individuo se capacite para el control de su salud, requiriendo acciones puntuales por parte del profesional, haciendo así necesaria la educación en salud. La educación en salud es una ganancia cualitativa del ser humano, lo cual muestra un sentido positivo de ayuda y una potenciación de la persona para la gestión de su propia salud, promoviendo comportamientos que lleven a forma de vida más saludable [45], así mismo la educación es un proceso que debe ayudar a la persona a lo largo de la vida a conocerse así mismo para generar cambios, donde el "educador" influye directamente. Evidenciando por tanto al médico como un educador dentro de su práctica médica [45]. En este proceso de educación aplicable en las intervenciones de atención primaria en salud, y por ende de promoción y prevención, se identifica el término de consejería descrito como un elemento de la educación, el cual debería ser utilizado en las acciones de salud [46]. 


\subsection{Consejería en salud}

Este término se describe como: "Un elemento de la educación para trasmitir conocimientos sobre salud y enfermedad, desarrollar habilidades en el cuidado de estas e igualmente promover cambios conductuales hacia estilos de vida saludables" [46].

Existen evidencias de que los tratamientos para la cesación de tabaquismo pueden ayudar a reducir la carga de enfermedades asociadas con este factor de riesgo en personas fumadoras. Por lo que se considera la consejería, la terapia farmacológica y la combinación de estas alternativas como una eficacia demostrada para la cesación del tabaquismo [47]

La OPS, 2005, menciona a la consejería como un proceso interactivo que involucra a un consejero profesionalmente capacitado y a un cliente que tiene el propósito de mejorar el nivel de funcionamiento. Donde el consejero y el cliente trabajan en conjunto ayudando el primero a crecer al segundo y donde se trabaja en base a objetivos. De igual manera se muestra al cliente nuevas formas de interpretar y manejar situaciones problemáticas enseñándole a utilizar los recursos internos y externos [48].

Un elemento para enfatizar es aquel que hace referencia a un consejero profesionalmente capacitado, donde el entrenamiento cobra importancia en estos profesionales permitiendo un médico seguro de su accionar y transmisor de mensajes adecuados. Es así que el entrenamiento o capacitación puede hacer referencia a congresos, jornadas, conferencias, curso y algunas otras actividades, llevando a desarrollar profesionales más competentes, capaces, líderes y seguros [49]. El entrenamiento o capacitación permitirá una fortaleza en el conocimiento; así como un proceso natural de nuestra mente, la cual comienza conociendo una realidad en concreta [50].

Otros atributos de la consejería los menciona la OPS en al año 2005, donde describe el encuentro, en donde el proveedor actúa como facilitador de cambios comportamentales en el individuo, ayudando a resolver un problema en una atmósfera comprensiva. También manifiesta que la consejería se centra en problemas de comportamiento específicos o en desafíos en la vida cotidiana más que en cambios de personalidad, se describe a un consejero como un apoyo en los procesos como el escuchar. Adicionalmente uno de los beneficios que se presentan en la consejería es su funcionalidad en los problemas de salud, tanto física y también psico-social. 
La Organización de las Naciones Unidas para la Educación, la Ciencia y la Cultura - UNESCO, en 1999 describe a el consejero como un ser que debe de tener la "capacidad para responsabilizarse de la salud", incorporando la importancia de la seguridad en la toma de decisiones propias en relación con esta, además tener los conocimientos y habilidades necesarias para poder participar en la toma de decisiones. Este expuesto incorpora la lectura de información referente a la salud, actualización constante y la utilización de esta información adecuadamente, convirtiéndola en conocimiento.

\subsubsection{Consejería en cesación de tabaquismo}

La consejería, entendida como la orientación, y el apoyo para dejar de fumar, es considerada como una intervención de primera línea y su uso sistemático debe ser propuesto en todo fumador y en cada contacto con los servicios de salud [51]. Viéndose como una actividad comunicativa entre el profesional de la salud y el paciente, donde se promueve el desarrollo de herramientas que motiven a dejar de fumar. Intercambiando información, mensajes verbales, o definida también como toda intervención comportamental para la cesación del tabaquismo [47].

La consejería puede ser aplicada por un profesional de salud que esté capacitado. Una vez que se identifica al fumador, esta intervención es considerada como comportamental inicial para la cesación del tabaco. Esta puede ser realizada en menos de 10 minutos y en un episodio único [52]. La consejería breve o corta es la intervención que se debe brindar de manera inicial una vez se identifique la adicción. No obstante, The National Institute for Health and Care Excellence - NICE, del Reino Unido, considera como breves aquellas intervenciones hasta de 30 minutos e incluye en este concepto acciones diferentes de consejería realizables en ese tiempo [47].

El tamizaje se evalúa como intervención breve, debido a que es la base para iniciar la cesación y tiene efecto sobre el comportamiento del profesional de la salud [47].

La consejería intensiva, se debe basar en más de diez minutos, dividida en cuatro sesiones o más, en ocasiones se denomina "intervención comportamental", refiriéndose a la acción no farmacológica sobre conductas de riesgo [53]. 
Lo anterior sugiere que la consejería breve no es intervención comportamental, lo cual no coincide con su propósito, igual que puede decirse en este caso de la terapia farmacológica [47].

Existen varios métodos estructurados, que pueden servir de guía para realizar estas intervenciones breves de consejería contra el tabaquismo, éstas orientan en el proceso correcto para conversar con los pacientes acerca del consumo de tabaco y ofrecer asesoramiento como la estrategia de las $5 \mathrm{As}$ y la estrategia de las $5 \mathrm{Rs}$ [52].

La estrategia de la 5As: sirve para ayudar a las personas a abandonar el tabaco. Consta de cinco pasos (Averiguar, Aconsejar, Evaluar, Ayudar y Organizar) y resume todas las actividades que un prestador de atención primaria puede hacer para ayudar a un consumidor de tabaco, puede ser aplicado entre 3 - 5 minutos. Este modelo puede guiarlo a través del proceso correcto para hablar con los pacientes que están listos para dejar el tabaco [54].

Estrategia de las 5R: sirve para aumentar la motivación para dejar de fumar. Esta estrategia, es útil para trabajar con aquellas personas que no desean hacer el intento de dejar de fumar "ahora". Consiste en una intervención motivacional que se puede implementar después de haber AVERIGUADO que el paciente es fumador y que no está motivado para dejar de fumar, al menos no antes de un mes, y se emplea al ACONSEJAR. Permite personalizar el consejo y ayuda a aumentar el nivel de motivación hacia la cesación del consumo [54].

En general, el principal objetivo de toda intervención breve consiste en ayudar al paciente a que comprenda el riesgo que implica consumir tabaco y así mismo enseñarle y que entienda los beneficios de abandonar el consumo, a fin de motivarlo para que intente dejar de fumar [52]. Es posible emplear estas intervenciones breves para inducir a los fumadores a solicitar una derivación a un especialista o aceptar que se les indique un tratamiento más intensivo en el caso de ser necesario. Se estima que alrededor del $40 \%$ de los consumidores de tabaco hacen algún intento de abandonar el consumo en respuesta al consejo de un médico [52], por tanto, se debe de incorporar esta estrategia dentro de la consulta médica. 


\subsubsection{Etapas o fases de cambio}

Actualmente uno de los modelos más usados para explicar un cambio de comportamiento, en la adicción al tabaco, es el modelo transteórico del cambio de comportamiento en saludMT, este modelo explica el cambio del comportamiento según cinco variables, categorizándose de la siguiente manera [55]:

Pre-contemplación: Es la etapa en la cual las personas no tienen intención de cambiar, de realizar una acción específica de cambio en su comportamiento de riesgo para la salud, usualmente en el lapso de los siguientes seis meses $[55,56]$. En este grupo se encuentran parte de población con una adicción que no poseen información sobre las consecuencias a corto, mediano o largo plazo de su adicción o comportamiento, así como gran parte de pacientes que en algún momento intentaron dejar el consumo y fracasaron $[55,56]$.

Por lo general las personas que se encuentran en este grupo, evitan leer, hablar y pensar sobre sus comportamientos de riesgo que podrían ser modificados; están a la defensiva por las presiones sociales para cambiar y, principalmente, no están ni motivados ni interesados en participar en programas o intervenciones de promoción o educación en salud $[55,56]$.

Contemplación: Es la etapa en la que la persona tiene una intención de cambio y, potencialmente, hará un intento formal de modificar su comportamiento en los próximos meses. Estos individuos están conscientes de los beneficios del cambio, pero no asumen directamente el compromiso para actuar en este sentido, ellos pueden estar por largos periodos de tiempo en esta etapa contemplando la opción de cambio por un largo tiempo, "diciéndose a sí mismos que van a cambiar algún día" [55, 56].

Preparación: En esta etapa las personas ya toman una decisión de cambio y tienen un compromiso propio para hacerlo; realizan pequeños cambios e intentan efectivamente cambiar en el futuro inmediato, regularmente los próximos 30 días. Personas en preparación, por lo general, ya tienen experiencias concretas con relación al cambio, principalmente en el último año calendario y, además, tienen una conciencia muy definida sobre los pros de cambiar su comportamiento. Estas personas tienen un plan para actuar o participar de alguna actividad, por lo cual tienen un gran potencial para participar en 
programas orientados a la acción y son las típicamente reclutadas por las intervenciones $[55,56]$.

Acción: Es la etapa en la que las personas realizan cambios objetivos, mesurables y exteriorizados de su comportamiento, regularmente en un período de tiempo que varía de uno a seis meses. La etapa de acción es realmente observable. Las personas en esta etapa tienen una valoración muy grande de los pros de cambiar y demuestran un nivel mayor de autoeficacia, aquí ocurren los diversos procesos de cambio, es ideal para intervenir en la población en general. Sin embargo, esta etapa es reconocida como inestable por el potencial de recaída o la rápida progresión a la etapa de mantenimiento $[55,56]$.

Mantenimiento: Es caracterizada por las tentativas de estabilización del cambio comportamental ya manifestado. Es un período que incluye al menos seis meses después del cambio observable, aquí los individuos trabajan activamente en la prevención de la recaída o el relapso, usando una variada y específica serie de procesos de cambio. En esta etapa las personas tienen cada vez menos tentación por volver al comportamiento modificado y aumentan progresivamente su autoconfianza para mantener el cambio comportamental. Esta etapa dura regularmente de seis meses a dos años $[55,56]$.

Terminación: Esta fase es la última en el proceso, aquí las personas no tienen tentaciones de ninguna naturaleza con relación al hábito del cigarrillo, existe un real cambio y tienen una total confianza, de autoeficacia frente a situaciones que previamente eran tentadoras $[55,56]$.

Por lo general se sabe que el llegar del todo a una cesación tabáquica no es fácil, es un proceso en donde debe existir un compromiso total del individuo y un acompañamiento constante del personal de salud $[55,56]$. 


\section{OBJETIVOS}

\subsection{Objetivo general}

Investigar el consumo de tabaco de los médicos generales de la Federación Argentina de Médicos Generales - FAMG, y la relación de su consumo de tabaco con la consejería en la cesación del consumo de tabaco en sus pacientes en Argentina en 2011.

\subsection{Objetivos específicos}

- Describir la consejería del MG de la FAMG sobre cesación de tabaquismo en sus pacientes.

- Identificar las barreras percibidas por el MG de la FAMG para dar consejería en cesación de tabaquismo a sus pacientes.

- Indagar sobre sus creencias sobre la consejería de cesación de tabaquismo del MG de la FAMG a sus pacientes.

- Indagar sobre los conocimientos sobre la temática en cesación de tabaquismo de los MG de la FAMG.

- Indagar la relación entre la realización del hábito de fumar del MG de la FAMG y la consejería que realizan. 


\section{METOdologíA}

\subsection{Diseño del estudio}

Tipo de diseño exploratorio.

Responde también a un estudio descriptivo, ya que se describirán las características de la consejería y barreras en la prescripción de la cesación del tabaquismo en los médicos generales con su respectiva triangulación.

\subsection{Población}

Participantes registrados en el XXVI Congreso anual de la FAMG.

\subsection{Muestra y cálculo de la muestra}

\subsubsection{Número de muestra}

EI XXVI congreso de la FAMG celebrado en octubre del 2011 con una inscripción de 660 médicos generales. Los participantes llegaron de las siguientes provincias del país: Buenos Aires, Santa Fe, Tucumán, La Pampa, Neuquén, Corrientes, Córdoba, Río negro, Tierra de fuego, Chubut, Santiago del Estero, San Luis. Santa Cruz, Chaco, Catamarca, Entre Ríos.

\subsubsection{Calculo de la muestra}

Se aplicaron dos tipos de muestra para esta investigación.

Un tipo de muestra fue probabilístico [57], para aportar a los elementos en las decisiones y su relación con la práctica teniendo la libertad de participar en el estudio los médicos generalistas, se contó con la participación de 119 médicos.

Así mismo para enriquecer la caracterización de la consejería, trabajo e identificación de las barreras, se aplicó una muestra a conveniencia [57], donde los médicos generalistas participantes presentaran las siguientes características: haber participado en el XXVI congreso anual de la FAMG, realizar consejería en cesación de tabaquismo, tener 
disposición y tiempo para participar de la entrevista de grupo focal, identificándose 9 voluntarios participantes.

\subsection{Criterios de inclusión y exclusión}

\subsubsection{Criterios de inclusión}

Médicos generales participantes del XXVI. Congreso anual Miembro de la FAMG en Mar del Plata, Argentina en 2011.

\subsubsection{Criterios de exclusión}

Médicos Generales, quienes no quisieron participar en la encuesta.

Encuestas con datos incompletos, respeto a las variables para el análisis de este estudio.

\subsection{Características de la recolección de datos}

\subsubsection{Encuestas}

La encuesta fue suministrado a los médicos generales participantes en el congreso, el cuestionario fue diligenciado por 119 médicos, para una tasa de respuesta de $18 \%$.

La encuesta se distribuyó a la totalidad de participantes del evento, estas preguntas allí incorporadas fueron tomadas de la Encuesta Global de Profesionales de la Salud, desarrollada y validada por la Organización Mundial de la Salud (OMS), los Centros para el Control y la Prevención de Enfermedades (CDC) y la Asociación Canadiense de Salud Pública (CPHA) en 2005, en donde se recopilaron datos sobre el uso del tabaco y el asesoramiento para dejar de fumar entre los estudiantes de profesión de la salud en todos los estados miembros de la OMS.

Global Health Professionals Survey Pilot Study, 10 Countries, 2005 (GHPS), este estudio consistió en 16 encuestas realizadas en 10 países, incluido Argentina, en donde participaron en el proceso de validación un total de 348 estudiantes de medicina. El GHPS se desarrolló entre estudiantes de tercer año en cuatro disciplinas de profesión de la salud (odontología, medicina, enfermería y farmacia) durante el primer trimestre de 2005 [58]. 
La información analizada en esta investigación se obtuvo del cuestionario para profesionales médicos, de Argentina, que se diseñó para la recolección de información relacionada con actividad física y tabaquismo, las preguntas que allí se encontraban se tomaron de la Encuesta Global de Profesionales de la Salud (GHPS).

El diligenciamiento de la encuesta fue en papel y electrónicamente, a través de los participantes del XXVI congreso de la FAMG. El diligenciamiento de la encuesta en forma virtual se llevó a cabo a través de la plataforma del programa SurveyMonkey https://www.surveymonkey.com/s/FAMG, para los médicos que asistieron a este congreso, pero no completaron la encuesta en papel.

\subsubsection{Entrevista - grupo focal}

Adicionalmente para favorecer la caracterización de la consejería y la identificación de barreras se tuvo la participación de nueve médicos generales para dinámica de grupo focal. Se identificaron 9 participantes a través de una muestra a conveniencia, a ellos se les realizo una entrevista, bajo la metodología de grupo focal, con el fin de caracterizar la consejería e identificar las barreras, en esta entrevista se tuvo en cuenta el interés de los médicos generales participantes sobre el tema de cesación de tabaquismo y buscando que cumplieran con las siguientes características: Que realicen la consejería en cesación del tabaquismo y que contaran con la disposición y tiempo para participar de la entrevista de grupo focal.

\subsection{Instrumentos utilizados para la recolección de la información}

Se entregó a cada médico general participante en el XXVI congreso de la FAMG, una encuesta estructurada en papel para su auto diligenciamiento de manera física; posterior al congreso a las personas que no habían diligenciado se dio la oportunidad de realizarlo de manera virtual, a través de la plataforma SurveyMonkey; dicho instrumento incorporo preguntas cerradas, estas preguntas se justificaron por el material bibliográfico, Global Health Professionals Survey Pilot Study, cuyo estudio incorporo a la Argentina. Así la siguiente referencia bibliográfica hace mención de la validación y aplicación del material usado, dentro de las más relevantes se encuentran en la siguiente descripción [59, 60, 61]. 
1. National cancer Institute, National Institute of diabetes and digestive and kidney disease, National Institute of Child Health and Human Development, Office of behavioral and Social Sciences Research and centers for Disease Control and Prevention. Physician Survey of Practices on Diet, Physical Activity, and Weight Control.

2. Centre for Physican Health and Well-being. Canadian physician Health Study 20072008.

3. Frank, Segura Health practices of Canadian Physicians publicado por la revista Canadian Family Physician.

La traducción de las preguntas estuvo a cargo por los investigadores de la universidad de los andes Colombia y el CDC.

Se resalta que la Argentina participo en la fase de validación de las preguntas que fueron usadas en esta investigación; esta participación se dio en el desarrollo de la investigación Health Professionals Survey Pilot Study [58, 62].

Para la aplicación del instrumento en Argentina se contó con un equipo de trabajo liderado por Dr. Felipe Lobelo miembro del CDC, Dr. Noël C. Horacio Boggiano presidente FAMG, Lorena Ramírez, estudiante de Doctorado y encargada del componente actividad física y consejería de esta temática, y Ruby Trejo, investigadora, responsable de este trabajo en el tema de cesación de tabaquismo y consejería de esta temática. Estas personas trabajaron en dicho instrumento para avalarlo y realizar su aplicación, basándonos en el estudio piloto Global Health Professionals Survey.

En forma general la encuesta incorporo varias secciones, entre ellas una introducción donde se hizo referencia al decreto 995 del 2000 en respuesta a esta investigación, donde se realzo la importancia del médico en el quehacer de la promoción y prevención, así como la necesidad de conocer sus hábitos y prácticas, se describió el porqué del diligenciamiento del instrumento.

Finalmente, para dar cierre a la introducción se muestra la existencia de un equipo de trabajo que participo en este estudio haciendo referencia a FAMG, FunPRECAL y el Centers for Disease Control and Prevention (CDC). 
Es importante resaltar que el instrumento plantea diferentes temáticas relacionadas con hábitos en salud, siendo estos la alimentación, tabaquismo y realización de actividad física. Igualmente indaga sobre la temática de consejería. De igual manera para el cumplimiento de los objetivos planteado en esta investigación se centró las temáticas de cesación de tabaquismo y su consejería.

\subsubsection{Definición de variables}

Este estudio uso datos de la encuesta cuantitativa aplicada y de la entrevista al grupo focal.

A continuación, se menciona el ítem de las preguntas que responden a los objetivos de esta investigación, que se encuentran en el instrumento (ver anexo $N^{\circ} 1$ )

\begin{tabular}{|c|c|}
\hline 1.1 Año Nacimiento & Numérico, año \\
\hline \multirow{3}{*}{ 1.2 Sexo } & 1: F - Femenino \\
\hline & 2: M - Masculino \\
\hline & 14: No responde \\
\hline \multirow{6}{*}{ 1.3 Estado civil } & 1: Casado(a) \\
\hline & 2: Soltero(a) \\
\hline & 3: Unión libre \\
\hline & 4: Separado(a) \\
\hline & 5: Viudo(a) \\
\hline & 14: No responde \\
\hline \multirow{3}{*}{ 1.4 Tiene hijos } & 1: No \\
\hline & $2: \mathrm{Si}$ \\
\hline & 14: No responde \\
\hline \multirow{4}{*}{$\begin{array}{l}\text { 4.1(c) ¿Que tanto entrenamiento recibió } \\
\text { en aconsejar a sus pacientes cesación } \\
\text { de tabaquismo? }\end{array}$} & 1: Ninguno \\
\hline & 2: Alguno \\
\hline & 3: Mucho \\
\hline & 14: No responde \\
\hline \multirow{6}{*}{$\begin{array}{l}\text { 4.2.b ¿En pacientes sin enfermedades } \\
\text { crónicas relacionadas con peso, con } \\
\text { dieta poco saludable, inactividad, } \\
\text { sobrepeso, que tan seguido da } \\
\text { consejería cesación de tabaquismo? }\end{array}$} & 1: Siempre \\
\hline & 2: Casi siempre \\
\hline & 3: Algunas veces \\
\hline & 4: Casi nunca \\
\hline & 5: Nunca \\
\hline & 14: No responde \\
\hline \multirow{3}{*}{$\begin{array}{l}\text { 4.3.f ¿En pacientes con enfermedades } \\
\text { crónicas relacionadas con peso, con } \\
\text { dieta poco saludable, inactividad, }\end{array}$} & 1: Siempre \\
\hline & 2: Casi siempre \\
\hline & 3: Algunas veces \\
\hline
\end{tabular}




\begin{tabular}{|c|c|}
\hline $\begin{array}{l}\text { sobrepeso, que tan seguido da } \\
\text { consejería cesación de tabaquismo? }\end{array}$ & $\begin{array}{l}\text { 4: Casi nunca } \\
\text { 5: Nunca } \\
\text { 14: No responde }\end{array}$ \\
\hline $\begin{array}{l}\text { 4.6.a ¿Si usted evalúa el consumo de } \\
\text { tabaco de sus pacientes? ¿Hace } \\
\text { preguntas generales si fuma o no? }\end{array}$ & $\begin{array}{l}\text { 1: Si } \\
\text { 0: No } \\
\text { 14: No responde }\end{array}$ \\
\hline $\begin{array}{l}\text { 4.6.b ¿Si usted evalúa el consumo de } \\
\text { tabaco de sus pacientes? ¿Hace } \\
\text { preguntas generales de los } \\
\text { comportamientos asociados? }\end{array}$ & $\begin{array}{l}\text { 1: Si } \\
\text { 0: No } \\
\text { 14: No responde }\end{array}$ \\
\hline $\begin{array}{l}\text { 4.6.c ¿Si usted evalúa el consumo de } \\
\text { tabaco de sus pacientes? ¿Hace } \\
\text { preguntas generales acerca de intentos } \\
\text { dejar de fumar? }\end{array}$ & $\begin{array}{l}\text { 1: Si } \\
\text { 0: No } \\
\text { 14: No responde }\end{array}$ \\
\hline $\begin{array}{l}\text { 4.6.d ¿Si usted evalúa el consumo de } \\
\text { tabaco de sus pacientes? Hace } \\
\text { preguntas generales acerca del número } \\
\text { de cigarrillos diarios/ fumados en la } \\
\text { vida/intentos de dejar de fumar? }\end{array}$ & $\begin{array}{l}\text { 1: Si } \\
\text { 0: No } \\
\text { 14: No responde }\end{array}$ \\
\hline $\begin{array}{l}\text { 4.6.e ¿Si usted evalúa el consumo de } \\
\text { tabaco de sus pacientes? Utiliza } \\
\text { cuestionario estandarizado? }\end{array}$ & $\begin{array}{l}\text { 1: Si } \\
\text { 0: No } \\
\text { 14: No responde }\end{array}$ \\
\hline $\begin{array}{l}\text { 4.6.f Si usted evalúa el consumo de } \\
\text { tabaco de sus pacientes y usa otra } \\
\text { pregunta, especificar }\end{array}$ & $\begin{array}{l}\text { 1: Si } \\
\text { 0: No } \\
\text { 14: No responde } \\
\text { Especificar: }\end{array}$ \\
\hline $\begin{array}{l}\text { 4.9.c ¿Usted ha prescrito alguna vez } \\
\text { tratamiento farmacológico para dejar } \\
\text { fumar? }\end{array}$ & $\begin{array}{l}\text { 1: Si } \\
\text { 0: No } \\
\text { 14: No responde }\end{array}$ \\
\hline $\begin{array}{l}\text { 4.9.d ¿Usted ha prescrito alguna vez o } \\
\text { actualmente a referido tratamiento } \\
\text { psiquiátrico-psicológico para dejar de } \\
\text { fumar? }\end{array}$ & $\begin{array}{l}\text { 1: Si } \\
\text { 0: No } \\
\text { 14: No responde }\end{array}$ \\
\hline
\end{tabular}




\begin{tabular}{|c|c|}
\hline \multirow{5}{*}{$\begin{array}{l}\text { 5.1.a Barreras para la evaluación y } \\
\text { manejo tabaquismo. } \\
\text { No tengo suficiente tiempo }\end{array}$} & 1: Barrera importante \\
\hline & 2: Barrera moderada \\
\hline & 3: Barrera menor \\
\hline & 4: No es una barrera \\
\hline & 14: No responde \\
\hline \multirow{5}{*}{ 5.1.b No es parte de mi trabajo } & 1: Barrera importante \\
\hline & 2: Barrera moderada \\
\hline & 3: Barrera menor \\
\hline & 4: No es una barrera \\
\hline & 14: No responde \\
\hline \multirow{5}{*}{$\begin{array}{l}\text { 5.1.c No estoy lo suficientemente } \\
\text { entrenado en esta área }\end{array}$} & 1: Barrera importante \\
\hline & 2: Barrera moderada \\
\hline & 3: Barrera menor \\
\hline & 4: No es una barrera \\
\hline & 14: No responde \\
\hline \multirow{5}{*}{$\begin{array}{l}\text { 5.1.d Es muy difícil evaluar y manejar } \\
\text { estos temas }\end{array}$} & 1: Barrera importante \\
\hline & 2: Barrera moderada \\
\hline & 3: Barrera menor \\
\hline & 4: No es una barrera \\
\hline & 14: No responde \\
\hline \multirow{5}{*}{$\begin{array}{l}\text { 5.1.e No hay un adecuado pago por este } \\
\text { tipo de actividades. }\end{array}$} & 1: Barrera importante \\
\hline & 2: Barrera moderada \\
\hline & 3: Barrera menor \\
\hline & 4: No es una barrera \\
\hline & 14: No responde \\
\hline \multirow{5}{*}{$\begin{array}{l}\text { 5.1.f Falta de sistemas adecuados de } \\
\text { referencia para estos temas. }\end{array}$} & 1: Barrera importante \\
\hline & 2: Barrera moderada \\
\hline & 3: Barrera menor \\
\hline & 4: No es una barrera \\
\hline & 14: No responde \\
\hline \multirow{5}{*}{$\begin{array}{l}\text { 5.1.g Los pacientes no están } \\
\text { interesados en mejorar sus hábitos. }\end{array}$} & 1: Barrera importante \\
\hline & 2: Barrera moderada \\
\hline & 3: Barrera menor \\
\hline & 4: No es una barrera \\
\hline & 14: No responde \\
\hline \multirow{5}{*}{ 5.1.h Temor de ofender a un paciente } & 1: Barrera importante \\
\hline & 2: Barrera moderada \\
\hline & 3: Barrera menor \\
\hline & 4: No es una barrera \\
\hline & 14: No responde \\
\hline \multirow{2}{*}{$\begin{array}{l}\text { 5.1.i Es muy difícil para los pacientes } \\
\text { cambiar sus hábitos. }\end{array}$} & 1: Barrera importante \\
\hline & 2: Barrera moderada \\
\hline
\end{tabular}




\begin{tabular}{|c|c|}
\hline & $\begin{array}{l}\text { 3: Barrera menor } \\
\text { 4: No es una barrera } \\
\text { 14: No responde }\end{array}$ \\
\hline \multirow{5}{*}{$\begin{array}{l}\text { 5.1.j Falta de herramientas adecuadas y } \\
\text { de información para darle a los } \\
\text { pacientes. }\end{array}$} & 1: Barrera importante \\
\hline & 2: Barrera moderada \\
\hline & 3: Barrera menor \\
\hline & 4: No es una barrera \\
\hline & 14: No responde \\
\hline \multirow{5}{*}{$\begin{array}{l}\text { 5.1.k Falta de opciones de tratamiento } \\
\text { efectivas. }\end{array}$} & 1: Barrera importante \\
\hline & 2: Barrera moderada \\
\hline & 3: Barrera menor \\
\hline & 4: No es una barrera \\
\hline & 14: No responde \\
\hline \multirow{6}{*}{ 5.1.I Otra / especificar } & 1: Barrera importante \\
\hline & 2: Barrera moderada \\
\hline & 3: Barrera menor \\
\hline & 4: No es una barrera \\
\hline & 14: No responde \\
\hline & Descripción de barrera \\
\hline \multirow{3}{*}{$\begin{array}{l}6.3 \text { ¿Ha fumado usted al menos } 100 \\
\text { cigarrillos en su vida? }\end{array}$} & $1: \mathrm{Si}$ \\
\hline & 2: No \\
\hline & 14: No responde \\
\hline \multirow{4}{*}{$\begin{array}{l}6.4 \text { ¿Actualmente fuma usted cigarrillos } \\
\text { todos los días, algunos días o no fuma? }\end{array}$} & 1: Todos los días \\
\hline & 2: Algunos días \\
\hline & 3: No fumo \\
\hline & 14: No responde \\
\hline \multirow{5}{*}{6.5 ¿Cuándo usted dejo de fumar? } & 1: Hace $<1$ año \\
\hline & 2: 1 a 2 años atrás \\
\hline & 3: De 3 a 5 años atrás \\
\hline & 4: Hace mas de 5 años \\
\hline & 14: No responde \\
\hline \multirow{2}{*}{$\begin{array}{l}\text { 6.6 En promedio, en el último mes en } \\
\text { los días que fumo, ¿cuántos cigarrillos } \\
\text { se fumó al día? }\end{array}$} & Número: \\
\hline & 14: No responde \\
\hline $\begin{array}{l}6.15 \text { ¿Cuál de las siguientes } \\
\text { afirmaciones describe mejor su } \\
\text { situación actual? (Marque con una X) }\end{array}$ & $\begin{array}{l}\text { 1: Si fumo y no tengo } \\
\text { intención de dejar de fumar } \\
\text { en } 6 \text { meses. } \\
2: \text { Si fumo, estoy } \\
\text { considerando seriamente } \\
\text { dejar de fumar en los } \\
\text { próximos } 6 \text { meses. } \\
\text { 3: Si fumo, pero he decidido } \\
\text { dejar de fumar en los } \\
\text { próximos } 30 \text { días }\end{array}$ \\
\hline
\end{tabular}


4: Soy ex fumador. Dejé de fumar hace menos de 6 meses

5: Soy ex fumador. Dejé de fumar hace más de 6 meses.

6: Nunca he fumado

14: No responde

1: Fuertemente en desacuerdo

Creencias personales y conocimientos. 8.1.b(d) Tendré la capacidad de aconsejar a mis pacientes de una forma más coherente y efectiva su yo no fumo?

2: En desacuerdo

3: Ni en acuerdo ni en desacuerdo

4: De acuerdo

5: Fuertemente de acuerdo

14: No responde

1: Fuertemente en desacuerdo

2: En desacuerdo

8.1.e(d) Existen estrategias y/o herramientas efectivas para ayudar a los pacientes a dejar de fumar.

3: Ni en acuerdo ni en desacuerdo

4: De acuerdo

5: Fuertemente de acuerdo

14: No responde

1: Fuertemente en desacuerdo

2: En desacuerdo

8.1.f(d) Tengo confianza en mí habilidad para aconsejar a mis pacientes sobre el tabaquismo.

3: Ni en acuerdo ni en desacuerdo

4: De acuerdo

5: Fuertemente de acuerdo

14: No responde

1: Fuertemente en desacuerdo

2: En desacuerdo

8.1.g(d) Soy efectivo en ayudar a mis pacientes a la cesación del tabaquismo.

3: Ni en acuerdo ni en desacuerdo

4: De acuerdo

5: Fuertemente de acuerdo

14: No responde

1: Fuertemente en desacuerdo

8.1.h Doctores necesitan más

2: En desacuerdo entrenamiento en prevención

3: Ni en acuerdo ni en desacuerdo

4: De acuerdo

5: Fuertemente de acuerdo 
14: No responde

1: Fuertemente en desacuerdo

2: En desacuerdo

8.1.i) La prevención es menos

3: Ni en acuerdo ni en interesante que el tratamiento desacuerdo

4: De acuerdo

5: Fuertemente de acuerdo

14: No responde

1: Fuertemente en

desacuerdo

2: En desacuerdo

8.1.j Pacientes no están interesados en la prevención

3: Ni en acuerdo ni en desacuerdo

4: De acuerdo

5: Fuertemente de acuerdo

14: No responde

1: Fuertemente en desacuerdo

2: En desacuerdo

8.1.k Acceso al sistema de salud básico es un derecho humano fundamental

3: Ni en acuerdo ni en desacuerdo

4: De acuerdo

5: Fuertemente de acuerdo

14: No responde

1: Fuertemente en

8.1.I Tengo el tiempo adecuado para desacuerdo dedicar a mi paciente durante la consulta

2: En desacuerdo

3: Ni en acuerdo ni en desacuerdo

4: De acuerdo

5: Fuertemente de acuerdo

14: No responde

1: Fuertemente en desacuerdo

8.1.m Tengo la libertar de tomar las decisiones para cumplir las necesidades de mis pacientes

2: En desacuerdo

3: Ni en acuerdo ni en desacuerdo

4: De acuerdo

5: Fuertemente de acuerdo

14: No responde

1: Fuertemente en desacuerdo

8.1.n Es posible brindarles atención de alta calidad a todos mis pacientes

2: En desacuerdo

3: Ni en acuerdo ni en desacuerdo

4: De acuerdo 
5: Fuertemente de acuerdo

14: No responde

8.14. Falso o verdad.

El cigarrillo es una causa contributaria importante en la patogénesis de las siguientes enfermedades.

\begin{tabular}{|c|c|}
\hline \multirow{3}{*}{ 8.14. a) Cáncer de vejiga } & 1: Falso \\
\hline & 2: Verdadero \\
\hline & 14: No responde \\
\hline \multirow{3}{*}{ 8.14. b) Bronquitis crónica } & 1: Falso \\
\hline & 2: Verdadero \\
\hline & 14: No responde \\
\hline \multirow{3}{*}{ 8.14. c) Cáncer de piel } & 1: Falso \\
\hline & 2: Verdadero \\
\hline & 14: No responde \\
\hline \multirow{3}{*}{ 8.14.d) Cáncer de cavidad oral } & 1: Falso \\
\hline & 2: Verdadero \\
\hline & 14: No responde \\
\hline \multirow{3}{*}{ 8.14.e) Enfermedad de Alzaheimer } & 1: Falso \\
\hline & 2: Verdadero \\
\hline & 14: No responde \\
\hline \multirow{3}{*}{ 8.14. f) Enfisema pulmonar } & 1: Falso \\
\hline & 2: Verdadero \\
\hline & 14: No responde \\
\hline \multirow{3}{*}{ 8.14. g) Enfermedad coronaria } & 1: Falso \\
\hline & 2: Verdadero \\
\hline & 14: No responde \\
\hline \multirow{3}{*}{ 8.14. h) Cáncer de laringe } & 1: Falso \\
\hline & 2: Verdadero \\
\hline & 14: No responde \\
\hline \multirow{6}{*}{$\begin{array}{l}\text { 8.15 Para que una persona que deja de } \\
\text { fumar alcance la cifra de mortalidad de } \\
\text { los no fumadores se requiere. }\end{array}$} & 1: $1-5$ años \\
\hline & 2. 5-10 años \\
\hline & 3: $20-30$ años \\
\hline & $\begin{array}{l}\text { 4. Tiempo proporcional al } \\
\text { que fumo }\end{array}$ \\
\hline & 5. No se \\
\hline & 14: No responde \\
\hline \multirow{4}{*}{$\begin{array}{l}8.16 \text { ¿Qué porcentaje se aproxima más } \\
\text { a la prevalencia de tabaquismo en la } \\
\text { población Argentina? }\end{array}$} & $1: 10 \%$ \\
\hline & 2. $20 \%$ \\
\hline & 3. $30 \%$ \\
\hline & 4. $40 \%$ \\
\hline
\end{tabular}


5. $50 \%$

6. No sé

14: No responde

\begin{tabular}{|c|c|}
\hline $\begin{array}{l}8.17 \text { Con respecto a los fumadores } \\
\text { pasivos conteste Falso o Verdadero. } \\
\text { Los niños que son fumadores pasivos } \\
\text { tienen mayor riesgo de morir. }\end{array}$ & $\begin{array}{l}\text { 1: Falso } \\
\text { 2: Verdadero } \\
\text { 3: No se } \\
\text { 14: No responde }\end{array}$ \\
\hline $\begin{array}{l}\text { 8.17 Con respecto a los fumadores } \\
\text { pasivos conteste Falso o Verdadero. } \\
\text { Los niños que son fumadores pasivos } \\
\text { tienen mayor riesgo de desarrollar } \\
\text { infecciones de oído }\end{array}$ & $\begin{array}{l}\text { 1: Falso } \\
\text { 2: Verdadero } \\
\text { 3: No se } \\
\text { 14: No responde }\end{array}$ \\
\hline $\begin{array}{l}\text { 8.17 Con respecto a los fumadores } \\
\text { pasivos conteste Falso o Verdadero. } \\
\text { Los fumadores pasivos tienen } 20 \% \text { más } \\
\text { de riesgo de sufrir cáncer de pulmón } \\
\text { que los no fumadores }\end{array}$ & $\begin{array}{l}\text { 1: Falso } \\
\text { 2: Verdadero } \\
\text { 3: No se } \\
\text { 14: No responde }\end{array}$ \\
\hline $\begin{array}{l}\text { 8.17 Con respecto a los fumadores } \\
\text { pasivos conteste Falso o Verdadero. } \\
\text { Los fumadores pasivos tienen } 30 \% \text { más } \\
\text { de riesgo de sufrir de enfermedad } \\
\text { cardiaca que los no fumadores }\end{array}$ & $\begin{array}{l}\text { 1: Falso } \\
\text { 2: Verdadero } \\
\text { 3: No se } \\
\text { 14: No responde }\end{array}$ \\
\hline
\end{tabular}

Las variables cuantitativas basadas en el cuestionario aplicado fueron: variables sociodemográficas, la consejería en cesación del tabaquismo, con dimensiones de presencia, evaluación, creencias, práctica y conocimientos. Con la existencia de variables dicotómicas y politómicas.

El segundo instrumento aplicado se llevó a cabo a través de la entrevista semi estructurada, aplicada por medio de la dinámica de grupo focal, las preguntas realizadas respondieron de acuerdo al marco teórico y al cumplimiento de los objetivos de esta parte de la investigación. Las preguntas fueron las siguientes:

¿Cuáles son los parámetros a tener en cuenta en los pacientes para realizar la consejería sobre cesación de tabaquismo?

¿Ustedes realizan consejería en cesación de tabaquismo en todas las consultas con los pacientes? 
¿Ustedes como definen la consejería sobre tabaquismo

¿Qué rol o participación cumple el paciente dentro de la consejería que ustedes realizan?

¿Dentro de la consulta que ustedes realizan cuento tiempo le dedican a la consejería?

¿Cuáles considera usted como criterios o pasos específicos que tienen en cuenta dentro de la consejería?

¿Ustedes han recibido algún entrenamiento para realizar consejería de este tipo?

¿Ustedes cuales creen que deberían de ser los criterios mínimos para aconsejar este tipo de intervención, y lograr una cesación tabáquica?

¿Qué barreras perciben dentro de la consulta para realizar este tipo de consejería?

¿Que los motivaría para que realicen este tipo de intervenciones?

\subsection{Sistematización}

La sistematización de la encuesta se realizó con la incorporación de los resultados en una matriz de datos específica en Microsoft Office Excel 2007.

El material obtenido de las entrevistas a través de grabación, se incorporaron por medio de la transcripción textual de las respuestas dadas por los 9 participantes, estas respuestas fueron abiertas.

\subsection{Tipo de análisis y forma de presentación}

\subsubsection{Encuestas}

Para la encuesta se realizó un diseño cuantitativo con la presentación de tablas pertinentes para el estudio de acuerdo a las variables objeto de análisis. 
El análisis de los datos fue realizado utilizando el programa IBM SPSS Statistics versión 20. Los resultados se presentan en términos descriptivos, mostrando la frecuencia de cada una de las categorías. Para el análisis descriptivo de las variables se determinaron la media, deviación estándar y frecuencias. Se aplicó la prueba de la Chi-Cuadrado y prueba de Fischer para comparar variables categóricas. Se aplicó un diagnóstico de colinealidad entre las variables.

Se usaron modelos de regresión logística ajustado por edad para investigar las asociaciones entre el tabaquismo de los médicos, la consejería que realizan y las creencias sobre la consejería de cesación de tabaquismo a sus pacientes. Se presentan los odds ratios y los intervalos de confianza de $95 \%$. Dado que no se encontraron diferencias en la distribución de las variables según sexo, y que sexo no tuvo una asociación estadísticamente significativa con las variables dependientes, no se estratifico por esta variable. Para el nivel de significación estadística se definió un valor $p<0,05$.

\subsubsection{Entrevista}

Por su parte, para la entrevista bajo la metodología de grupo focal, se realizaron preguntas estructuradas en el tema de tabaquismo y cesación tabáquica, con el fin de obtener respuestas abiertas que complementaran el abordaje del análisis cualitativo.

Para el desarrollo de este análisis, se tuvo en cuenta las respuestas dadas por los participantes, nueve médicos participantes del congreso, quienes fueron elegidos de manera intencional. Durante la entrevista la investigadora sirvió de moderadora, y las preguntas que se realizaron a los participantes fueron revisadas previamente con un grupo de médicos generales de la FAMG, que estaban a cargo de la organización del congreso, con quienes además se revisó toda la metodología de desarrollo de la investigación dentro del congreso.

Esta entrevista de grupo focal se realizó en un lugar diferente al lugar donde se realizaba en congreso, así como en un horario donde no había actividades programadas en el mismo.

Después de realizar la entrevista se revisó el material grabado con el fin de verificarlo y tener la certeza de la grabación. A través de este se evidenciaron las percepciones u opiniones de los médicos generales, analizando así información de primera fuente. 


\subsection{Consideraciones éticas}

El proyecto fue avalado por la Comisión de Evaluación del Doctorado de Ciencias de la Salud del Instituto Universitario de Ciencias de la Salud Fundación H.A Barceló, Buenos Aires, Argentina. La encuesta fue de carácter confidencial, sin mencionar información que comprometa al participante. Al final de la encuesta se estableció la autorización para usar la información recolectada en investigaciones por parte de la FAMG, así como datos específicos del participante en caso de que este quisiera que lo contactáramos nuevamente para una investigación futura.

La información recolectada para este estudio permanecerá bajo carácter estrictamente confidencial, y toda la información personal que de ello se genere se tratará conforme a la Ley Habeas Data (Decreto 995 de 2000) [63], por lo tanto, su almacenamiento y administración se realizará conforme a dicha normatividad, siguiendo así las normativas de Buenas Prácticas Clínicas de la Declaración de Helsinki (Anexo № 2) y lo establecido en la reglamentación del Ministerio de Salud de la Nación Argentina, a través de la guía de buenas prácticas de investigación clínica en seres humanos, aprobada por Resolución $\mathrm{N}^{\circ}$ 1490 del 14 de noviembre de 2007, siguiendo su lema "Que toda investigación que involucra seres humanos debe basarse en valores éticos fundados en el respeto por la dignidad de las personas, el bienestar y la integridad física y mental de quienes participan en ella" [64]. 


\section{RESULTADOS}

\subsection{Encuestas}

\subsubsection{Características de los participantes}

Las características de los participantes del estudio según sexo en 2011 están presentadas en la Tabla 1. Aquí no se observaron diferencias en el promedio de edad entre los médicos femeninos y masculinos (34 años vs. 37 años). Tampoco se observaron diferencias en la distribución de los hábitos de tabaquismo entre las mujeres y los hombres (valor p 0.751). Mientras un $54 \%$ de los médicos varones eran no fumadores y un $25 \%$ fumadores actuales, las prevalencias correspondientes en las mujeres fueron de $49 \%$ (no fumadores) y $21 \%$ (fumadores).

Tabla 1. Características y hábitos tabáquicos de los participantes del estudio según sexo. Argentina, 2011.

\begin{tabular}{|c|c|c|c|c|c|}
\hline \multirow[b]{2}{*}{ Edad (años, DS) } & \multicolumn{2}{|c|}{ Hombres (N=24) } & \multicolumn{2}{|c|}{ Mujeres (N=57) } & \multirow{2}{*}{$\begin{array}{c}\text { valor } \mathbf{p} \\
0.078\end{array}$} \\
\hline & 37 & $(8)$ & 34 & (7) & \\
\hline Tabaquismo & $\%$ & (n) & $\%$ & (n) & 0.751 \\
\hline No fumador & 54 & $(13)$ & 49 & $(28)$ & \\
\hline Ex fumador (dejaron a fumar desde $>1$ año) & 21 & (5) & 30 & $(17)$ & \\
\hline Fumador actual & 25 & $(6)$ & 21 & $(12)$ & \\
\hline
\end{tabular}

Fuente: Elaboración propia en base a datos de encuesta.

\subsubsection{Consejería y prácticas del médico general de la FAMG sobre cesación de tabaquismo en sus pacientes}

En la consejería del médico general de la FAMG sobre cesación de tabaquismo en sus pacientes (Tabla 2). No se observaron diferencias entre Consejería y prácticas del médico 
general de la FAMG sobre cesación de tabaquismo en sus pacientes entre hombres y mujeres (Tabla 2). Todos valores de $\mathrm{p}$ de la prueba de $\mathrm{X}^{2}$ eran muy superiores a 0.05 . Un $84 \%$ de las médicas dan consejería sobre cesación de tabaquismo a pacientes que se presentan sin enfermedades crónicas relacionadas y un $96 \%$ a aquellos que se presentan con enfermedades crónicas. Mientras tanto, un $79 \%$ de los médicos ofrecen consejería sobre cesación de tabaquismo a pacientes que se presentan sin enfermedades crónicas relacionadas y todos a pacientes con enfermedades crónicas.

Respecto a si los médicos de la FAMG evalúan el consumo de tabaco de sus pacientes haciendo preguntas generales si el paciente fuma, se notó que nueve de diez médicas y ocho de cada diez médicos lo practican siempre o casi siempre. En relación a la evaluación del consumo de tabaco de sus pacientes haciendo preguntas generales de los comportamientos asociados, cuatro de cada cinco médicos lo hacen siempre o casi siempre. Un $84 \%$ de los médicos generales de la FAMG evalúan el consumo de tabaco de sus pacientes haciendo preguntas generales acerca de intentos de dejar de fumar. Además, un porcentaje muy similar también evalúa el consumo de tabaco de sus pacientes haciendo preguntas generales acerca del número de cigarrillos diarios, fumados en la vida y/o intentos de dejar de fumar siempre o casi siempre. Solo un $14 \%$ de las médicas y un $25 \%$ de los médicos generales está usando con la mayoría de sus pacientes cuestionarios estandarizados para evaluar el consumo de tabaco de sus pacientes.

Tabla 2. Consejería y prácticas del médico general de la FAMG sobre cesación de tabaquismo en sus pacientes. Argentina, 2011.

\begin{tabular}{|c|c|c|c|c|c|c|c|c|c|c|c|c|c|}
\hline & \multirow{2}{*}{\multicolumn{2}{|c|}{$\begin{array}{c}\text { Siempre/ } \\
\text { casi } \\
\text { siempre }\end{array}$}} & \multirow{2}{*}{\multicolumn{2}{|c|}{$\begin{array}{c}\text { Mujeres } \\
\text { Algunas } \\
\text { veces }\end{array}$}} & \multirow{2}{*}{\multicolumn{2}{|c|}{$\begin{array}{c}\text { Casi } \\
\text { nuncal } \\
\text { Nunca }\end{array}$}} & \multicolumn{6}{|c|}{ Hombres } & \multirow{3}{*}{ Valor $\mathrm{p}$} \\
\hline & & & & & & & $\begin{array}{r}\text { Sie } \\
\text { c } \\
\text { sie }\end{array}$ & $\begin{array}{l}\text { prel } \\
\text { si } \\
\text { pre }\end{array}$ & & $\begin{array}{l}\text { nas } \\
\text { es }\end{array}$ & & & \\
\hline & $\%$ & (n) & $\%$ & (n) & $\%$ & (n) & $\%$ & $(n)$ & $\%$ & (n) & $\%$ & (n) & \\
\hline $\begin{array}{l}\text { En pacientes que se } \\
\text { presentan sin } \\
\text { enfermedades } \\
\text { crónicas } \\
\text { relacionadas, ¿qué } \\
\text { tan seguido da } \\
\text { consejería sobre } \\
\text { cesación de } \\
\text { tabaquismo? }\end{array}$ & 84 & (47) & 16 & (9) & 0 & $(0)$ & 79 & (19) & 21 & (5) & 0 & $(0)$ & 0.708 \\
\hline $\begin{array}{l}\text { ¿En pacientes que } \\
\text { se presentan con } \\
\text { enfermedades } \\
\text { crónicas que tan } \\
\text { seguido da }\end{array}$ & 96 & (53) & 4 & (2) & 0 & $(0)$ & 100 & (24) & 0 & $(0)$ & 0 & $(0)$ & 0.616 \\
\hline
\end{tabular}




\begin{tabular}{|c|c|c|c|c|c|c|c|c|c|c|c|c|c|}
\hline \multirow[b]{2}{*}{$\begin{array}{l}\text { ¿Usted evalúa el } \\
\text { consumo de tabaco } \\
\text { de sus pacientes } \\
\text { haciendo preguntas } \\
\text { generales si el } \\
\text { paciente fuma o no? } \\
\text { ¿Usted evalúa el } \\
\text { consumo de tabaco } \\
\text { de sus pacientes } \\
\text { haciendo preguntas } \\
\text { generales de los } \\
\text { comportamientos } \\
\text { asociados? }\end{array}$} & \multicolumn{2}{|c|}{ Si } & \multicolumn{2}{|c|}{ No } & \multicolumn{2}{|c|}{$\begin{array}{c}\text { No } \\
\text { contesto }\end{array}$} & \multicolumn{2}{|c|}{ Si } & \multicolumn{2}{|c|}{ No } & \multicolumn{2}{|c|}{$\begin{array}{c}\text { No } \\
\text { contesto }\end{array}$} & \\
\hline & 81 & (53) & 18 & (10) & 1 & $(1)$ & 79 & (19) & 13 & (2) & 8 & (2) & 0.325 \\
\hline $\begin{array}{l}\text { ¿Usted evalúa el } \\
\text { consumo de tabaco } \\
\text { de sus pacientes } \\
\text { haciendo preguntas } \\
\text { generales acerca de } \\
\text { intentos de dejar de } \\
\text { fumar? }\end{array}$ & 84 & (48) & 12 & $(7)$ & 4 & (2) & 84 & $(20)$ & 8 & (2) & 8 & (2) & 0.596 \\
\hline $\begin{array}{l}\text { Usted evalúa el } \\
\text { consumo de tabaco } \\
\text { de sus pacientes } \\
\text { haciendo preguntas } \\
\text { generales acerca de } \\
\text { numero de cigarrillos } \\
\text { diarios, fumados en } \\
\text { la vida y/o intentos } \\
\text { de dejar de fumar? }\end{array}$ & 86 & (49) & 12 & $(7)$ & 1 & (2) & 84 & $(20)$ & 8 & (2) & 8 & (2) & 0.329 \\
\hline $\begin{array}{l}\text { ¿Usted evalúa el } \\
\text { consumo de tabaco } \\
\text { de sus pacientes } \\
\text { utilizando } \\
\text { cuestionarios } \\
\text { estandarizados? }\end{array}$ & 14 & (8) & 77 & (44) & 9 & (5) & 25 & (6) & 67 & (16) & 8 & (2) & 0.489 \\
\hline
\end{tabular}

Fuente: Elaboración propia en base a datos de encuesta.

\subsubsection{Barreras importantes percibidas por el médico general de la FAMG para dar consejería en cesación de tabaquismo a sus pacientes.}

Las barreras importantes percibidas por el médico general de la FAMG para dar consejería en cesación de tabaquismo a sus pacientes están presentadas en la Tabla 3. No se observaron diferencias en las barreras identificadas entre mujeres y hombres (valores de $p$ superior a 0.05). Las barreras más frecuentes identificadas por los médicos generales eran la dificultad que los pacientes cambien sus hábitos (51\% de las mujeres y $33 \%$ de los 
hombres) y que los pacientes no están interesados en mejorar sus hábitos (44\% de las médicas y $21 \%$ de los médicos). Además, los médicos contaron que la falta de sistemas adecuados de referencia para cesación de tabaquismo es un obstáculo importante para ellos (26\% de mujeres; $29 \%$ de hombres). También, la falta de tiempo fue una barrera importante observada por los médicos generales de la FAMG para dar consejería en cesación de tabaquismo a sus pacientes ( $21 \%$ de las mujeres y un $33 \%$ de los hombres). No se observaron diferencias entre médicas y médicos generales en la identificación de las barreras a dar consejería a sus pacientes. Otras barreras identificadas eran la falta de herramientas adecuadas y de información para darle a los pacientes (16\% de mujeres, $8 \%$ de hombres), la falta de opciones de tratamientos efectivas ( $14 \%$ de las médicas) y la falta de pago adecuado para ofrecer consejería en cesación de tabaquismo ( $9 \%$ de médicas, $13 \%$ de los médicos).

Tabla 3. Barreras importantes percibidas por el médico general de la FAMG para dar consejería en cesación de tabaquismo a sus pacientes. Argentina, 2011.

\begin{tabular}{|c|c|c|c|c|c|}
\hline & \multicolumn{2}{|c|}{ Mujeres } & \multicolumn{2}{|c|}{ Hombres } & \multirow[b]{2}{*}{ valor $p$} \\
\hline & $\%$ & $(n)$ & $\%$ & (n) & \\
\hline No tengo suficiente tiempo & 21 & (12) & 33 & $(8)$ & 0.268 \\
\hline No es parte de mi trabajo & 5 & (3) & 0 & $(0)$ & 0.551 \\
\hline $\begin{array}{l}\text { No estoy lo suficientemente entrenado en ofrecer } \\
\text { consejos de cesación de tabaquismo. }\end{array}$ & 4 & $(2)$ & 4 & (1) & 1 \\
\hline $\begin{array}{l}\text { Dificultades de evaluar y manejar temas de cesación de } \\
\text { tabaquismo }\end{array}$ & 5 & (3) & 4 & (1) & 1 \\
\hline $\begin{array}{l}\text { Falta de pago adecuado para ofrecer consejería en } \\
\text { cesación de tabaquismo }\end{array}$ & 9 & (5) & 13 & (3) & 0.689 \\
\hline $\begin{array}{l}\text { Falta de sistemas adecuados de referencia para estos } \\
\text { temas }\end{array}$ & 26 & (15) & 29 & $(7)$ & 0.79 \\
\hline $\begin{array}{l}\text { Los pacientes no están interesados en mejorar sus } \\
\text { hábitos }\end{array}$ & 44 & $(25)$ & 21 & $(5)$ & 0.077 \\
\hline Temor de ofender la privacidad de un paciente & 4 & $(2)$ & 0 & $(0)$ & 1 \\
\hline Dificultad para los pacientes cambiar sus hábitos & 51 & $(29)$ & 33 & $(8)$ & 0.222 \\
\hline $\begin{array}{l}\text { Falta de herramientas adecuadas y de información para } \\
\text { darle a los pacientes }\end{array}$ & 16 & (9) & 8 & $(2)$ & 0.492 \\
\hline
\end{tabular}


Fuente: Elaboración propia en base a datos de encuesta.

\subsubsection{Creencias sobre la consejería de cesación de tabaquismo del médico general de la FAMG a sus pacientes.}

No se observaron diferencias estadísticamente significativas entre las médicas generalistas y los médicos generales de la FAMG con respecto a las creencias sobre la consejería de cesación de tabaquismo del médico general de la FAMG a sus pacientes. Cuatro de cinco medicas estaban convencidas que son capaces de aconsejar a sus pacientes de forma coherente y efectiva en el caso que no fuman. La gran mayoría de los médicos perciben que existen estrategias y herramientas efectivas para ayudar a los pacientes a dejar de fumar (mujeres $92 \%$, hombres $81 \%$ ) y tiene la confianza en sus habilidades para aconsejar a sus pacientes para dejar de fumar ( $90 \%$ de las médicas y $74 \%$ de los médicos). Sin embargo, un $88 \%$ de las médicas y un $83 \%$ de los médicos generales están de acuerdo que necesitan entrenamiento en la prevención del tabaquismo. Respecto si los pacientes están interesados en la prevención o no, se observaron diferentes opiniones. En las médicas generalistas, un $46 \%$ pensaban que los pacientes si están interesados en temas de la prevención, mientras un $30 \%$ estuvieron indecisos, y un $24 \%$ creen que los temas de prevención no son interesantes para sus pacientes. Las prevalencias correspondientes en los médicos generales eran 39\% (los pacientes están interesados en la prevención), 22\% (indecisos) y 39\% (a los pacientes no les interesa la prevención). 
Tabla 4. Creencias sobre la consejería de cesación de tabaquismo del médico general de la FAMG a sus pacientes. Argentina, 2011.

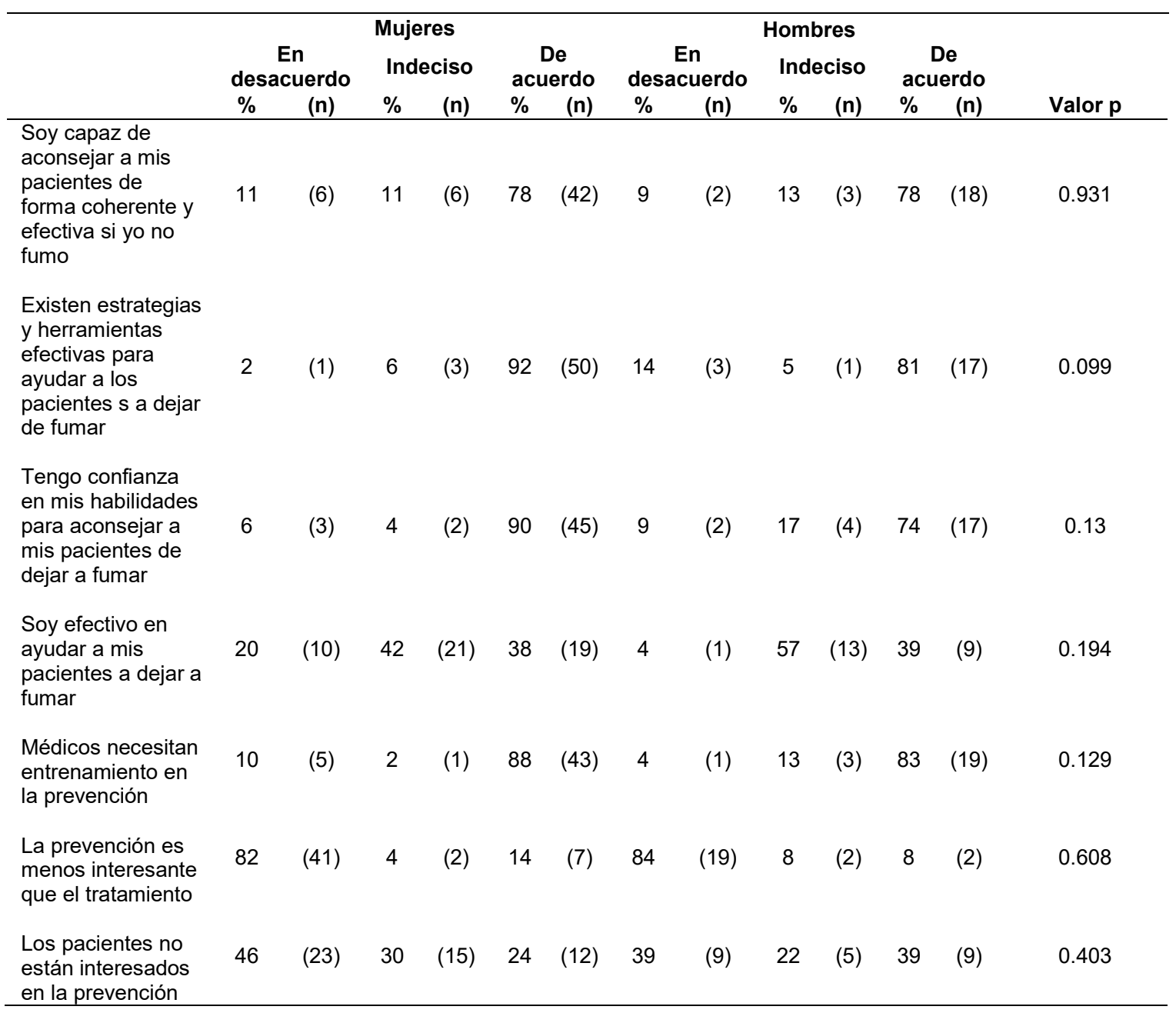

Fuente: Elaboración propia en base a datos de encuesta.

\subsubsection{Conocimientos sobre los efectos del tabaquismo de los médicos generales de la FAMG.}

Los conocimientos sobre los efectos del tabaquismo de los médicos generales de la FAMG están presentados en la Tabla 5. El porcentaje corresponde a aquellos que contestaron correctamente a la pregunta. Generalmente, existe un buen conocimiento sobre los efectos adversos de los cigarrillos en la patogenia de la bronquitis crónica (100\%), las 
enfermedades coronarias (100\%), el enfisema pulmonar (98-100\%) y del cáncer de la cavidad oral (96-98\%), cáncer de vejiga (88-91\%) y del cáncer de laringe (88-92\%). Sin embargo, solo un $45 \%$ de las médicas y un $62 \%$ de los médicos generales sabían que los cigarrillos también contribuyen de la manera significativa en la patogenia del cáncer de piel. Con respecto a los daños del tabaquismo pasivo, los conocimientos no llegaron a los niveles del tabaquismo activo. Mientras las médicas (96\%) y los médicos (83\%) saben que los niños que fuman pasivamente tienen mayor riesgo de morir, no estaban al tanto que los niños fumadores pasivos tienen un riesgo de cáncer de pulmón $20 \%$ mayor o un riesgo de enfermedades cardiacas $30 \%$ mayor que los no fumadores, con cerca de $40 \%$ de las médicas y un $26 \%$ de los médicos generales de la FAMG con respuestas incorrectas.

Tabla 5. Conocimientos sobre los efectos del tabaquismo de los médicos generales de la FAMG que contestaron correctamente a la pregunta. Argentina, 2011.

\begin{tabular}{lccccc}
\hline & \multicolumn{2}{c}{ Mujeres } & \multicolumn{2}{c}{ Hombres } & \\
& $\%$ & (n) & $\%$ & (n) & valor \\
\hline $\begin{array}{l}\text { El cigarrillo es causa contribuyente importante } \\
\text { a la patogénica del cáncer de vejiga }\end{array}$ & 88 & $(44)$ & 91 & $(19)$ & 0.766 \\
$\begin{array}{l}\text { El cigarrillo es causa contribuyente importante } \\
\text { a la patogénica de la bronquitis crónica }\end{array}$ & 100 & $(52)$ & 100 & $(22)$ & 1 \\
$\begin{array}{l}\text { El cigarrillo es causa contribuyente importante } \\
\text { a la patogénica del cáncer de piel }\end{array}$ & 45 & $(22)$ & 64 & $(14)$ & 0.217 \\
$\begin{array}{l}\text { El cigarrillo es causa contribuyente importante } \\
\text { a la patogénica del cáncer de cavidad oral }\end{array}$ & 98 & $(51)$ & 96 & $(21)$ & 0.515 \\
$\begin{array}{l}\text { El cigarrillo es causa contribuyente importante } \\
\text { a la patogénica del enfisema pulmonar }\end{array}$ & 98 & $(50)$ & 100 & $(22)$ & 1 \\
$\begin{array}{l}\text { El cigarrillo es causa contribuyente importante } \\
\text { a la patogénica de las enfermedades } \\
\text { coronarias }\end{array}$ & 100 & $(51)$ & 100 & $(22)$ & 1 \\
$\begin{array}{l}\text { El cigarrillo es causa contribuyente importante } \\
\text { a la patogénica del cáncer de laringe } \\
\text { Los niños que fuman pasiva tienen riesgo más }\end{array}$ & 88 & $(50)$ & 92 & $(22)$ & 0.766 \\
alto de morir & 96 & $(52)$ & 83 & $(19)$ & 0.62 \\
$\begin{array}{l}\text { Los niños que fuman pasiva tienen un riesgo } \\
\text { más alto de infección de oído }\end{array}$ & 82 & $(44)$ & 87 & $(20)$ & 0.623 \\
$\begin{array}{l}\text { Los niños que fuman pasiva tienen un riesgo } \\
\text { de cáncer pulmón 20\% más alto que los no } \\
\text { fumadores }\end{array}$ & 57 & $(31)$ & 74 & $(17)$ & 0.381 \\
\end{tabular}


Los niños que fuman pasiva tienen un riesgo de enfermedades cardiaca $30 \%$ más alto que

los no fumadores

Fuente: Elaboración propia en base a datos de encuesta.

\subsubsection{Relación entre el hábito de fumar del médico general de la FAMG y la consejería que realizan.}

En general, con una excepción, no se observaron asociaciones entre la realización del hábito de fumar del médico general de la FAMG y la consejería que realizan (Tabla 6). Los médicos generales que fuman tuvieron una probabilidad más alta de aconsejar sobre cesación de tabaquismo en pacientes que se presentan sin enfermedades crónicas relacionadas comparando con los médicos que no fuman (OR 1.49; 95\%IC 2.27-48.60). No se encontraron asociaciones entre el hábito de tabaquismo de los médicos y la conserjería de cesación de tabaquismo en pacientes que se presentan con enfermedades crónicas (OR 3.34; 95\% IC 10.15-80.42) o en varias formas de la evaluación de los hábitos de tabaquismo de sus pacientes.

Tabla 6. Relación entre el hábito de fumar del médico general de la FAMG y la consejería que realizan. Argentina, 2011.

\begin{tabular}{|c|c|c|c|c|c|}
\hline \multirow{2}{*}{ Pregunta } & No Fum & \multicolumn{2}{|c|}{$\begin{array}{l}\text { Tabaquismo } \\
\text { Ex Fumador }\end{array}$} & \multicolumn{2}{|c|}{ Fumador Actual } \\
\hline & $\begin{array}{ll}\text { OR } & \text { IC } \\
& (95 \%)\end{array}$ & OR & IC (95\%) & & IC (95\%) \\
\hline $\begin{array}{l}\text { En pacientes que se presentan sin } \\
\text { enfermedades crónicas } \\
\text { relacionadas, ¿Que tan seguido } \\
\text { da consejería sobre cesación de } \\
\text { tabaquismo? }\end{array}$ & Ref & 1.82 & $(0.33-10.19)$ & 1.49 & $(2.27-48.60)$ \\
\hline $\begin{array}{l}\text { ¿En pacientes que se presentan } \\
\text { con enfermedades crónicas que } \\
\text { tan seguido da consejería } \\
\text { cesación de tabaquismo? }\end{array}$ & Ref & $\mathrm{Na}$ & $\mathrm{Na}$ & 3.43 & $(0.15-80.42)$ \\
\hline $\begin{array}{l}\text { ¿Usted evalúa el consumo de } \\
\text { tabaco de sus pacientes haciendo } \\
\text { preguntas generales si el paciente } \\
\text { fuma o no? }\end{array}$ & Ref & 1.48 & $(0.14-15.78)$ & 1.27 & $(0.12-13.29)$ \\
\hline $\begin{array}{l}\text { ¿Usted evalúa el consumo de } \\
\text { tabaco de sus pacientes haciendo }\end{array}$ & Ref & 0.63 & $(0.17-2.36)$ & $\mathrm{Na}$ & $\mathrm{Na}$ \\
\hline
\end{tabular}


preguntas generales de los

comportamientos asociados?

¿Usted evalúa el consumo de tabaco de sus pacientes haciendo preguntas generales acerca de

Ref

1.38

$(0.23-8.28)$

0.97

$(0.17-5.67)$

intentos de dejar de fumar?

Usted evalúa el consumo de

tabaco de sus pacientes haciendo Ref preguntas generales acerca de

numero de cigarrillos diarios,

fumados en la vida y/o intentos de

dejar de fumar?

¿Usted evalúa el consumo de Ref

tabaco de sus pacientes utilizando

cuestionarios estandarizados?

Fuente: Elaboración propia en base a datos de encuesta.

\subsubsection{Relación entre el hábito de fumar del médico general de la FAMG y las creencias sobre la consejería de cesación de tabaquismo a sus pacientes.}

Tampoco se observaron asociaciones entre la realización del hábito de fumar del médico general de la FAMG y las creencias sobre la consejería de cesación de tabaquismo a sus pacientes (Tabla 7). Los hábitos de tabaquismo de los médicos generales, por ejemplo, no estuvieron asociados con las creencias, si los médicos son efectivo en ayudar a sus pacientes a dejar de fumar (OR 0.52; 95\% IC 0.15-1.82), si la prevención es menos interesante que el tratamiento (OR 1.19; 95\% IC 0.19-7.50) o si los pacientes están interesados en la prevención (OR 0.28; 95\% IC 0.05-1.45).

Tabla 7. Relación entre el hábito de fumar del médico general de la FAMG y las creencias sobre la consejería de cesación de tabaquismo a sus pacientes. Argentina, 2011.

\begin{tabular}{|c|c|c|c|c|c|}
\hline \multirow{3}{*}{ Pregunta } & \multirow[b]{2}{*}{ No Fumador } & \multicolumn{2}{|r|}{ Tabaquismo } & \multirow{2}{*}{\multicolumn{2}{|c|}{ Fumador Actual }} \\
\hline & & & Ex Fumador & & \\
\hline & $\begin{array}{cc}\text { OR } & \text { IC } \\
& (95 \%)\end{array}$ & OR & IC $(95 \%)$ & OR & IC $(95 \%)$ \\
\hline $\begin{array}{l}\text { Soy capaz de aconsejar a mis } \\
\text { pacientes de forma coherente y } \\
\text { efectiva si yo no fumo }\end{array}$ & Ref & 1.91 & $(0.35-10.39)$ & 0.36 & $(0.10-1.30)$ \\
\hline \multirow{2}{*}{$\begin{array}{l}\text { Existen estrategias y herramientas } \\
\text { efectivas para ayudar a los } \\
\text { pacientes } \mathrm{s} \text { a dejar de fumar }\end{array}$} & Ref & 1.34 & $(0.11-16.36)$ & 0.16 & $(0.02-1.08)$ \\
\hline & Ref & 0.68 & $(0.16-2.91)$ & 1.32 & $(0.23-7.76)$ \\
\hline
\end{tabular}


Tengo confianza en mis
habilidades para aconsejar a mis

pacientes de dejar a fumar

Soy efectivo en ayudar a mis

pacientes a dejar a fumar

La prevención es menos

interesante que el tratamiento

Los pacientes no están

interesados en la prevención
Ref

Ref

Ref

Fuente: Elaboración propia en base a datos de encuesta.
$0.57 \quad(0.18-1.77) \quad 0.52$

$1.16 \quad(0.23-5.97) \quad 1.19$

$(0.19-7.50)$

$(0.05-1.45)$

\subsection{Entrevista focal}

Complementando la información recolectada a través de las encuestas se realizó la entrevista focal; entrevista cualitativa que contó con la participación de 9 médicos, aquí el grupo de médicos generales entrevistados dieron su punto de vista hacia lo indagado con respecto a prescripción en cesación de tabaquismo, dejando todo documentado a través de la grabación, lo que permitió posteriormente hacer un análisis de lo indagado y una clasificación de variables en cuanto a la consejería en cesación de tabaquismo y las dimensiones de consulta, médico y barreras.

Dentro de los parámetros a tener en cuenta por parte de los médicos generales ante sus pacientes para realizar la consejería en cesación de tabaquismo, coincidieron en que el primer paso es indagar si fuma o no, ante el hecho que, si fuma, mencionan que hay que resaltar los beneficios que se obtienen al dejar de fumar y coordinar un seguimiento para este paciente, algunas apreciaciones en la entrevista:

"Indagar si el paciente fuma, explicarle lo importante que es dejar de fumar"

"Cuando uno pregunta en la consulta si fuma y dicen que sí, uno les dice que es perjudicial para la salud, y trata de explicar lo importante que es dejar de fumar".

"Primer paso preguntar si fuma o no, preguntar si ha pensado dejar de fumar, si dice que no, entonces mencionar lo negativo de tabaquismo, si está interesado en dejar de fumar, coordinar otra cita para hablar solo de ese tema y motivarlo a dejar de fumar". 
"Consejería de dejar de fumar y mirar en qué nivel de abandono esta, si está registrado como un problema o si está en fase de abandono reforzar para que dejen de fumar, que lo empiece a ver como un problema".

Los 9 médicos participantes en la entrevista realizan consejería en cesación de tabaquismo en todas las consultas con los pacientes, resaltando el seguimiento posterior en la historia clínica.

"Si, si el tiempo lo permite, por lo menos el hecho de decirle que deje de fumar". "En pacientes a partir de 11 años les pregunto a todos si fuman o no, y pido que se registre en la historia clínica el estado de tabaquismo del paciente"

Los médicos indagados en su totalidad recibieron entrenamiento para realizar consejería de este tipo, en la universidad, residencia, cursos o congresos. "En la Residencia, posgrado, y congresos donde se abarca la cesación tabáquica y el ministerio nos manda un remediar, una planilla, un libro sobre deshabituación tabáquica".

La manera de definir la consejería sobre tabaquismo de los médicos generales, incluyen a partir del hecho de identificar un fumador y la motivación que ellos como profesionales de salud deben de dar a esta persona para que abandone el hábito, aportando herramientas que faciliten el proceso de abandono, haciendo énfasis en los beneficios positivos que esto brindaría a su salud; adicionalmente fortaleciendo el acompañamiento interdisciplinario.

"En si cuando el paciente está fumando, lo estímulo a que deje el hábito, estimulándolo a que lo deje, mencionándolo que es lo más saludable, recordándoles que uno está para encararlo y acompañarlo para una terapéutica en conjunto, a los pacientes, mencionar el respeto hacia los ambientes libres de tabaco y no promover fumadores pasivos".

De esa manera se propicia una consejería, dando herramientas y conocimiento claro sobre las implicaciones tanto a nivel individual, nuestro entorno y en general en la salud pública. 
El rol o participación que cumple el paciente dentro de la consejería que realizan los médicos generales, en su mayoría y de forma inicial cumplen un rol pasivo, dado que la mayoría de los casos llegan sin interés para dejar el hábito, fase de pre contemplación, aquí por lo general escuchan solamente lo que dice el médico, en aquellos que se encuentran en la fase contemplativa, se debe acompañar de cerca porque son aquellos que tienen el deseo, y quizá en algún momento no contaron con el apoyo suficiente para dejar el hábito. En general y dependiendo de la fase en la que se encuentre el paciente, se debe identificar la necesidad, dar herramientas y reforzar los esfuerzos, haciendo énfasis en lograr una motivación del paciente para hacer los cambios necesarios.

"La mayoría de las veces en forma pasiva, salvo que llegue con el deseo de dejar de fumar, de intentar transformarlo a que tenga un rol activo en el abandono del hábito".

"Rol pasivo, en la etapa contemplativa uno estimula y activa cuando ya esté en preparación para dejar de fumar, ahí es donde uno acompaña”.

El tiempo dedicado dentro de la consulta a la consejería, varía de acuerdo al motivo de esta; si el objetivo es diferente a dejar de fumar, en promedio le dedican entre 2 a 3 minutos, tiempo para iniciar una motivación, por lo general si el paciente manifiesta deseo y en la historia clínica se evidencian factores de riesgo, se programa una siguiente cita específicamente para ese tema de abandono o cesación de tabaco y si por el contrario la cita es específicamente por la motivación en dejar de fumar se destina todo el tiempo de la consulta a este tema.

"Depende del tiempo que uno disponga con el paciente y de la predisposición del paciente, no hay un tiempo".

"Si el motivo de consulta es dejar de fumar, todo el tiempo de la consulta, si se encuentra entre uno de los factores de riesgo del paciente 2 o 3 minutos, dependiendo de los factores de riesgo". 
Los criterios o pasos específicos que tienen en cuenta dentro de la consejería los médicos incluyen los establecidos en guías, estos se basan principalmente de acuerdo al estadio del paciente, y la predisposición para escuchar lo que se establece en la consejería, así como el compromiso para abandonar el hábito. En general describen que en la consulta indagan si el paciente ha contemplado el abandono o no del tabaco, haciendo énfasis en los daños que este genera y mencionando las opciones de tratamiento que se pueden realizar, así mismo en una siguiente visita indagar más sobre barreras u obstáculos presentados, importante involucrar el medio ambiente y la familia.

"Depende del estadio, pre contemplativo, contemplativo o etapa de cambio, son las estrategias que vamos a tener en cada fase. Si no tiene ningún problema, se debe recomendar que deje de fumar, si está en otra fase, el diario para dejar de fumar, se dan los consejos para que una persona deje de fumar".

“En general hay pasos que están nomenclados, dependiendo de estadio en que se encuentre el paciente, y se tiene que tener eso en cuenta, en q estadio está el paciente y la predisposición del paciente para escuchar esa consejería”.

Los criterios mínimos que consideran tener en cuenta para aconsejar este tipo de intervención, de cesación tabáquica, incluyen que el médico no fume, esto basa el ejemplo hacia el paciente, el fortalecimiento en cada individuo que fuma hacia el abandono del hábito, partiendo que es un problema de salud pública que se debe intervenir, dado que es un factor de riesgo para múltiples enfermedades y aporta grandemente a la carga de la enfermedad. Entienden que es una pregunta que se debe hacer dentro de la consulta, brindando un breve consejo y haciendo énfasis en el abandono.

"Yo creo que el solo hecho de saber que fumar es malo, ya con eso todo médico debería indicar que todo paciente deje de fumar".

"Cualquier médico que incluso no haya hecho ninguna residencia de posgrado debería de aconsejar dejar de fumar, y debería de estar en los programas de pre y posgrado, dando formación en esto". 
"Entender que hay que preguntar a cada paciente sobre tabaquismo y que se dé un consejo breve, 2 minutos son costo efectivos, diciendo al paciente que deje de fumar por su salud y luego tener las herramientas para ayudar al paciente a que deje de fumar".

Las barreras que los médicos han percibido dentro de la consulta para realizar este tipo de consejería, van desde el interés o no del paciente para aceptar la consejería, la motivación hacia el cambio en el paciente fumador (proceso que lleva tiempo), económico, dado que muchas veces el tratamiento incluye pasar por varias etapas donde se requieren otro tipo de terapias que cuestan y el paciente no contempla que al no fumar tiene un ahorro de dinero que puede destinar para otro tipo de gastos como lo terapéutico, y el más resaltado por todos tiempo en la consulta, aquí los médicos lo sobresalen, dado que no es fácil preguntar a todos los pacientes que consulta por otra afectación si fuma o no, y en el caso de que si fume hacer una intervención.

"Dentro de las barreras para mí el tiempo es lo fundamental, puede haber un choque o una barrera cultural porque en algunos lados es muy aceptada la idea del tabaquismo como algo normal y ni hablar que dentro de ámbitos cerrados, dentro de su casa, sin contar los terceros que están en su alrededor y con el tema de medicación y eso, lo mismo, por ahí en la parte económico es lo mismo, por ahí es factible que dejando de fumar unos meses se pague el tratamiento, pero por ahí a veces hay limitantes en el tema de conseguir la medicación".

“En realidad las barreras serian el interés o no del paciente para aceptar esa consejería, otra barrera la económica, donde digamos uno aconseja a alguien dejar y se pasa a una etapa donde se necesitar otros métodos y en algunos niveles es medio inaccesible".

"Falta de tiempo, no es fácil preguntar a un paciente que este en consulta con otra afectación preguntar si fuma o no, hay que preguntar a todos. Romper la barrera y preguntar a todos".

La motivación que tienen los médicos generalistas para realizar este tipo de intervenciones concuerda con el mejoramiento de la calidad de vida del individuo y su 
entorno, dado que este hábito en gran parte genera un gran número de fumadores pasivos a su alrededor, y son múltiples los beneficios en la comunidad al lograr el abandono de este hábito en su población.

"En realidad el saber que el paciente va a mejorar su calidad de vida, ya eso es una motivación para que uno lo haga".

"Personalmente, si la motivación es el beneficio hacia el paciente, y el saber que además de mejorar su calidad de vida, prevenimos lesiones que después, obviamente a nosotros nos daría más dolores de cabeza y por ahí otra motivación que puede ser hacia el estímulo del reconocimiento económico y cultural, por ahí de abordar la deshabituación tabáquica que por ahí eso no se tiene en cuenta” 


\section{DISCUSIÓN}

\subsection{Prevalencia de tabaquismo en médicos}

En Argentina, de acuerdo a la tercera Encuesta Nacional de Factores de Riesgo (ENFR), realizada en 2015 , la prevalencia de consumo de tabaco fue de $25,1 \%$ en las encuestas anteriores las cifras fueron de $29,7 \%$ y $27,1 \%$ para los años 2005 y 2009 respectivamente, de acuerdo a estos resultados se ve reflejado que se ha contribuido a una disminución de estas cifras [65]. En este país, el consumo diario de cigarrillos de los habitantes de Buenos Aires es superior al de otras capitales de Latinoamérica y el costo de los cigarrillos es uno de los más bajos de la región [66], por lo que se puede relacionar al aumento de cifras de consumo, dado el fácil acceso a través de bajo costo. Este estudio evidenció un consumo de tabaco dentro del personal médico participante; con cifras en hombres fumadores actuales del $25 \%$ y el $21 \%$ que dejaron de fumar hace más de un año, entre las mujeres el $21 \%$ fuman y el $30 \%$ son exfumadoras, así cerca de la mitad de los encuestados han tenido/tienen contacto con el tabaco, prevalencias que son cercanas al panorama nacional argentino que se ha visto en los últimos años.

En la Argentina, se tiene cifras del estudio TAMARA, quizá el más representativo del país, aquí se ha investigado la prevalencia de tabaquismo en médicos de la Argentina, los factores asociados con su consumo y la conducta frente a sus pacientes fumadores, para el año 2004, a través del estudio TAMARA, se identificó una prevalencia de fumadores del $30 \%$ y de ex fumadores, del 22\% [67]. En este estudio se identificó que la proporción de médicos fumadores fue inferior a la tasa de tabaquismo de la población general del país para ese año (2004), que oscilaría entre el 33\% y el 39\% de los adultos [67]. Para el año 2013, se tienen cifras a través del estudio TAMARA II, de una proporción de fumadores del $19,7 \%$ y de exfumadores del $21,7 \%$ [68]. De igual modo, la prevalencia de tabaquismo encontrada en el TAMARA II cayó más de 10 puntos con respecto al anterior estudio [68].

Estas cifras son muy semejantes a los resultados obtenidos en la presente investigación, sin embargo, se considera que es difícil conocer la prevalencia de tabaquismo en médicos en distintos países que permita hacer comparaciones, ya que la 
mayor parte de los estudios se realizan con series no muy grandes y no abordan similares componentes [68].

Sería razonable esperar que la prevalencia de tabaquismo entre los médicos fuera mucho menor, ya que a diario ellos tratan los efectos de este hábito sobre la salud [69], de igual manera se creería que en especialidades como la medicina general que aborda un manejo integral del paciente no se presentaran este tipo de hábitos y por el contrario se ejerciera mayor intervención sobre cesación tabáquica en sus pacientes, sin embargo las cifras demuestran prevalencias muy similares en la población general.

Otros estudios realizados a nivel internacional han mostrado dentro de las prevalencias de tabaquismo entre médicos, una prevalencia mayor en países como Francia (34\%), Grecia (44-54\%), los Países Bajos (38\%) y Dinamarca (33\%) [7]. Estudios como el realizado por Barengo et al, en Finlandia, mostro cambios en la prevalencia de tabaquismo en los médicos de este país, identificando una prevalencia del hábito significativamente menor que la población general finlandesa; el porcentaje de médicos que fumaban diariamente disminuyó significativamente del $24 \%$ al $7 \%$ en hombres y del $17 \%$ a $3 \%$ en mujeres durante el período 1969 a 1995 [7], aunque si bien son poblaciones con características tal vez diferentes, tienen en común la profesión médica.

Una revisión de la literatura, realizada por Abdullah et al, entre 1987-2010, evidenció que existen variaciones regionales en la prevalencia actual de fumar, las intenciones para dejar de fumar y los servicios para dejar de fumar entre los médicos. La prevalencia de tabaquismo fue más alta en Europa Central / del Este (37\%), seguida de África (29\%), América Central y del Sur (25\%) y Asia (17.5\%) [70]. La prevalencia del consumo de tabaco fue variable en todos los estudios involucrados, dado que se presentaron unas tasas desde un $63 \%$ en Filipinas [71] y un $62 \%$ en México [70, 72], hasta un $3 \%$ en Nigeria [73]. En ocho estudios, el consumo general de tabaco, la tasa de prevalencia fue inferior al $10 \%$ y en cuatro estudios fue del $50 \%$ o superior. Este mismo estudio de Abdullah et al, mostró que las tasas de prevalencia de tabaquismo entre los médicos en América del Sur variaron de $6.4 \%$ [70, 74] a 62\% [75] (mediana: 25\%). La prevalencia en Europa Central / Oriental de acuerdo a la investigación de Squier et al, publicada en 2006 muestra variaciones de 14\% entre los médicos ucranianos [76] y refleja en Letonia un 59\%. 
En este estudio el promedio de edad entre los participantes oscilo entre 37 años para hombres y 34 años en mujeres. Los médicos jóvenes tienden a presentar tasas bajas de tabaquismo que se incrementan con la edad y luego declinan a partir de los 45 años [77]. El mayor porcentaje de tabaquismo coincide con la época de mayor productividad en la profesión y priva al médico de la oportunidad de influir con su ejemplo sobre un numeroso grupo de pacientes, lo cual constituye un agravante adicional [77].

Según un estudio francés, los hábitos de fumar variaban según la edad del médico, si se consideraba a los no fumadores médicos actuales, el grupo de más edad suele ser exfumadores, mientras que los más jóvenes suelen ser los que nunca han fumado. En comparación con la información obtenida en 1980 de la población médica, se observó que hubo una caída en el nivel de médicos que fuman, mientras que la proporción de médicos que nunca han fumado aumento considerablemente durante el mismo período, especialmente entre los médicos jóvenes [78].

De igual manera existen algunos estudios que han documentado diferencias relacionadas con la edad en las tasas de tabaquismo de los médicos; los médicos de mayor edad en su mayor parte son más propensos a ser fumadores actuales [79]. Sin embargo, en China [80], Japón [81, 82], México [83] e India [84], el consumo de tabaco en realidad fue más frecuente en los médicos más jóvenes. Este último resultado sugiere que aún queda por delante un desafío para los responsables de las políticas de salud pública en países con altos índices de tabaquismo entre los médicos jóvenes [79]. Adicionalmente, once estudios que informaron la edad de inicio encontraron que la media eran menores de 20 años [74, 80, 81]. En general, los hombres empezaron a fumar antes que las mujeres, generalmente antes de los 18 [76, 82, 83, 84]. Un estudio de Brasil muestra que el inicio del hábito de fumar con mayor frecuencia estuvo entre los 10 y 19 años [74].

\subsection{Consejería y prácticas del médico general de la FAMG sobre cesación de tabaquismo en sus pacientes}

Es importante la identificación del estatus de fumador de los pacientes y el ofrecimiento de tratamiento de cesación para aquellos que son fumadores en todas las áreas relacionadas con la salud cardiovascular $[85,86]$. 
En cuento a la consejería y prácticas del médico general de la FAMG sobre cesación de tabaquismo en sus pacientes, nuestro estudio no mostró una asociación entre hombres y mujeres.

Existe evidencia que demuestra que esta intervención es eficaz, por lo que las guías para la cesación de tabaquismo recomiendan aconsejar a todos los fumadores suspender el consumo de tabaco [47]. Esta recomendación se sostiene parcialmente en evidencia (consejo médico), pero también en la seguridad y facilidad de implementación (consejo breve por parte de profesionales no médicos), aspectos que merecen una observación detenida [47].

En la literatura se identificaron siete estudios en donde se registraron preguntas sobre el uso del tabaco, de ello surge que, en al menos tres cuartas partes de los médicos, más frecuentemente entre los no fumadores, interrogaron a sus pacientes sobre el consumo de tabaco o conocían su estado de fumador $[73,76,87,88,89,90]$. En un estudio turco [85], los médicos preguntaron acerca del hábito de fumar casi la mitad del tiempo, mientras que solo el $30 \%$ de los médicos cubanos siempre preguntaron sobre ese hábito [91].

La efectividad de la intervención puede verse afectada por la pertenencia a diferentes subgrupos demográficos como raza, etnia, sexo, edad y nivel de educación, o variables de 91comportamiento de fumar (tiempo hasta el primer cigarrillo, intento de abandono más prolongado, número de intentos en el último año, número de cigarrillos, y etapa de cambio). Investigaciones previas sobre estos 2 conjuntos de variables han producido resultados mixtos [92].

Asesorar a los pacientes para dejar de fumar difirió según los estudios. En Estonia, casi todos los médicos (96\%) informaron que aconsejaban a los pacientes que dejaran de fumar [93]. En China, el $70 \%$ de los médicos aconsejó dejar de fumar a los pacientes que egresaban del hospital en el último año [94]. Aproximadamente la mitad de los médicos en Malasia [95], Guatemala [90] y Rusia [96] aconsejaron a los pacientes que abandonaran el hábito de fumar, mientras que menos de un tercio de los médicos en un estudio chino [82] lo hicieron. En Sudáfrica [88] y Malasia [95], el consejo para dejar de fumar depende de que el paciente tenga una afección asociada con el hábito de fumar. Los métodos más utilizados para alentar a los pacientes a dejar de fumar fueron el asesoramiento breve y la educación sobre los peligros del hábito de fumar en varios estudios [76, 87, 82, 95]. 
Sin embargo, también existen conclusiones que indican en asesoramiento médico para dejar de fumar, que un consejo simple tiene un pequeño efecto en las tasas de cesación de tabaquismo, se estima una tasa de abandono no asistida del 2 al 3\%, una intervención de consejo breve puede aumentar el abandono en un 1 a 3\% adicional. Así se concluyó en este estudio de Stead et al, que los componentes adicionales parecen tener solo un pequeño efecto, aunque hay un pequeño beneficio adicional de intervenciones más intensivas en comparación con intervenciones muy breves [97]. Todas estas intervenciones van de la mano con el entrenamiento sobre cesación tabáquica que reciba el médico, en Argentina, de acuerdo con el estudio TAMARA II, el 56\% de los profesionales habían recibido algún tipo de entrenamiento en tabaquismo, este entrenamiento estaba relacionado en su mayoría con el consejo de cesación tabáquica [68], este mismo estudio "resalta la importancia de la implementación de programas de capacitación antitabaco para los profesionales de la salud" [68].

Varios estudios informaron tasas de abandono, que fueron principalmente tasas naturales de abandono del hábito entre los médicos (el ex hábito de fumar, definido como fumar en el pasado, pero no en el momento de la encuesta). Veinticinco estudios informaron la prevalencia de ex fumadores en todos los estudios. Las tasas de fumadores anteriores oscilaron entre un $2 \%$ entre los médicos chinos [98] y un $40 \%$ entre los médicos costarricenses [87]. la razón más común dada por los médicos para dejar de fumar, que a veces incluía la preocupación por la salud de los demás, así como por su propia salud [99, $81,90,100]$. Los fumadores pesados tuvieron más dificultades para dejar de fumar y fueron más resistentes a aceptar el apoyo para dejar de fumar [76]. Un estudio en Armenia indicó que las mujeres fumadoras tenían 1.5 veces más probabilidades de dejar de fumar que los hombres [101].

\subsection{Barreras importantes percibidas por el MG de la FAMG para dar consejería en cesación de tabaquismo a sus pacientes}

Si bien en este estudio se percibieron algunas barreras, la que más sobresalió fue la dificultad de parte del médico para que sus pacientes adopten o cambien sus hábitos. La falta de recursos, rutinas y colaboración para trabajar integralmente en torno al abandono del tabaco, carencia de una estructura de referencia y contra referencia para los pacientes, 
identificándose como una barrera importante relacionándose con la falta de herramientas adecuadas y de información para brindar a sus pacientes.

La falta de tiempo fue una barrera importante, dado que mayoritariamente los pacientes acuden a la consulta por circunstancias diferentes a cesación tabáquica y el médico tiene que resolver esta situación y luego en el tiempo restante si le queda, hacer un poco de indagación sobre consumo de tabaco y su cesación, además el tiempo de consulta médica es un poco limitado para profundizar en temas tan relevantes como este. Un estudio de la Sociedad Argentina de Cardiología demostró que al $70 \%$ de los profesionales se les exige ofrecer turnos de 10 a 15 minutos, en tanto que ellos pensaban que lo correcto sería que las consultas tuvieran una duración entre 20 y 30 minutos; de igual manera consideraron que constituye una falta a la ética aceptar atender pacientes en un tiempo inadecuado [95], razón que dificulta el accionar médico, limitado por el tiempo.

Algunos médicos indicaron la falta de pago adecuado para dar la consejería como una barrera en la realización de esta $9 \%$ de médicas y $13 \%$ de médicos.

El acceso al tratamiento para los pacientes estuvo limitado por el costo del tratamiento, los largos tiempos de espera y el enfoque en la orientación cara a cara [102].

Las intervenciones para promover el abandono del hábito de fumar entre los médicos describen que los programas que promueven el abandono del hábito de fumar entre los médicos es escaso en los países en desarrollo. Solo tres estudios proporcionaron información breve sobre la naturaleza de tales intervenciones de cesación. Mirra y Rosemberg [74] informaron que en Brasil hay pocos programas de reducción del consumo de tabaco o para dejar de fumar que los médicos seleccionados, pero los detalles sobre esos programas no estaban disponibles. Barnoya informó que los fumadores de médicos que habían dejado de fumar en el pasado, habían usado principalmente el método de "cold turkey", y ninguno había probado la terapia de reemplazo de nicotina NRT [90]. Viegas [103] informó, también en Brasil, que las tres cuartas partes de los fumadores eran informados por sus propios médicos compañeros para dejar de fumar. Algunos estudios sugirieron diferentes medidas para reducir el consumo de tabaco entre los médicos $[74,76,87,98$, 88, 104]. Estos incluyen la introducción de la educación para el control del tabaco en la escuela de medicina; una iniciativa de política para prohibir a los médicos que entren a sms para dejar de fumar como parte del plan de acción nacional; una campaña de 
concientización personalizada para los médicos, y servicios de apoyo para dejar de fumar personalizados para los médicos.

\subsection{Creencias sobre la consejería de cesación de tabaquismo del médico general de la FAMG a sus pacientes}

Con respecto a las creencias sobre la consejería de cesación de tabaquismo entre los médicos no se observaron diferencias, sin embargo, cuatro de cinco medicas estaban convencidas que son capaces de aconsejar a sus pacientes de forma coherente y efectiva en el caso que no fuman.

En Israel, Samuels [10] preguntó a los médicos si aconsejaban o no a los pacientes que dejaran de fumar durante las consultas y no encontraron diferencias entre los fumadores y los no fumadores. Un estudio longitudinal de médicos chinos también reveló que los efectos del hábito de fumar en el comportamiento de asesoramiento variaron entre 1987 y 1996 [105]. En 1987, por ejemplo, el comportamiento de fumar era un factor influyente, mientras que en 1996 había dejado de serlo [105].

Alrededor del $90 \%$ los médicos indicaron necesitar entrenamiento sobre prevención del tabaquismo, si bien los médicos han recibido durante su formación en el pregrado o especialidad entrenamiento sobre este tema, es importante generar espacios donde se actualicen sobre el comportamiento del evento y las indicaciones terapéuticas a seguir, este tipo de entrenamientos o capacitación, están directamente relacionadas al accionar médico

y no se encontró evidencia que sea algo impartido por el Ministerio de Salud (Nacional o Provincial).

En la Argentina un estudio sobre asesoramiento médico a mujeres embarazadas sobre tabaquismo activo y de segunda mano, mostro que sólo el $22 \%$ había recibido capacitación en consejería para dejar de fumar y el 48,5\% reportó conocimientos insuficientes para proporcionar consejos para dejar de fumar [106].

Según un estudio en Grecia, solo la mitad de los médicos fumadores participaron en la asesoría para dejar de fumar, en comparación con el $100 \%$ de sus colegas que no fuman [107]. Varios estudios japoneses revelaron diferencias en los consejos para dejar de fumar [108] y en el historial de tabaquismo de un paciente [109], siendo ambos mucho más 
comunes entre los médicos que no fuman. También se observaron hallazgos similares en Finlandia [110], mientras que Pärna et al [100] revelaron que los médicos de Estonia que fumaban se mostraban reacios a perturbar la privacidad de un paciente al preguntar por su consumo de tabaco.

\subsection{Conocimientos sobre los efectos del tabaquismo de los médicos generales de la FAMG}

En general los médicos tenían conocimientos sobre los efectos adversos del hábito de fumar, su relación con ciertas enfermedades, así como la patogenia.

Aun así, están fuera de toda duda los efectos nocivos del tabaco sobre la salud de los fumadores, habiéndose relacionado su consumo con más de 25 enfermedades, entre ellas el $30 \%$ de los cánceres diagnosticados en la población. Aunque se relaciona el tabaquismo con neoplasias de la cavidad oral, laringe, faringe, esófago, vejiga y riñones, es con el cáncer de pulmón con el que directamente está asociado [111]. Así como la enfermedad pulmonar obstructiva crónica EPOC, enfermedad con la que muchos de los fumadores tienen que convivir [112]; a pesar de que su pronóstico ha ido mejorando en el tiempo, continúa suponiendo una morbimortalidad importante que precisa de amplios recursos asistenciales y sociales para su tratamiento [113, 114]. Sin embargo, en este estudio algunos médicos no tenían la certeza del riesgo para el desencadenamiento de algunas enfermedades especialmente para los niños expuestos pasivamente al humo del tabaco, quienes tienen un $20 \%$ más riesgo de desarrollar cáncer de pulmón y $30 \%$ más de presentar enfermedades cardiacas comparado con los no fumadores [115].

No se puede dejar a un lado el consumo de tabaco en la mujer embarazada, este efecto negativo del humo del tabaco afecta el feto, implicando además la dificultad de las madres para dejar el consumo y la limitación que existe en la ayuda farmacológica que se les puede aportar $[116,117]$. Seguir fumando después del cáncer afecta negativamente la calidad de vida y la supervivencia, pero una quinta parte de los sobrevivientes de cáncer aún fuman [118].

El hábito de fumar a menudo ocurre en grupos sociales, por lo tanto, las intervenciones dirigidas a familias e individuos pueden ser más exitosas. Este estudio cualitativo de Wells 
et al, "Barriers and facilitators to smoking cessation in a cancer context: A qualitative study of patient, family and professional views", exploró los puntos de vista de pacientes, familiares y profesionales de la salud acerca de fumar y dejar de fumar después del cáncer, para informar futuras intervenciones [118].

En la Argentina, la exposición habitual al humo de tabaco ajeno ha descendido entre las tres encuestas nacionales (52\% en $2005,40,4 \%$ en 2009 y $36,3 \%$ en 2013). Mientras que la exposición en lugares de trabajo bajó del $34 \%$ al $25 \%$ y en bares y restaurantes del $47,2 \%$ al $23,5 \%$ entre 2009 y 2013 [65]. Los médicos exfumadores, en relación con los fumadores y los no fumadores, tenían más edad y mayor prevalencia de factores de riesgo vascular, mayor proporción de eventos vasculares y, además, fueron sometidos a procedimientos de revascularización con más frecuencia. Posiblemente estos antecedentes pudieron haber influido sobre su conducta frente al tabaco [67].

\subsection{Relación entre el hábito de fumar del médico general de la FAMG y la consejería que realizan}

Se puede afirmar que los médicos generales están en condiciones de influir en el comportamiento de la población general, especialmente en lo que respecta a sus hábitos de fumar [78].

En este estudio, los médicos generales que fuman tuvieron una probabilidad más alta de aconsejar sobre cesación de tabaquismo en pacientes que se presentan sin enfermedades crónicas relacionadas comparando con los médicos que no fuman. No se encontraron asociaciones entre el hábito de tabaquismo de los médicos y la aconsejaría de cesación de tabaquismo en pacientes que se presentan con enfermedades crónicas.

En la Argentina se estimó a través del estudio TAMARA que alrededor de un tercio de los profesionales médicos fuman y que un número importante de ellos reúnen criterios de dependencia moderados a mayores [67].

El 94,3\% de los médicos daban consejo a sus pacientes para dejar de fumar en forma ocasional o frecuente y la proporción de los médicos ex fumadores y no fumadores fue superior a la de los médicos fumadores. En otros registros se pudo observar que la frecuencia de profesionales que brindaban consejo a los pacientes tabaquistas fue variable [67]. 
Con respecto a las prácticas antitabaco, la mayoría de los médicos en un estudio británico [119] consideraron que deberían recomendar a los pacientes que dejen de fumar, y en Francia [16] más de la mitad del consumo de tabaco por parte de los médicos había realizado al menos un intento serio de dejar de fumar. Sin embargo, en Italia [120], más de la mitad de los médicos que fumaban actualmente no habían intentado dejar de fumar, y en Japón [41] solo el $60 \%$ de los fumadores manifestaron su intención de reducir su consumo de tabaco o dejar de fumar por completo. Otros autores ya han sugerido que los médicos japoneses pueden no estar dando un buen ejemplo a este respecto [109].

Según el estudio TAMARA, realizado en Argentina, existe una gran asociación entre la capacitación en tabaquismo y la frecuencia del consejo médico y/o la utilización de tratamiento farmacológico para dejar de fumar [67]. Ese estudio identifico que el $30 \%$ de los médicos se habían capacitado, habían realizado algún curso o habían participado en alguna reunión sobre tabaquismo, y estos a su vez brindaban significativamente más frecuente consejo y tratamiento farmacológico a sus pacientes para lograr el abandono del hábito de fumar [67]. TAMARA II también identifico una asociación significativa entre la presencia de antecedentes de familiares fumadores y el inicio y mantenimiento del tabaquismo en los médicos [68, 121, 122].

En Canadá, a través de un estudio de Tremblay et al," Physicians Taking Action Against Smoking: an intervention program to optimize smoking cessation counselling by Montreal general practitioners" [123] comprobaron, luego de la terminación de entrenamiento sobre tabaquismo a médicos, que se incrementaba la prevalencia de médicos brindando asistencia a pacientes fumadores. El desarrollo de esta actividad podría generar un gran impacto en la salud pública por el gran beneficio que se logra y el bajo costo de la intervención [67, 124, 125].

Los profesionales de la salud pueden intervenir, al influir en la percepción y actitudes de los individuos frente a esta adicción. Pueden educar en el momento de la asistencia médica, ejercer ejemplo a seguir y sensibilizar sobre los problemas de salud que son consecuencia del tabaquismo [126]. 
Es importante para la salud pública la enseñanza sobre los efectos del tabaquismo y el entrenamiento a los médicos en métodos para dejar de fumar, ya que la actitud del profesional con respecto al tabaco va a estar en relación directa con la información que ellos tengan [67].

Los ex fumadores se iniciaron en el tabaquismo a edades más tempranas. Los médicos fumadores fumaban más frecuentemente en las áreas que no estaban autorizadas o mientras se encontraban cumpliendo sus funciones en el hospital. También, el $30 \%$ de Estos fumaban al despertar, más del $70 \%$ lo hacía por la mañana y un tercio lo hacía aun cuando padecían de alguna enfermedad [121].

Las instituciones donde trabajan los médicos también pueden desempeñar un papel importante en el control del tabaco. Un estudio de los Estados Unidos [127] demuestra que la política de no fumar en el hospital fue útil para ayudar a reducir la tasa general de fumadores entre el personal. Los hospitales en los Estados Unidos fueron la primera industria en declarar una prohibición nacional de fumar a principios de la década de 1990, y más tarde influyeron en las normas sociales y probablemente redujeron las tasas generales de consumo de tabaco [128].

Aun así, se observa una prevalencia del hábito no solo entre la población general, sino también entre los profesionales de la salud, si bien los médicos tienen información científica y cualificada sobre el daño del tabaco, aportan un alto porcentaje en la adicción.

En Argentina, el estudio TAMARA II identifico un alto número de médicos $(85,6 \%)$ que fumaban en su ámbito laboral, como son los hospitales [68].

En este tipo de instituciones de salud, vendría bien una estricta implementación de una política hospitalaria libre de humo, lo que permitiría seguramente entre otros aspectos un control de tabaco en el personal de salud.

Sin embargo y a pesar de que, en Argentina, los médicos fuman, en un porcentaje similar al de la población general. De los que fuman, un $40 \%$ lo hace durante su trabajo en el hospital, incluso en zonas donde rige la prohibición de hacerlo. Coincidentemente, los médicos que fuman omiten con mayor frecuencia el consejo a sus pacientes. En cambio, quienes recibieron algún tipo de entrenamiento en tabaquismo brindan consejo y prescriben fármacos para el cese más frecuentemente [66]. 
Se considera que independientemente de las razones que llevan a fumar a los médicos, trabajadores de la salud, que ven a diario las consecuencias de la adicción en los pacientes que atienden, fuman igual que los pacientes que seguramente atienden [129], mientras no se revierta esta situación y se tome real conciencia de los daños a la salud individual y colectiva, cualquier estrategia de prevención del tabaquismo estará abocada al fracaso [129].

Los médicos exfumadores presentaron mayor prevalencia de factores de riesgo vascular y brindaron más consejos a sus pacientes para abandonar el tabaco [67].

El comportamiento personal de fumar de un médico afecta su actitud profesional y el comportamiento clínico representa un problema en la política de salud pública, ya que los médicos están en la primera línea de la atención primaria de salud [79].

Si bien los profesionales médicos tienen muchas oportunidades para reducir la prevalencia del hábito de fumar entre sus pacientes, es posible que los médicos aún no hayan maximizado sus esfuerzos para enfrentar la epidemia del tabaco. Los médicos incurren en cierta responsabilidad como ejemplares para los pacientes con respecto a la conducta saludable $[79,130]$, así como la imagen pública que retratan inadvertidamente fuera del entorno laboral $[79,131]$. Tener médicos que fuman puede aumentar el escepticismo público, y las personas se inclinan a preguntar ¿por qué deberían dejar de fumar cuando su médico continúa haciéndolo? [18].

En el estudio de Addullah et al, se mostró que de acuerdo a las prácticas de asesoramiento para dejar de fumar entre médicos y otros profesionales de la salud, consideraron que ayudar a los pacientes a dejar de fumar era parte de su trabajo [96, 88, 89]. En BosniaHerzegovina [132] y Senegal [87], los médicos consideraron que los pacientes probablemente escucharían sus consejos para dejar de fumar. Sin embargo, en Turquía [93] y China [105], los médicos consideraron que su papel era menor en la decisión del paciente de renunciar.

Estudios de diferentes países de Latino América, mostraron las cifras de la población interesada en dejar de fumar, en Brasil el 73,3\% de los fumadores ya han tratado de dejar de fumar [83]. En Chile, el 45\% de los fumadores están interesados en dejar de fumar [133]. En Guatemala, el $40 \%$ de los residentes que fumaron dijeron que lo hicieron en el trabajo. $76 \%$ de los fumadores dijeron que les gustaría dejar de fumar [90], y en Costa Rica, el 29\% 
de los fumadores de médicos quieren dejar de fumar y el $44 \%$ ha dejado de hacerlo en algún momento en el pasado [87]. Así se evidencia cifras importantes de población sensibilizada e interesada en dejar el hábito de fumar, población en la cual se deben de profundizar las acciones integrales en salud y fortalecer el acompañamiento integral para la cesación de tabaquismo.

\subsection{Relación entre el hábito de fumar del médico general de la FAMG y las creencias sobre la consejería de cesación de tabaquismo a sus pacientes}

El médico, a través de sus consejos y actitudes, debe ser ejemplo para sus pacientes, así estimularlos y ayudarlos a adoptar hábitos de vida saludables, de esta manera evitan el desarrollo de enfermedades futuras [67].

El estudio TAMARA II, "destaca la influencia que los médicos fumadores, como padres, pueden ejercer sobre la posibilidad de que sus hijos adquieran la adicción al tabaco, alcanzando una probabilidad casi 4 veces mayor" [68]. En este mismo estudio mostro que los médicos que tenían capacitación en tabaquismo mostraron una mayor probabilidad de dar siempre el consejo para el cese del consumo de tabaco a sus pacientes [68]. De igual manera otro estudio realizado en Argentina mostró que un escaso entrenamiento antitabaco se asociaba negativamente con el ofrecimiento de consejo [106].

En este estudio, los hábitos de tabaquismo de los médicos general no fueron asociados con las creencias.

Los pacientes, al observar que sus médicos fuman, pueden interpretar erróneamente que el tabaquismo no es perjudicial para la salud, de modo que es importante que los médicos abandonen el consumo de tabaco por la influencia que ejercen naturalmente sobre sus pacientes [67, 134, 135].

La investigación alrededor del tabaco conforma importantes grupos de científicos que de forma multidisciplinar profundizan en su estudio. Por todo ello, el consumo de tabaco ha sido reconocido como la causa aislada más importante de morbimortalidad prematura prevenible [112]. 
Fumar tabaco generalmente genera una imagen negativa en la profesión del cuidado de la salud mucho antes de que lo haga en la comunidad en general [136]. En este sentido, los médicos están bien equipados para evaluar el conocimiento científico, y puede esperarse razonablemente que actúe sobre nuevos descubrimientos, si está justificado [137]. Además, las tasas de tabaquismo en los países desarrollados tienden a disminuir con el tiempo debido a un efecto generacional, ya que el clima social de un país cambia y más personas dejan de fumar, incluidos los médicos [138].

En la Argentina existe específicamente la guía de práctica clínica nacional de tratamiento de la adicción al tabaco, que incluye el accionar médico y de profesionales del área de la salud hacia el manejo integral de los pacientes fumadores y cuyo objetivo basado en la evidencia científica es proveer al equipo de salud, las herramientas necesarias para intervenir en la recuperación de la dependencia del tabaco; aquí se describen las recomendaciones acerca de tratamientos a aplicar para ayudar a dejar de fumar, basadas en evidencia de alta calidad y adaptada al marco local. Esta es sin duda una herramienta importante en la lucha contra el tabaquismo y la adicción [56]. Sin embargo, en esta guía ni

en las reglamentaciones existentes existen reglas o indicadores para que no haya consumo de tabaco dentro del personal de salud, indicador que generaría ejemplo y estándares en la aplicabilidad de este documento.

Este análisis hace un abordaje general de la dependencia entre el médico fumador o consumidor de tabaco y su relación con la consejería en cesación de tabaquismo hacia sus pacientes, describiendo la consejería del médico, identificando barreras, creencias sobre consejería, indagando sobre conocimientos sobre la temática y la relación entre la realización del hábito de fumar del médico general y la consejería que realizan.

\subsection{Limitaciones del estudio}

Esta investigación tenía como objetivo contar con la participación de la totalidad 660 de los médicos generales inscritos en el congreso realizado por la FAMG, institución que agrupa estos profesionales argentinos; sin embargo, solo se obtuvo un $18 \%$ de participación. 
La encuesta fue distribuida a la totalidad de los participantes, no todos la respondieron, solo 119 de ellos lo hicieron, y de estos solo 81 respondieron la totalidad de la encuesta, el restante (38 participantes), lo hicieron de manera incompleta; quizá para tener en cuenta en un futuro donde se aplique este material, hacer un acompañamiento a los profesionales para que se facilite su diligenciamiento y una sensibilización previa sobre la importancia del diligenciamiento completo de este material.

Una de las limitaciones de nuestra investigación, es que el estudio consistió de una muestra por conveniencia. Por eso, a pesar de tener una validez interna buena, la validez externa es baja, y no permite generalizar los resultados de la parte descriptiva a todos los MG de la FAMG. Una razón para no encontrar asociaciones estadísticamente significativas pudo haber sido por la falta de poder del estudio, esto debido a la baja tasa de respuesta, dado que se podría estimar que la cantidad de profesionales no fueron suficientes para responder a las preguntas planteadas.

Sin embargo, el complemento de este estudio con el análisis cualitativo permite obtener información interesante para el desarrollo de nuevas preguntas de investigación e hipótesis para estudios más grandes en muestras representativas.

Al realizarse la investigación con la fuente principal de información basada en el auto reporte, a través de la encuesta, no fue posible identificar claramente si la totalidad de informantes que reportaron ser fumadores realmente lo fueran o aquellos que informaron no fumar, verificar si realmente ese era su estado. Si bien no se estimó en este estudio verificar este estado, sería importante para investigaciones futuras incorporar muestras objetivo como por ejemplo niveles de nicotina en orina, para así confirmar si los participantes son fumadores o no, y que tanto se puede sesgar el estudio con respuestas abiertas de este tipo.

El estudio tuvo la limitación en el tiempo, dado que esta información fue analizada años posteriores a la aplicación de la encuesta, lo que tal vez hubiese permitido dar continuidad en la aplicación de la encuesta, fortalecimiento de acción e intervención en años siguientes, dado que el escenario académico de la FAMG es amplio y constante y tiene profesionales vinculados en todo el país. 
Otro punto por considerar es la limitada información disponible sobre estudios de este tipo, que permitiera realizar comparaciones más puntuales y un análisis desde otra óptica. 


\section{CONCLUSIONES Y RECOMENDACIONES}

\subsection{Conclusiones}

De este estudio se concluye que, si bien se han fortalecido las acciones en torno a la disminución del consumo de tabaco en el país, y se han fortalecido diversos escenarios de forma integral (etiquetado, espacios libres de humo entre otros), aun es necesario fortalecer la lucha para el logro de hospitales libres de humo y la disminución de este consumo dentro del personal de salud, para que existan herramientas más claras en la prescripción de cesación de consumo en la población.

La Argentina, es un país que ha venido fortaleciendo las acciones de manera integral para luchar contra el fenómeno del tabaquismo. Las cifras demuestran el gran trabajo multisectorial que ha realizado el gobierno local, provincial y nacional entorno al fortalecimiento de acciones para disminuir la población afectada por el tabaco. Importantes avances que se tienen que fortalecer en torno al consumo y la exposición del humo de tabaco, es necesario intensificar y fortalecer las acciones de comunicación y educación en salud, garantizando el cumplimiento de las leyes y la aplicación de guías para tratamiento y adicción al tabaco.

El papel del médico dentro de la población en general sigue siendo pieza clave para el cambio de hábitos en las comunidades, de ahí que, si los médicos están entrenados y conscientes de los perjuicios que causa el tabaquismo, con su ejemplo en no fumar, se influiría positivamente en los cambios de hábitos.

Es importante contar desde la formación académica con la enseñanza de los efectos perjudiciales del tabaquismo. El fenómeno del tabaquismo está contribuyendo a una epidemia, donde no solo la persona que realiza el consumo afecta su salud, sino también el entorno que lo rodea. 
Es importante dar las herramientas intelectuales a los profesionales del área de la salud, para que se implementen programas para dejar de fumar y hacer énfasis en los efectos colaterales que este hábito genera.

\subsection{Recomendaciones}

Sensibilizar al personal médico y de salud en general, sobre la importancia de la consejería en cesación de tabaquismo, el escenario de la FAMG es un excelente espacio para propiciar este tipo de actividades, así mismo repetir la encuesta, dado que este cuenta con validaciones en países que incluyen Argentina y estándares en donde se pueden medir específicamente variables de interés, que permitirían la construcción de indicadores de mejora en un tema tan importante como el tabaquismo. Así mismo se generan espacios de empoderamiento en el papel del médico en la consejería.

Si bien tanto las acciones de prevención y control que se están adelantando en el país, en torno al consumo de tabaco se han articulado con varios sectores importantes, no se puede dejar a un lado el sector educativo, e involucrar a la academia, el papel importante de los profesionales del área de salud, y su formación desde el pregrado para que enfaticen a sus pacientes en el desarrollo de actividades en torno a la prevención en salud y control de enfermedades, favoreciendo espacios de hábitos y estilo de vida saludable.

Direccionamiento nuevo en las estrategias en el servicio de salud que permitan el seguimiento y control de pacientes que ingresa en los servicios de cesación de tabaquismo, con el fin de llegar al objetivo de abandono del hábito y mejora de la calidad de vida. 


\section{BIBLIOGRAFIA}

1. Centro para el Control y la Prevención de Enfermedades CDC. El cáncer y el consumo de tabaco. [Internet]. [Consultado octubre 15 de 2018]. Disponible en: https://www.cdc.gov/spanish/signosvitales/cancer-tabaquismo/index.html

2. Ministerio de la Salud, Presidencia de la Nación Argentina. Guía de Práctica Clínica Nacional de Tratamiento de la Adicción al Tabaco. Recomendaciones basadas en la evidencia científica. 2016. [Internet]. [Consultado octubre 15 de 2018]. Disponible en: http://www.msal.gob.ar/images/stories/bes/graficos/0000000536cnt-2017-06 guiatratamiento-adiccion-tabaco guia-breve.pdf

3. Rossi S, Roger ME, Leguiza J, Irurzun A. Carga global de enfermedad por tabaquismo en la Argentina" resumen de los resultados. [Internet]. [Consultado octubre 16 de 2018]. Disponible en http://www.msal.gob.ar/images/stories/bes/graficos/0000000034cntcarga-global-enfermedad-tabaquismo-argentina.pdf

4. Ministerio de la Salud, Presidencia de la Nación Argentina. Encuesta Mundial de Tabaquismo en Adultos. 2012. [Internet]. [Consultado octubre 16 de 2018]. Disponible en: $\quad$ http://www.msal.gob.ar/tabaco/images/stories/info-equipos-de-salud/pdf/201309 encuesta-tabaquismo-adultos-25-junio.pdf

5. Konfino J, Ondarsuhu D, Goldberg, et al. Encuesta mundial de tabaquismo en adultos 2012: resultados de la primera implementación en Argentina. Rev. Argent salud pública, [Internet]. 2013 [Consultado octubre 15 de 2018]; 4(16):6-15. Disponible en: http://rasp.msal.gov.ar/rasp/edicion-completa/RASPVolumen-XVI.pdf

6. Van Reek, Adriaanse H. Smoking by physicians in Scandinavia: 1952-1989. Scand J Soc Med [Internet]. 1991 [Consultado octubre 20 de 2018]; Dec; 19(4):256-9. Disponible en: https://www.ncbi.nlm.nih.gov/pubmed/1775961

7. Barengo N, Sandström P, Vesa J, et al. Changes in smoking prevalence among Finnish physicians 1990-2001. European Journal of Public Health [Internet], 1 June 2004, [Consultado octubre 10 de 2018]; Volume 14, Issue 2, Pages 201-203. Disponible en: https://www.ncbi.nlm.nih.gov/pubmed/15230511 
8. Bener A1, Gomes J, Anderson JA. Smoking habits among physicians in two Gulf countries. J R Soc Health [Internet], 1993 [Consultado octubre 12 de 2018]; Dec; 113(6):298-301. Disponible en: https://www.ncbi.nlm.nih.gov/pubmed/8308847

9. Lancaster T, Silagy C, Fowler G. Training health professionals in smoking cessation. Cochrane Database Syst Rev. [Internet] 2000 [Consultado octubre 10 de 2018]; (3):CD000214.

Disponible

en:

https://www.cochranelibrary.com/cdsr/doi/10.1002/14651858.CD000214/abstract

10. Samuels $\mathbf{N}$. Smoking among hospital doctors in Israel and their attitudes regarding antismoking legislation. Public Health. [Internet] 1997 [Consultado octubre 12 de 2018]; Sep; 111(5):285-8. Disponible en: https://www.cochranelibrary.com/cdsr/doi/10.1002/14651858.CD000214/abstract

11. Kaetsu A, Fukushima T, Moriyama M, Shigematsu T. Change of the smoking behavior and related lifestyle variables among physicians in Fukuoka, Japan: a longitudinal study. J Epidemiol. [Internet] 2002 [Consultado septiembre 1 de 2018]; May;12(3):208-16.z. Disponible en: https://www.ncbi.nlm.nih.gov/pubmed/12164322.

12. Kaetsu A, Fukushima T, Moriyama M, Shigematsu T. Smoking behavior and related lifestyle variables among physicians in Fukuoka, Japan: a cross sectional study. J Epidemiol. [Internet] 2002 [Consultado septiembre 1 de 2018]; May;12(3):199-207. Disponible en: https://ci.nii.ac.jp/naid/130000797574

13. Mcllvain HE, Backer EL, Crabtree BF, Lacy N. Physician attitudes and the use of office-based activities for tobacco control. Fam Med. [Internet] 2002 [Consultado septiembre 16 de 2018]; Feb; 34(2):114-9. Disponible en: https://nebraska.pure.elsevier.com/en/publications/physician-attitudes-and-the-use-ofoffice-based-activities-for-to

14. Liu JLY, Tang JL. Doctors are ethically obliged to advise patients to quit smoking. BMJ [Internet] 1998; [Consultado octubre 10 de 2018]; 317:1588. Disponible en: https://www.ncbi.nlm.nih.gov/pmc/articles/PMC1114397/

15. McEwen A, West R. Smoking cessation activities by general practitioners and practice nurses. Tobacco Control [Internet] 2001; [Consultado octubre 10 de 2018]; 10:27-32. Disponible en: https://tobaccocontrol.bmj.com/content/10/1/27

16. Tessier JF, Rene L, Nejjari C, Belougne D, et al. Attitudes and opinions of French general practitioners towards tobacco. Tob Control. [Internet] 1993 [Consultado octubre 
11 de 2018]; Sep; 2(3): 226-230. Disponible en: https://www.ncbi.nlm.nih.gov/pmc/articles/PMC1759269/

17. Willaing I, Jørgensen T, Iversen L. How does individual smoking behaviour among hospital staff influence their knowledge of the health consequences of smoking? Scandinavian Journal of Public Health [Internet] 2003 [Consultado octubre 15 de 2018]; First Published March 1, 2003 other https://doi.org/10.1080/14034940210164876. Disponible en: https://journals.sagepub.com/doi/abs/10.1080/14034940210164876

18. Eckert T, Junker C. Motivation for smoking cessation: what role do doctors play? Swiss Med Wkly [Internet] 2001 [Consultado octubre 13 de 2018] Sep 8; 131(35-36):521-6. Disponible en: Swiss medical weekly: official journal of the Swiss Society of Infectious Diseases, the Swiss Society of Internal Medicine, the Swiss Society of Pneumology

19. Ruggiero L, Redding CA, Rossi JS, Prochaska JO. A stage-matched smoking cessation program for pregnant smokers. Am J Health Promot [Internet] 1997 [Consultado octubre 11 de 2018] Sep-Oct; 12(1):31-3. Disponible en: https://journals.sagepub.com/doi/10.4278/0890-1171-12.1.31

20. Velicer WF, Prochaska JO, Rossi JS, Snow MG. Assessing outcome in smoking cessation studies. Psychol Bull. [Internet] 1992 [Consultado octubre 16 de 2018] Jan; 111(1):23-41. Disponible en: https://www.researchgate.net/publication/21616814 Assessing Outcome in Smoking Cessation Studies

21. Doran C, Valenti L, Robinson M, Mattick R. Smoking status of Australian general practice patients and their attempts to quit. Addictive Behaviors. [Internet] 2006 [Consultado octubre 15 de 2018] Volume 31, Issue 5, May 2006, Pages 758-766. Disponible en: https://www.sciencedirect.com/science/article/abs/pii/S0306460305001590?via\%3Dihu $\underline{\mathrm{b}}$

22. Chapman S. Doctors who smoke. BMJ. [Internet] 1995 [Consultado octubre 15 de 2018] Jul 15; 311(6998):142-3. Disponible en: https://www.bmj.com/content/311/6998/142

23. Adriaanse H, Van Reek. Tobacco prevention in hospitals needs prolonged and sustained effort. Br J Addict. [Internet] 1991 [Consultado octubre 15 de 2018] Jun; 86(6):703-4. Disponible en: https://onlinelibrary.wiley.com/doi/abs/10.1111/j.1360$\underline{0443.1991 . t b 03094 . x}$ 
24. Organización Mundial de la Salud OMS. Tabaco. Datos y cifras. [Internet]. [Consultado octubre 15 de 2018]. Disponible en: https://www.who.int/es/newsroom/fact-sheets/detail/tobacco

25. Zurro A, Caro J. Atención primaria, conceptos, organización y práctica clínica. [Internet]. 2003. [Consultado octubre 10 de 2018]. Elsevier p 135. Disponible en: https://www.elsevier.es/es-revista-medicina-clinica-2-articulo-critica-libros$\underline{\mathrm{S} 0025775311004283}$

26. Engler T. El médico general y los servicios médicos a la comunidad. Educ Med Salud. [Internet] 1981. [Consultado octubre 13 de 2018]; 15(2):115-23. Disponible en: http://hist.library.paho.org/Spanish/EMS/5743.pdf

27. Ledesma F, Martínez $\mathbf{O}$. Medicina familiar: la auténtica especialidad en atención medica primaria. Medicina familiar. [Internet] 2008 [Consultado octubre 18 de 2018]; 116 (4) 330-340. Disponible en: https://www.researchgate.net/publication/262588576 Medicina familiar la autentica especialidad en atencion medica primaria

28. Pracilio H. Perfil profesional del Médico General Familiar, Programa de Educación Continua a distancia "MGF21", Cap. 1, Centro INUS, Facultad de Ciencias Médicas, UNLP, La Plata. 2003

29. Organización Mundial de la Salud OMS. Prevención de las enfermedades crónicas: Una inversión vital. Panorama general. Disponible: https://www.who.int/chp/chronic disease report/overview sp.pdf?ua=1

30. Gimenez B, Kazue R, Nishikawa Yagi MC, et al. Enfermedades cardiovasculares antes y después del Programa Salud de la Familia, Londrina, Paraná. Arq. Bras. Cardiol. [Internet]. 2009 vol.93 no.6 São Paulo Dec. 2009 [Consultado octubre 18 de 2018]; Epub Oct 09, $2009 . \quad$ Disponible en: http://www.scielo.br/scielo.php?script=sci arttext\&pid=S0066782X2009001200014\&lng=pt\&tlng=es

31. Sánchez M, Aparicio G. La distribución del tiempo como definición operativa del estilo de vida. Alambique, Vol. 2, No 2, 36-53. 2000

32. Sanabria P, González L, Urrego D. Estilos de vida saludable en profesionales de la salud colombianos. Revista médica Universidad Militar Nueva Granada. [Internet] 2007 [Consultado octubre 17 de 2018]; 15 (2): 207-217, 2017. Disponible en: 
https://www.researchgate.net/publication/28184919 Estilos de vida saludable en pr ofesionales de la salud colombianos Estudio exploratorio

33. Andersen R, Blair S, Cheskin LJ, Bartlett S, et al. Encouraging Patients to Become More Physically Active: The Physician's Role. Ann Intern Med. [Internet] 1997 [Consultado octubre 17 de 2018]; Sep 1; 127(5):395-400. Disponible en: https://annals.org/aim/article-abstract/710792/encouraging-patients-become-morephysically-active-physician-s-role

34. Elley CR, Verse N, Arroll B, Robinson E. Effectiveness of counseling patients on physical activity in general practice: Cluster randomised controlled trial. BMJ. [Internet] 20031997 [Consultado octubre 17 de 2018]; Apr 12; 326(7393): 793. doi: 10.1136/bmj.326.7393.793.

Disponible

en: https://www.ncbi.nlm.nih.gov/pmc/articles/PMC153098/

35. Butler CC, Pill R, Stott NC. Qualitative study of patients' perceptions of doctors' advice to quit smoking: implications for opportunistic health promotion. BMJ [Internet] 1998 [Consultado octubre 17 de 2018]; 316. doi: https://doi.org/10.1136/bmj.316.7148.1878. Disponible en: https://www.ncbi.nlm.nih.gov/pmc/articles/PMC28587/

36. Wallace PG, Brennan PJ, Haines AP. Are general practitioners doing enough to promote healthy lifestyle? Findings of the Medical Research Council's general practice research framework study on lifestyle and health. Br Med J (Clin Res Ed) [Internet] 1987 [Consultado octubre 17 de 2018]; 294: 940-2. 1987. Disponible en: https://www.ncbi.nlm.nih.gov/pmc/articles/PMC1246006/

37. Coleman T, Wilson A. Anti-smoking advice in general practice consultations: general practitioners' attitudes, reported practice and perceived problems. $\mathrm{Br} J$ Gen Pract. [Internet] 1996 Feb; 1987 [Consultado octubre 17 de 2018]; 46(403): 87-91. Disponible en: https://www.ncbi.nlm.nih.gov/pmc/articles/PMC1239536/

38. Ellerbeck EF, Ahluwalia JS, Jolicoeur DG, Mosier MC et al. Direct observation of smoking cessation activities in primary care practice. J Fam Pract. [Internet] 2001 [Consultado octubre 19 de 2018]; Aug; 50(8):688-93. Disponible en: https://www.mdedge.com/familymedicine/article/60611/addiction-medicine/directobservation-smoking-cessation-activities

39. Heywood A, Firman D, Sanson-Fisher R, Mudge P, Ring I. Correlates of physician counselling associated with obesity and smoking. Prev Med [Internet] 1996 [Consultado octubre 19 de 2018]; 25: 268-76. Disponible en: 
https://www.researchgate.net/publication/14421851 Correlates of Physician Counsel ing Associated with Obesity and Smoking

40. Christensen B. General practitioners and smoking. General practitioners' knowledge, attitudes and smoking habits and the relationship between these assessed by a questionnaire study in the county of Aarhus. [Internet] 1993 [Consultado octubre 19 de 2018]; Ugeskr Laeger 155:307-10. Disponible en: https://www.ncbi.nlm.nih.gov/pubmed/8447001

41. Kawakami M, Nakamura S, Fumimoto H, Takizawa J, Baba M. Relation between smoking status of physicians and their enthusiasm to offer smoking cessation advice. Intern Med. [Internet] 1997 [Consultado octubre 19 de 2018]; Mar; 36(3):162-5. Disponible

en: https://www.jstage.jst.go.jp/article/internalmedicine1992/36/3/36 $3 \quad 162 /$ article

42. World Health Organization - WHO Chron. Declaration of Alma-Ata. International Conference on Primary Health Care. [Internet] 1978 [Consultado octubre 19 de 2018] Nov; 32(11):428-30. Disponible en https://www.who.int/publications/almaata declaration en.pdf

43. Restrepo H, Malaga H. Promoción de la salud: Como construir vida saludable. [Internet] 2001 [Consultado octubre 20 de 2018] ISBN: 958-9181-55-4. 2001. Disponible en: https://books.google.com.co/books?id=g4gU P7vAEMC\&printsec=frontcover\&hl=es\&s ource $=g b s$ ge summary $r \& c a d=0 \# v=$ onepage $\& q \& f=f a l s e$

44. Anderson D, Keith J, Novak P, Elliot M. Diccionario Mosby Pocket medicina, enfermería y ciencias de la salud. Hacourt España, El Sevier [Internet] 2003. [Consultado octubre 20-25 de 2018] Disponible en: https://books.google.com.co/books?id=FjFO90C-

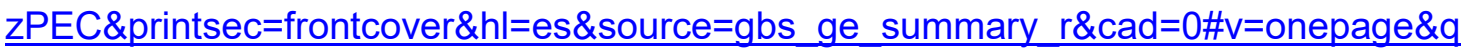
$\underline{\& f=f a l s e}$

45. Perea R. Educación para la Salud, Reto de nuestro tiempo. [Internet] Díaz de Santos. Universidad Nacional de Educación a Distancia. Disponible en: http://revistas.uned.es/index.php/educacionXX1/article/viewFile/361/314

46. Millán T, Morera I, Vargas NA. Teenager counselling in primary care. Rev Med Chil. [Internet] 2007 [Consultado octubre 30 de 2018] Apr; 135(4):457-63. Epub 2007 May 16. 
47. Alba L, Murillo R, Castillo JS. Intervenciones de consejería para la cesación de la adicción al tabaco: revisión sistemática de la literatura. Salud pública [Internet] 2013. [Consultado octubre 28 de 2018] Méx vol.55 no.2 Cuernavaca mar. labr. 2013. Disponible en: http://www.redalyc.org/html/106/10625599010/index.html

48. Faiver C, Eisengart S, Colonna R. The counselor intern's handbook. Australian Journal [Internet] 2004 [Consultado octubre 30 de 2018] of Guidance and Counselling 10:157. $\begin{array}{lllll}\text { November } 2000 & \text { (2nd } \quad \text { Ed.). ISBN }\end{array}$ https://doi.org/10.1017/S1037291100004210. Disponible en: https://www.worldcat.org/title/counselor-interns-handbook/oclc/52760419

49. Gines, A. Educación médica continua y permanente. Revista de Psiquiatría de Uruguay. [Internet] 2001 [Consultado octubre 30 de 2018]. Volumen 65 № 2 Octubre 2001/página 2. Disponible

en: http://www.saidem.org.ar/docs/Textos/Gin\%E9s\%20A.M.Educaci\%F3n\%20m\%E9dica \%20permanente\%20y\%20continua.pdf

50. Martínez, M. Conocimiento Científico General y Conocimiento Ordinario Cinta Moebio [Internet] 2006 [Consultado octubre 30 de 2018]. 27: 1-10. Disponible en: http://www.facso.uchile.cl/publicaciones/moebio/27/martinez.pdf

51. Fiore MC, Baker TB. Treating smokers in the health care setting. $\mathrm{N}$ Engl $\mathrm{J}$ Med. [Internet] 2011 [Consultado octubre 30 de 2018]. 365:1222-1231. DOI: 10.1056/NEJMcp1101512.

Disponible

en: https://www.nejm.org/doi/full/10.1056/NEJMcp1101512

52. Sandoval Y. ABECÉ cesación del consumo de tabaco: consejería breve. Ministerio de salud, Subdirección de Enfermedades No Transmisibles. Dirección de Promoción y Prevención. Colombia. [Internet] 2018 [Consultado octubre 29 de 2018]. Disponible en: https://www.minsalud.gov.co/sites/rid/Lists/BibliotecaDigital/RIDE/VS/PP/ENT/abececonsejeria-breve.pdf

53. Mottillo S, Filion KB, Bélisle P, Gervais A, et al. O'Loughlin J et al. Behavioral interventions for smoking cessation: a meta-analysis of randomized controlled trials. Eur Heart J. [Internet] 2009; 30:718-730. [Consultado octubre 29 de 2018]. Disponible en: https://academic.oup.com/eurheartj/article/30/6/718/641485.

54. Sociedad Española de Neumología y Cirugía Torácica. Guía de tratamiento del tabaquismo. Public Health Service. Barcelona. [Internet] 2010. [Consultado octubre 27 de 2018].

Disponible

en: 
https://www.ahrq.gov/sites/default/files/wysiwyg/professionals/cliniciansproviders/guidelinesrecommendations/tobacco/clinicians/update/treating tobacco use08 sp.pdf

55. Cabrera G. El modelo transteórico del comportamiento en salud. The transtheoretical model of health behavior. Rev. Fac. Nac. Salud Pública [Internet] 2000; 18(2): 129-138 [Consultado octubre 28 de 2018]. Disponible en: revistaestudiospoliticos.udea.edu.co/index.php/fnsp/article/download/997/869

56. Prochaska J, Velicer W. The transtheoretical model of health behavior change. American Journal of Health Promotion. [Internet] 1997; 12:38-48. [Consultado octubre 27 de 2018]. Disponible en: https://www.ncbi.nlm.nih.gov/pubmed/10170434

57. Polit, D. y Hungler, B. Investigación científica en Ciencias de la Salud ( $5^{\mathrm{a}}$ ed.). [Internet] 2000. México: McGraw-Hill.

58. Centers for Disease Control and Prevention (CDC). Tobacco Use and Cessation Counseling --- Global Health Professionals Survey Pilot Study, 10 Countries, 2005. MMWR Morb Mortal Wkly Rep. [Internet] 2005 [Consultado noviembre 5 de 2018] May 27; 54(20):505-9. Disponible en: https://www.ncbi.nlm.nih.gov/pubmed/15917734

59. Hubert-Lutecka A, Bartusik-Aebisher D, Żal M, et al. European Journal of Clinical and Experimental Medicine [Internet] 2018; [Consultado noviembre 6 de 2018] 3 | 177183. Disponible en: http://yadda.icm.edu.pl/yadda/element/bwmeta1.element.mhp9c71f5f9-ddda-4ba4-9b88-714e157a68be.

60. Compton M, Frank E. Mental health concerns among Canadian physicians: results from the 2007-2008 Canadian Physician Health Study. Comprehensive Psychiatry [Internet] 2011; [Consultado noviembre 12 de 2018] Volume 52, Issue 5, September-October 2011, Pages 542-547. Disponible en: https://www.sciencedirect.com/science/article/abs/pii/S0010440X10001690

61. Frank E, Segura C. Health practices of Canadian physicians Canadian Family Physician. Le Médecin de famille canadien [Internet] 2009; [Consultado noviembre 20 de 2018] Vol. 55: august - août 2009. Disponible en: https://www.cfp.ca/content/cfp/55/8/810.full.pdf

62. Duperly J, Lobelo F, Segura C, et al. The association between Colombian Medical students' healthy personal habits and a positive attitude toward preventive counseling: cross-sectional analyses. [Internet], 2009; [Consultado noviembre 20 de 2018] BMC Public Health, 2009. Disponible en: https://www.ncbi.nlm.nih.gov/pubmed/19575806 
63. Ministerio de salud de la República Argentina. Decreto 995 / 2000, poder ejecutivo Nacional. [Internet] 2000; [Consultado noviembre 26 de 2018]. Disponible en: https://www.argentina.gob.ar/normativa/nacional/decreto-995-2000-64791/texto

64. Ministerio de salud de la República Argentina. Guía para la investigación con Seres Humanos. [Internet], 2011 [Consultado noviembre 26 de 2018]. Disponible en: http://www.uba.ar/archivos secyt/image/Resolucion1480-11\%20Naci\%C3\%B3n.pdf

65. Instituto Nacional de Estadísticas y Censos, Ministerio de Salud, Presidencia de la Nación Argentina. Tercera encuesta nacional de factores de riesgo para enfermedades no transmisibles. [Internet], 2015. [Consultado noviembre 20, 21 y 26 de 2018].

Disponible

en:

http://www.msal.gob.ar/images/stories/bes/graficos/0000000544cnt-

20150904 encuesta nacional factores riesgo.pdf

66. Ministerio de Salud Presidencia de la Nación Argentina. Guía de Práctica Clínica Nacional de Tratamiento de la Adicción al Tabaco. [Internet] 2016. . [Consultado noviembre 20, 21 y 26 de 2018]. Disponible en: http://www.msal.gob.ar/images/stories/bes/graficos/0000000536cnt-2017-06 guiatratamiento-adiccion-tabaco guia-breve.pdf

67. Zylbersztejn HM, Cardone A, Vainstein N, et al. Tabaquismo en médicos de la República Argentina. Estudio TAMARA. [Internet] 2007; [Consultado diciembre 3 de 2018]; Rev. argent. cardiol. v.75 n.2 Buenos Aires mar. /abr. 2007. Disponible en: http://www.scielo.org.ar/scielo.php?script=sci arttext\&pid=S1850-37482007000200006

68. Zylbersztejn HM, Masson WM, Lobo LM et al. Tabaquismo en médicos de la República Argentina II. Estudio TAMARA II [Internet] 2015; [Consultado 15 de septiembre de 2018]; Revista Argentina De Cardiología / Vol. 83 N 33 / junio 2015. Disponible en: https://www.sac.org.ar/wp-content/uploads/2015/07/v83n3a10-es-1.pdf

69. Patiño C. El rol del médico en la lucha anti tabáquica. Alerg Inmunol Clin. [Internet] 2000; [Consultado 15 de septiembre de 2018]; 17(Suppl 1):s26.

70. Abdullah A, Stillman F, Yang L, Luo H et al. Tobacco Use and Smoking Cessation Practices among Physicians in Developing Countries: A Literature Review (1987-2010). Int. J. Environ. Res. Public Health [Internet] 2014; [Consultado septiembre 15 de 2018]; 11, 429-455; doi: 10.3390/ijerph110100429. Disponible en: https://www.ncbi.nlm.nih.gov/pmc/articles/PMC3924453/ 
71. Tobacco or Health: A global Status Report. Disponible en: http://whqlibdoc.who.int/publications/1997/924156184X eng.pdf.

72. Rady, M.; Sabbour, S.M. Behavioral risk factors among physicians working at Faculty of Medicine-Ain Shams University. J. Egypt. Public Health Assoc. [Internet] 1997 [Consultado septiembre 15 de 2018]; 72, 233-256. Disponible en: https://www.researchgate.net/publication/6584535 Behavioral risk factors among ph ysicians working at Faculty of Medicine - Ain Shams University

73. Nollen, N.L.; Adewale, S.; Okuyemi, et al. Workplace tobacco policies and smoking cessation practices of physicians. J. Natl. Med. Assoc. [Internet] 2004 [Consultado septiembre 16 de 2018]; 96, 838-842. Disponible en: https://www.ncbi.nlm.nih.gov/pmc/articles/PMC2568351/

74. Mirra, A.P.; Rosemberg, J. Inquérito sobre prevalência do tabagismo na classe médica brasileira. Rev. Assoc. Med. Bras. [Internet] 1997 [Consultado diciembre 15 de 2018]; 43, 209-216. Disponible en: https://www.researchgate.net/publication/26367339 Inquerito sobre prevalencia do $t$ abagismo na classe medica brasileira

75. Ramirez-Casanova, M.E.; Gonzalez, E.; Ocampo, A.; Sanchez, S.; et al. The tobacco habit among the workers in a general hospital. A survey report (in Spanish). Gac. Med. Mex. [Internet] 1991 [Consultado diciembre 8 de 2018] 127, 283-288.

76. Squier, C.; Hesli, V.; Lowe, J.; et al. Tobacco use, cessation advice to patients and attitudes to tobacco control among physicians in Ukraine. Eur. J. Cancer Prev. [Internet] 2006, 15, 458-463. [Consultado octubre 28 de 2018]. Disponible en: https://reference.medscape.com/medline/abstract/16912576

77. Sánchez $\mathbf{P}$, Lisanti $\mathbf{N}$. Prevalencia de tabaquismo y actitud hacia ese hábito entre médicos del Azuay, Ecuador. Rev Panam Salud Publica/Pan Am J Public Health14 (1), [Internet] 2003 [Consultado diciembre 10 de 2018]. Disponible en: https://www.scielosp.org/article/rpsp/2003.v14n1/25-30/.

78. Tredaniel J, Karsenty S, Chastang C, et al. Smoking habits of French general practitioners. Results of representativa sample of 1,012 physicians. Rev Mal Respir [Internet] 1993; 10:35-8. [Consultado diciembre 14 de 2018]. Disponible en: https://academic.oup.com/eurpub/article/15/1/33/506614

79. Smith D. Leggat P. An international review of tobacco smoking in the medical profession: [Internet] 1974-2004. [Consultado diciembre 17 de 2018] BMC Public 
Health20077:115. https://doi.org/10.1186/1471-2458-7-115. Disponible en: https://www.ncbi.nlm.nih.gov/pmc/articles/PMC1906758/

80. Tessier, J.F.; Nejjari, C.; Bennani-Othmani, M. Smoking in Mediterranean countries: Europe, North Africa and the Middle East. Results from a co-operative study. Int. J. Tuberc. Lung Dis. [Internet] 1999, 3, 927-937. [Consultado diciembre 17 de 2018]. Disponible

en: https://www.ingentaconnect.com/content/iuatld/ijtld/1999/00000003/00000010/art0001 $\underline{4}$

81. Mohan, S.; Pradeepkumar, A.S.; Thresia, C.U.; et al. Tobacco use among medical professionals in Kerala, India: The need for enhanced tobacco cessation and control efforts. Addict. Behav. [Internet] 2006, 31, 2313-2318. [Consultado diciembre 15 de 2018].

Disponible

en: https://www.sciencedirect.com/science/article/abs/pii/S0306460306000487

82. Abdullah, A.S.; Zhou, J.; Huang, D.; et al. Smoking status and cessation counseling practices among physicians, Guangxi, China, 2007. Prev. Chronic Dis. [Internet] 2010, 7. A15. [Consultado diciembre 13 de 2018]. Disponible en: https://www.ncbi.nIm.nih.gov/pmc/articles/PMC2811510/

83. Balbani, A.P.S.; Montovani, J.C.; de Carvalho, L.R. Tabagismo, abandono do fumo e os otorrinolaringologías do estado de São Paulo. Rev. Bras. Otorrinolaringol. [Internet] 2006, 72, 96-103. [Consultado 24 de octubre de 2018]. Disponible en: https://repositorio.unesp.br/handle/11449/12541

84. Merrill, R.M.; Madanat, H.; Kelley, A.T.; et al. Nurse and physician patient counseling about tobacco smoking in Jordan. Glob. Health Promot. [Internet] 2008,15, 9-14.27. [Consultado diciembre 18 de 2018]. Disponible en: https://www.rti.org/publication/nurseand-physician-patient-counseling-about-tobacco-smoking-jordan

85. Sociedad Argentina de Cardiología. Consenso de Prevención Cardiovascular. Tabaquismo. Rev Argent Cardiol 2012;80:47-58

86. Pipe AL, Eisemberg MJ, Gupta A, et al. Smoking cessation and the cardiovascular specialist: Canadian Cardiovascular Society position paper. Can J Cardiol [Internet] 2011; 27:132-7. [Consultado diciembre 18 de 2018]. http://doi.org/dr7x6d Disponible en: https://www.sciencedirect.com/science/article/pii/S0828282X10000760

87. Grossman, D.W.; Knox, J.J.; Nash, C.; et al. Smoking: Attitudes of Costa Rican physicians and opportunities for intervention. Bull. World Health Organ. [Internet] 1999, 
77, 315-322. . [Consultado diciembre 15 de 2018]. Disponible en: https://www.ncbi.nlm.nih.gov/pmc/articles/PMC2557650/

88. Callander C., Rocke D.A. Smoking habits and attitudes of Durban metropolitan anaesthetists. South African Medical Journal. S. Afr. Med. J. [Internet] 1986; 70:589591. [Consultado enero 10 de 2019]. Disponible en: https://journals.co.za/content/m samj/70/5/AJA20785135 3797

89. Poanta L.I., Zdrenghea D., Albu A. Psychometric evaluation of Romanian version of job content questionnaire in physicians. Rom. J. Int. Med. [Internet] 2006; 44:183-199. [Consultado octubre 27 de 2018]. Disponible en: https://www.researchgate.net/publication/6567107 Psychometric evaluation of Roma nian version of Job Content Questionnaire in physicians

90. Barnoya J., Glantz S. Knowledge and use of tobacco among Guatemalan physicians. Cancer Causes Control. [Internet] 2002; 13:879-881. [Consultado octubre 27 de 2018]. doi: 10.1023/A:1020658519854. Disponible en: https://www.researchgate.net/publication/11007580 Knowledge and use of tobacco among Guatemalan physicians

91. Varona P., Bonet M., Fernández N., et al. Use of medical counseling for the prevention and control of smoking in the municipality of old Havana. J. Urban Health. [Internet] 2005;82:71-75. [Consultado octubre 28 de 2018]. doi: 10.1093/jurban/jti009. Disponible en: https://www.ncbi.nlm.nih.gov/pmc/articles/PMC3456631/

92. Velicer WF, Redding CA, Sun X, Prochaska JO. Demographic variables, smoking variables, and outcome across five studies. Health Psychol. [Internet] 2007 May;26(3):278-87. [Consultado diciembre 15 de 2018]. Disponible en: https://www.ncbi.nlm.nih.gov/pubmed/17500614

93. Icli F., Icli T., Gunel N., Arikan R. Cigarette smoking among young physicians and their approach to the smoking problem of their patients. J. Cancer Educ. [Internet] 1992;7:237-240. [Consultado noviembre 8 de 2018]. Disponible en: doi: 10.1080/08858199209528174.

https://www.ncbi.nlm.nih.gov/pmc/articles/PMC2902913/

94. Li H.Z., Fish D., Zhou X. Increase in cigarette smoking and decline of anti-smoking counseling among Chinese physicians: 1987-1996. Health Promot. Int. [Internet] 1999; 14:123-131. [Consultado noviembre 14 de 2018]. doi: 10.1093/heapro/14.2.123. Disponible en: https://academic.oup.com/heapro/article/14/2/123/625111 
95. Supramaniam V. Habits and attitudes of Malaysian military doctors towards smoking. Med. J. Malaysia. [Internet] 1980; 34:205-210. [Consultado enero 8 de 2019].

96. Schnoll R.A., Engstrom P.F., Subramanian S., et al. Smoking cessation counseling by Russian oncologists: Opportunities for intervention in the Russian Federation. Int. J. Behav. Med. 2006;13:8-15. [Consultado enero 8 de 2019]. doi: 10.1207/s15327558ijbm1301_2. Disponible en: https://link.springer.com/article/10.1207/s15327558ijbm1301 2

97. Stead LF, Buitrago D, Preciado N, et al. Physician advice for smoking cessation. Cochrane Database Syst Rev. [Internet] 2013 May 31;(5):CD000165. [Consultado enero 9 de 2019]. doi: 10.1002/14651858.CD000165.pub4. disponible en: https://www.cochranelibrary.com/cdsr/doi/10.1002/14651858.CD000165.pub4/abstract

98. Smith DR, Wei N, Zhang YJ, Wang RS: Tobacco smoking habits among a crosssection of rural physicians in China. Aust J Rural Health. [Internet] 2006 [Consultado enero 11 de 2019]. 14: 66-71. 10.1111/j.1440-1584.2006.00766.x. Disponible en: https://onlinelibrary.wiley.com/doi/full/10.1111/j.1440-1584.2006.00766.x

99. Sarkar D, Dhand R, Malhotra A, et al. Perceptions and attitude towards tobacco smoking among doctors in Chandigarh. Indian J Chest Dis Allied Sci. [Internet] 1990, 32: 1-9. [Consultado enero 12 de 2019]. https://www.researchgate.net/publication/20885565 Perceptions and attitude toward s tobacco smoking among doctors in Chandigarh

100. Parna K, Rahu K, Rahu M. Smoking habits and attitudes towards smoking among Estonian physicians. Public Health. [Internet] 2005, [Consultado enero 15 de 2019]. 119: 390-399. 10.1016/j.puhe.2004.07.005.

Disponible

en: https://www.sciencedirect.com/science/article/pii/S0033350604001908

101. Perrin P.C., Merrill R.M., Lindsay G.B. Patterns of smoking behavior among physicians in Yerevan, Armenia. BMC Public Health. [Internet] 2006;6 doi: 10.1186/1471-2458-6-139. [Consultado enero 18 de 2019]. Disponible en: https://bmcpublichealth.biomedcentral.com/articles/10.1186/1471-2458-6-139

102. Leppänen A, Ekblad S, Tomson T. Tobacco Cessation on Prescription as a primary health care intervention targeting a context with socioeconomically disadvantaged groups in Sweden: A qualitative study of perceived implementation barriers and facilitators among providers. PLoS One. [Internet] 2019 Feb 21;14(2): e0212641. [Consultado febrero 8 de 2019]. Disponible en: 
https://www.researchgate.net/publication/331264966 Tobacco Cessation on Prescri ption as a primary health care intervention targeting a context with socioeconom ically disadvantaged groups in Sweden A qualitative study of perceived impleme ntation barrie

103. De Assis Viegas C.A., de Andrade A.P.A., da Silva Silvestre R. Características do tabagismo na categoria médica do Distrito Federal. J. Bras. Pneumol. [Internet] 2007;33:76-80. [Consultado febrero 11 de 2019]. doi: 10.1590/S1806$37132007000100015 . \quad$ Disponible en: https://www.researchgate.net/publication/47364997 Caracteristicas do tabagismo na categoria medica do Distrito Federal

104. Kralikova E., Kozak J., Rames J., et al. Czech medical faculties and smoking. Cent. Eur. J. Public Health. [Internet] 1995; 3:97-99. [Consultado enero 11 de 2019]. Disponible en: https://ceiph.szu.cz/artkey/cip-199502-0008 Czech-medical-facultiesand-smoking.php

105. Li HZ, Fish D, Zhou X. Increase in cigarette smoking and decline of anti-smoking counselling among Chinese physicians: 1987-1996. Health Prom Int. [Internet] 1999, 14: 123-131. [Consultado febrero 20 de 2019]. Disponible en: 10.1093/heapro/14.2.123. https://academic.oup.com/heapro/article/14/2/123/625111

106. Mejia, R.; Martinez, V.G.; Gregorich, S.E.; et al. Physician counseling of pregnant women about active and secondhand smoking in Argentina. Acta. Obstet. Gynecol. Scand. [Internet] 2010 [Consultado febrero 24 de 2019]. 89, 490-495. Disponible en: https://www.ncbi.nlm.nih.gov/pmc/articles/PMC3158573/

107. Polyzos A, Gennatas C, Veslemes M, et al. The smoking-cessation promotion practices of physician smokers in Greece. J Cancer Educ. [Consultado febrero 22 de 2019].

Disponible

en:

https://www.tandfonline.com/doi/ref/10.1080/08858199509528339

108. Ohida T, Sakurai H, Mochizuki Y, et al. Smoking prevalence and attitudes toward smoking among Japanese physicians. JAMA. [Internet] 2001 [Consultado febrero 24 de 2019] 285:2643-2648. Disponible en: doi: 10.1001/jama.285.20.2643. http://europepmc.org/abstract/MED/11368741

109. Kawahara K, Ohida T, Osaki Y, et al: Study of the smoking behavior of medical doctors in Fukui, Japan and their antismoking measures. J Epidemiol. [Internet] 2000 [Consultado febrero 24 de 2019], 10: 157-162. 
110. Barengo NC, Sandstrom HP, Jormanainen VJ, Myllykangas M: Attitudes and behaviours in smoking cessation among general practitioners in Finland 2001. Soz Praventivmed. [Internet] 2005, 50: 355-360. [Consultado febrero 24 de 2019]. Disponible en: 10.1007/s00038-005-4097-z. https://link.springer.com/article/10.1007\%2Fs00038005-4097-z

111. Hernández-Hernández J, Heras-Gómez F, Cordovilla-Pérez, Antolín-García T, et al. Incidencia del cáncer broncopulmonar en Castilla y León y Cantabria durante el año [Internet] 2007 [Consultado febrero 24 de 2019]. Arch Bronconeumol, 46 (2010), pp. 7-14. Disponible en: https://www.sciencedirect.com/science/article/pii/S0300289609003809

112. De Granda-Orive JI, Solano-Reina S, Jiménez-Ruiz CA. Intervenciones en tabaquismo en pacientes con enfermedades cardiovasculares. Smoking intervention in patients with cardiovascular diseases. Aten Primaria. [Internet] 2013 [Consultado febrero 25 de 2019];45(2):115---120. Disponible en: https://doi.org/10.1016/i.aprim.2011.12.006.

https://www.sciencedirect.com/science/article/pii/S0212656712000194?via\%3Dihub

113. Solanes Gacía I, Casan C. Causas de muerte y predicción de mortalidad en la EPOC. Arch Bronconeumol, [Internet] 2010 [Consultado febrero 25 de 2019]. 46 (2010), pp. 343-346

114. Pozo Rodríguez F, Álvarez C, Castro A, et al. Auditoria clínica de los pacientes hospitalizados por exacerbación de EPOC en España (estudio AUDIPOC): método y organización. Arch Bronconeumol, [Internet] 2010 [Consultado febrero 26 de 2019]. 46 (2010). Disponible en:, pp. 349-357. https://www.sciencedirect.com/science/article/pii/S030028961000092X

115. Samet JM. Los riesgos del tabaquismo activo y pasivo. Salud pública Méx vol.44 supl.1 Cuernavaca. [Internet] 2002. [Consultado febrero 27 de 2019]. Disponible en: http://www.scielo.org.mx/scielo.php?script=sci arttext\&pid=S0036$\underline{36342002000700020}$

116. Frigues B, García Algar O, Puig C, et al. Exposición prenatal y postnatal al tabaco y síntomas respiratorios y alérgicos en los primeros años de vida. Arch Bronconeumol, [Internet] 2009. 45 (2009), pp. 585-59. [Consultado febrero 15 de 2019].

117. García Algar $\mathbf{O}$, Jané Checa M. Seguridad y efectividad del tratamiento sustitutivo con nicotina durante el embarazo. Arch Bronconeumol. [Internet] 2010. 46 (2010), pp. 
453-454. [Consultado febrero 18 de 2019]. Disponible en: https://www.archbronconeumol.org/es-seguridad-efectividad-del-tratamientosustitutivo-articulo-S0300289610000815

118. Wells $\mathbf{M}$, Aitchison $\mathbf{P}$, Harris $\mathbf{F}$, et al. Barriers and facilitators to smoking cessation in a cancer context: A qualitative study of patient, family and professional views. BMC Cancer. [Internet] 2017 May 19;17(1):348. [Consultado febrero 20 de 2019]. doi: 10.1186/s12885-017-3344-z. Disponible en: https://bmccancer.biomedcentral.com/articles/10.1186/s12885-017-3344-Z

119. Doll $\mathbf{R}$, Hill $\mathbf{A B}$. The mortality of doctors in relation to their smoking habits: $A$ preliminary report. 1954. BMJ. [Internet] 2004; 328:1529-1533. [Consultado febrero 10 de 2019]. doi: 10.1136/bmj.328.7455.1529. Disponible en: https://www.bmj.com/content/328/7455/1529

120. Franceschi S, Serraino D, Talamini R, et al. Personal habits and attitudes towards smoking in a sample of physicians from the north-east of Italy. Int J Epidemiol. [Internet] 1986, 15: 584-585. [Consultado febrero 21 de 2019].10.1093/ije/15.4.584. Disponible en: https://www.ncbi.nlm.nih.gov/pubmed/3818167

121. Zylbersztejn H, Cragnolino R, Francesia A, et al. Estudio epidemiológico del tabaquismo en médicos. Área de investigación, Sociedad Argentina de Cardiología. Revista Argentina De Cardiología [Internet] 2003. / Vol. 71 N 3 / Mayo-Junio 2003. [Consultado febrero 22 de 2019]. Disponible en: http://www.sac.org.ar/wpcontent/uploads/2014/04/749.pdf

122. Boyle MH, Sanford M, Szatmari $\mathbf{P}$, et al. Familiar influences on substance use by adolescents and young adults. Can J Public Health [Internet] 2001; 92:206-9. [Consultado febrero 23 de 2019]. Disponible en: https://www.researchgate.net/publication/11847450 Familial influence on substance use by adolescents and young adults

123. Tremblay $\mathbf{M}$, Gervais A, Lacroix C, et al. Physicians Taking Action Against Smoking: an intervention program to optimize smoking cessation counselling by Montreal general practitioners. CMAJ [Internet] 2001;165:601-7. [Consultado febrero 24 de 2019]. Disponible en: https://www.ncbi.nlm.nih.gov/pmc/articles/PMC81419/

124. Müller F. Capítulo 2, Las trampas del tabaco; Schoj V y Tambussi A. Capítulo 10, Intervenciones breves. En: Müller F, editor. Cesación tabáquica, tiempo de intervenir. $1^{\text {a }}$ 
impresión. Buenos Aires: Editorial Polemos; [Internet] 2006. p. 45-53 y 177-208. [Consultado febrero 25 de 2019]. Disponible en:

http://www.tematika.com/libros/ciencias de la salud naturales y divulgacion cientif ica--7/psicologia--5/trastornos y adicciones--4/cesacion tabaquica--434834.htm

125. Área de Normatizaciones y Consensos de la Sociedad Argentina de Cardiología. Consenso de Prevención Primaria y Secundaria de la Enfermedad Coronaria. Rev Argent Cardiol [Internet] 2001; 69:12-21. [Consultado febrero 25, marzo 8 de 2019].

126. Fernández Ruiz, M, Sánchez Bayle M. Evolución de la prevalencia de tabaquismo entre las médicas y enfermeras de la Comunidad de Madrid. Gac Sanit, [Internet] 2003. pp. 5-10. [Consultado febrero 25 de 2019]. Disponible en: https://www.lasdrogas.info/noticias/evolucion-de-la-prevalencia-de-tabaquismo-entrelas-medicas-y-enfermeras-de-la-comunidad-de-madrid/

127. Stillman FA, Becker DM, Swank RT, et al. Ending smoking at the Johns Hopkins Medical Institutions. An evaluation of smoking prevalence and indoor air pollution. JAMA. [Internet] 1990, 264: 1565-1569. [Consultado febrero 27 de 2019]. 10.1001/jama.264.12.1565. Disponible en: https://ihu.pure.elsevier.com/en/publications/ending-smoking-at-the-johns-hopkinsmedical-institutions-an-evalu-4

128. Bartscherer DJ, Reichert VC, Folan P, et al. Tobacco and the health care industry. Clin Occup Environ Med. [Internet] 2005, 5: 55-71. [Consultado febrero 27 de 2019]. Disponible en: https://www.researchgate.net/publication/7328166 Tobacco and the health care ind ustry

129. Hernández J, Jadraque Jiménez $\mathbf{P}$, Sánchez AL, et al. Prevalencia de consumo de tabaco entre los trabajadores del Área de Salud de la Isla de La Palma. Prevalence of tobacco consumption among healthcare workers on the island of La Palma. Medicina General y de Familia. [Internet] 2015. Volume 4, Issue 3, July-September 2015, Pages 63-67. [Consultado marzo 2 de 2019]. Disponible en: https://www.sciencedirect.com/science/article/pii/S1889543315000316

130. Adriaanse H, van Reek J. Physicians' smoking and its exemplary effect. Scand J Prim Health Care. [Internet] 1989, 7: 193-196. [Consultado marzo 3 de 2019]. Disponible en: 
https://www.researchgate.net/publication/20528825 Physicians' Smoking and Its Ex emplary Effect

131. Anon. Smoking and health: A physician's responsibility. A statement of the joint committee on smoking and health. American College of Chest Physicians, American Thoracic Society, Asia Pacific Society of Respirology, Canadian Thoracic Society, European Respiratory Society, International Union Against Tuberculosis and Lung Disease. Eur Respir J. [Internet] 1995, 8: 1808-1811. [Consultado marzo 3 de 2019]. 10.1183/09031936.95.08101808. Disponible

en:

https://www.ncbi.nlm.nih.gov/pubmed/9432410

132. Hodgetts G., Broers T., Godwin M. Smoking behaviour, knowledge and attitudes among family medicine physicians and nurses in Bosnia and Herzegovina. BMC Fam. Pract. [Internet] 2004 [Consultado marzo 5 de 2019]. Disponible en: doi: 10.1186/14712296-5-12. https://bmcfampract.biomedcentral.com/articles/10.1186/1471-2296-5-12

133. Bello, S.; Soto, M.; Michalland, S.; Salinas, J. A national survey on smoking habit among health care workers in Chile (in Spanish). Rev. Med. Chil. [Internet] 2004, 132, 223-232. [Consultado marzo 5 de 2019]. Disponible en: https://www.researchgate.net/publication/8264890 A national survey on smoking $h$ abit among health care workers in Chile.

134. Fernandez Ruiz ML, Sanchez Bayle M. Evolution of the prevalence of smoking aong female physicians and nurses in the Autonomous Community of Madrid, Spain. Gac Sanit 2003;17:5-10.

135. Parna K, Rahu K, Barengo NC, et al. Comparison of knowledge, attitudes and behaviour regarding smoking among Estonian and Finnish physicians. Soz Praventivmed [Internet] 2005; 50:378-88. [Consultado marzo 6 de 2019]. Disponible en: https://www.researchgate.net/profile/Mati Rahu/publication/7373812 Comparison of knowledge attitudes and behaviour regarding smoking among Estonian and Finnish physicians/links/09e41507d08eac9b4b000000.pdf?inViewer=true\&pdfJsDownl oad=true\&disableCoverPage=true\&origin=publication detail

136. Davis RM. When doctors smoke. Tob Control. [Internet] 1993, 2: 187-188. [Consultado marzo 9 de 2019]. Disponible en: http://europepmc.org/articles/PMC1759270/ 
137. Christmas BW, Hay DR. The smoking habits of New Zealand doctors: A review after ten years. NZ Med J. [Internet] 1976, 83 (565): 391-394. [Consultado marzo 8 de 2019]. Disponible en: https://www.ncbi.nlm.nih.gov/pubmed/1067482

138. Dekker HM, Looman CWN, Adriaanse HP, et al. Prevalence of smoking in physicians and medical students, and the generation effect in the Netherlands. Soc Sci Med. [Internet] 1993, 36: 817-822. [Consultado marzo 9 de 2019]. 10.1016/02779536(93)90042-3.

Disponible

en:

https://www.sciencedirect.com/science/article/abs/pii/0277953693900423 


\section{ANEXO No 1}

Universidad Nacional de La Plata

Facultad de Ciencias Médicas

Cuestionario para profesionales Médicos de Argentina. (Versión corta)
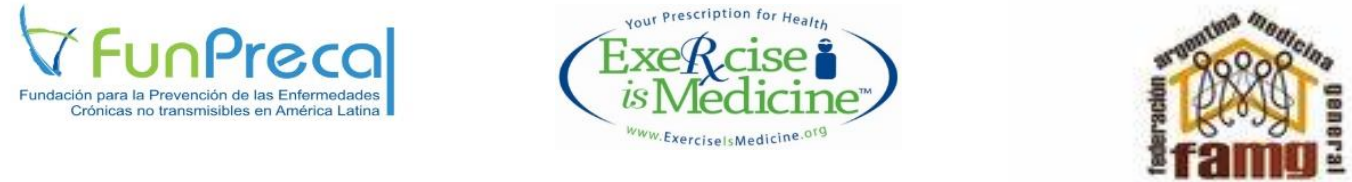

Federación Argentina de Medicina General

\section{SECCIÓN 1: VARIABLES SOCIODEMOGRAFICAS}

1.1 ¿En qué año nació usted? 19

1.2 Su sexo es (marque con una $x$ ):

$1 \square$ Femenino $2 \square \quad$ Masculino

\subsection{Su estado civil es:}

$1 \square$ Casado(a)

$2 \square$ Soltero(a)

$3 \square$ Unión libre

$4 \quad$ Separado(a)

$5 \square$ Viudo(a)

1.4 Tiene hijos: $\quad 1 \square$ No

$2 \square \mathrm{Si} \quad$ Sí SI, Indique cuántos son?

Cuántos tienen $\leq 6$ años

Cuántos tienen entre $1-18$ años

\section{SECCIÓN 2: ESTADO DE SALUD}

2.1 ¿Cuál es su estatura en centímetros? cm

2.2 ¿Cuál es su peso en kilogramos?

$\mathrm{kg}$;

Si está embarazada, por favor indique cuál era su peso antes del embarazo $\mathrm{Kg}$

2.3 Usted considera que su peso está en el rango: 
$1 \square$ Normal

$2 \square$ Bajo

$3 \square$ Sobrepeso

$4 \square$ Obesidad

2.4 Usted considera que en general su estado de salud es:

$1 \square$ Excelente

$2 \square$ Muy bueno

$3 \square$ Bueno

$4 \square$ Regular

$5 \square$ Malo

2.5 ¿Usted tienen un médico de cabecera para el cuidado de su salud?

$1 \square \mathrm{SI} 2 \square \mathrm{NO}$

2.6 ¿Qué tanto énfasis puso su médico en ayudarlo a mantenerse saludable y prevenir enfermedades más que en tratar sus problemas de salud?
Mucho
Algo
No mucho $\quad \square$ Ninguno

2.7 Cuándo fue la última vez que usted se realizó: (marque una única respuesta para cada pregunta)

\begin{tabular}{|c|c|c|c|c|c|c|c|}
\hline & $\begin{array}{l}<1 \\
\text { año }\end{array}$ & $\begin{array}{l}1 \text { a }<2 \\
\text { años }\end{array}$ & $\begin{array}{c}2 \text { a }<3 \\
\text { años }\end{array}$ & $\begin{array}{c}3 a>4 \\
\text { años }\end{array}$ & $\begin{array}{c}4 \text { a }<5 \\
\text { años }\end{array}$ & $\begin{array}{l}\geq 5 \\
\text { años }\end{array}$ & Nunca \\
\hline a) Examen Físico & $\square$ & $\square$ & $\square$ & $\square$ & $\square$ & $\square$ & $\square$ \\
\hline $\begin{array}{l}\text { b) Chequeo de presión } \\
\text { arterial }\end{array}$ & $\square$ & $\square$ & $\square$ & $\square$ & $\square$ & $\square$ & $\square$ \\
\hline $\begin{array}{l}\text { c) Examen de seno o } \\
\text { testicular (Clínico) }\end{array}$ & $\square$ & $\square$ & $\square$ & $\square$ & $\square$ & $\square$ & $\square$ \\
\hline $\begin{array}{l}\text { d) Vacuna contra la } \\
\text { influenza }\end{array}$ & $\square$ & $\square$ & $\square$ & $\square$ & $\square$ & $\square$ & $\square$ \\
\hline e) Medición de colesterol & $\square$ & $\square$ & $\square$ & $\square$ & $\square$ & $\square$ & $\square$ \\
\hline f) Cuadro hemático & $\square$ & $\square$ & $\square$ & $\square$ & $\square$ & $\square$ & $\square$ \\
\hline $\begin{array}{l}\text { g) Mamografía (solo } \\
\text { mujeres) }\end{array}$ & $\square$ & $\square$ & $\square$ & $\square$ & $\square$ & $\square$ & $\square$ \\
\hline h) Citología (mujeres) & $\square$ & $\square$ & $\square$ & $\square$ & $\square$ & $\square$ & $\square$ \\
\hline
\end{tabular}

2.8 ¿En las últimas 4 semanas, qué tan seguido su salud física le dificulto realizar sus actividades normales como médico? 
2.9 ¿En las últimas 4 semanas, que tan seguido su salud mental le dificulto realizar sus actividades normales como médico?

\section{SECCIÓN 3: CARACTERISTICAS DEL MÉDICO Y DE LA PRÁCTICA CLÍNICA}

3.1 Señale su ocupación (marque con una $x$ ):

$1 \square$ Médico internista

$2 \square$ Cardiólogo

$3 \square$ Endocrinólogo

$4 \square$ Ortopedista

$5 \quad$ Cirujano general

$6 \square$ Urólogo
$7 \square$ Pediatra

$8 \square$ Ginecólogo / Obstetra

$9 \square$ Psiquiatra

$10 \square$ Neurólogo

$11 \square$ Médico Generalista

$12 \square$ Otro:

$14 \square$ No responde

3.2 Señale el año en el que obtuvo el grado de médico general

3.3 Señale el año en el que obtuvo el posgrado de su especialidad

3.4 Señale la ciudad y provincia en que usted ejerce su práctica clínica:

Principal:

Ciudad

Provincia

Secundaria: Ciudad Provincia

3.5 Señale el nivel asistencial en el que usted trabaja:

$1 \square$ Primer nivel de atención

$2 \square$ Segundo nivel de atención

$3 \square$ Tercer nivel de atención 
3.6 ¿En promedio, estime el número total de horas que usted estuvo de guardia durante el último mes? horas/mes

3.7 Por favor indique las principales instituciones para las que usted trabaja:

3.8 ¿Durante un mes normal, aproximadamente qué porcentaje de su tiempo profesional usted le dedica a las siguientes actividades?

a) Consultas de atención primaria

b) Consultas de medicina especializada: (Por favor especifique)

c) Manejo hospitalario

d) Investigación

e) Enseñanza

f) Administración

g) Otra (Por favor especifique) Total

Porcentaje de su tiempo profesional

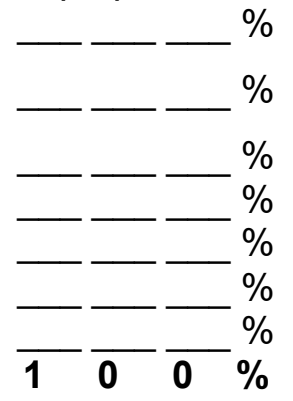

3.9 Por favor estime el número de consultas que usted atiende en una SEMANA NORMAL, Excluya pacientes que asistieron a la consulta mientras usted estaba de guardia.

\begin{tabular}{|l|l|l|}
\hline & & \\
Número de paciente atendidos
\end{tabular}

3.10 ¿Aproximadamente qué porcentaje de los paciente que usted trata son mujeres?

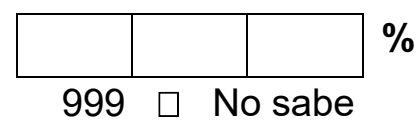

3.11 Por favor indique la población de paciente que usted trata:

SI NO
a) Usted atiende niños menores de 2 años
0 
b) Usted atiende niños entre 2 y 11 años

c) Usted atiende adolescentes entre 12 y 17 años

d) Usted atiende adultos entre 18 y 65 años

e) Usted atiende adultos mayores de 66 años

\begin{tabular}{|c|c|}
\hline$\square$ & $0 \square$ \\
\hline$\square$ & $0 \square$ \\
\hline$\square$ & $0 \square$ \\
\hline$\square$ & \\
\hline
\end{tabular}

1

0

\section{SECCIÓN 4: PRÁCTICA MÉDICA}

4.1 Qué tanto entrenamiento ha recibido usted en los siguientes temas: (Por favor marque con una " $X$ " en el interior de la casilla que considere correcta)

Aconseja a sus pacientes acerca de:

\begin{tabular}{|l|c|c|c|}
\cline { 2 - 4 } \multicolumn{1}{l|}{} & 1 Ninguno & 2 Alguno & 3 Mucho \\
\hline a) Práctica de actividad física regular & $\square$ & $\square$ & $\square$ \\
\hline b) $\begin{array}{l}\text { Consumo regular de frutas y } \\
\text { verduras }\end{array}$ & $\square$ & $\square$ & $\square$ \\
\hline c) Cesación de tabaquismo & $\square$ & $\square$ & $\square$ \\
\hline d) Control de peso sano & $\square$ & $\square$ & $\square$ \\
\hline
\end{tabular}

4.2 En un paciente SIN enfermedades crónicas relacionadas con peso, que tenga una dieta poco saludable, no sea lo suficientemente activo o tenga sobrepeso: Que tan seguido usted... (Por favor marque con una " $X$ " en el interior de la casilla que considere correcta)

\begin{tabular}{|c|c|c|c|c|c|}
\hline & 1 Siempre & $\begin{array}{l}2 \text { Casi } \\
\text { siempre }\end{array}$ & $\begin{array}{c}3 \text { Algunas } \\
\text { veces }\end{array}$ & 4 Casi nunca & 5 Nunca \\
\hline $\begin{array}{l}9 \text { ¿Da consejería general para } \\
\text { hacer un cambio en la dieta, la } \\
\text { actividad física o el peso? }\end{array}$ & $\square$ & $\square$ & $\square$ & $\square$ & $\square$ \\
\hline 10 Da consejería especifica en: & & & & & \\
\hline
\end{tabular}




\begin{tabular}{|c|c|c|c|c|c|c|}
\hline & $\begin{array}{l}\text { Dieta/nutrición (ej. "Comer } \\
\text { más frutas y verduras" o } \\
\text { "consumir más calcio") }\end{array}$ & $\square$ & $\square$ & $\square$ & $\square$ & $\square$ \\
\hline & $\begin{array}{lll}\text { Actividad } & \text { Física } & \text { (ej. } \\
\text { "aumentar el tiempo } & \text { de } \\
\text { caminata diario") } & \end{array}$ & $\square$ & $\square$ & $\square$ & $\square$ & $\square$ \\
\hline & $\begin{array}{l}\text { Control de peso (ej. Usted } \\
\text { debe perder X Kg contando } \\
\text { calorías ingeridas y ejercicio) }\end{array}$ & $\square$ & $\square$ & $\square$ & $\square$ & $\square$ \\
\hline & Cesación de Tabaquismo & $\square$ & $\square$ & $\square$ & $\square$ & $\square$ \\
\hline & $\begin{array}{l}\text { Refiere estos pacientes a otro } \\
\text { profesional de la salud o } \\
\text { programa fuera de su práctica } \\
\text { para una mejor evaluación y } \\
\text { manejo }\end{array}$ & $\square$ & $\square$ & $\square$ & $\square$ & $\square$ \\
\hline & $\begin{array}{l}\text { Realiza un seguimiento } \\
\text { sistemático de cada uno de estos } \\
\text { paciente para evaluar sus } \\
\text { hábitos y cambios en los mismo }\end{array}$ & $\square$ & $\square$ & $\square$ & $\square$ & $\square$ \\
\hline
\end{tabular}

4.3 En un paciente $\mathrm{CON}$ enfermedades crónicas relacionadas con peso, que tenga una dieta poco saludable, no sea lo suficientemente activo o tenga sobrepeso: Que tan seguido usted... (Por favor marque con una " $X$ " en el interior de la casilla que considere correcta)

\begin{tabular}{|c|c|c|c|c|c|}
\hline & 1 Siempre & $\begin{array}{l}2 \text { Casi } \\
\text { siempre }\end{array}$ & $\begin{array}{l}3 \text { Algunas } \\
\text { veces }\end{array}$ & 4 Casi nunca & 5 Nunca \\
\hline $\begin{array}{ll}13 \text { ¿Da consejería general para } \\
\text { hacer un cambio en la dieta, la } \\
\text { actividad física o el peso? }\end{array}$ & $\square$ & $\square$ & $\square$ & $\square$ & $\square$ \\
\hline 14 Da consejería especifica en: & & & & & \\
\hline $\begin{array}{l}\text { Dieta/nutrición (ej. "Comer } \\
\text { más frutas y verduras" o } \\
\text { "consumir más calcio") }\end{array}$ & $\square$ & $\square$ & $\square$ & $\square$ & $\square$ \\
\hline $\begin{array}{lcc}\text { Actividad } & \text { Física } & \text { (ej. } \\
\text { "aumentar el tiempo } & \text { de } \\
\text { caminata diario") } & \end{array}$ & $\square$ & $\square$ & $\square$ & $\square$ & $\square$ \\
\hline $\begin{array}{l}\text { Control de peso (ej. Usted } \\
\text { debe perder X Kg contando } \\
\text { calorías ingeridas y ejercicio) }\end{array}$ & $\square$ & $\square$ & $\square$ & $\square$ & $\square$ \\
\hline Cesación de Tabaquismo & $\square$ & $\square$ & $\square$ & $\square$ & $\square$ \\
\hline
\end{tabular}




\begin{tabular}{|c|c|c|c|c|c|c|}
\hline & $\begin{array}{l}\text { Refiere estos pacientes a otro } \\
\text { profesional de la salud o } \\
\text { programa fuera de su práctica } \\
\text { para una mejor evaluación y } \\
\text { manejo }\end{array}$ & $\square$ & $\square$ & $\square$ & $\square$ & $\square$ \\
\hline 16 & $\begin{array}{l}\text { Realiza un seguimiento } \\
\text { sistemático de cada uno de } \\
\text { estos paciente para evaluar sus } \\
\text { hábitos y cambios en los mismo }\end{array}$ & $\square$ & $\square$ & $\square$ & $\square$ & $\square$ \\
\hline
\end{tabular}

\section{4 ¿Si usted evalúa la dieta de un paciente, Cómo pregunta?} pregunta 4.5)

No aplica, Yo no pregunto acerca de la dieta de mis pacientes. (Pase a la

SI NO

a) Hace preguntas generales acerca de los grupos alimenticios $\begin{array}{lll}1 & 0\end{array}$ (ej. Frutas y verduras)

b) Hace preguntas generales acerca de patrones dietarios (ej. $1 \square \quad 0$ Consumo de comida rápida)

c) Hace preguntas específicas hacer de componentes dietéticos $1 \square \quad 0$ (ej. Calcio, proteínas)

d) Utiliza un cuestionario estandarizado

e) Otro, por favor especifique

\section{5 ¿Si usted evalúa la actividad física de sus pacientes, cómo pregunta?}

$\square$ No aplica, Yo no pregunto acerca de actividad física a mis pacientes. (Pase a la pregunta 4.6)

SI NO
a) Hace preguntas generales acerca de la cantidad de actividad física.
b) Hace preguntas generales acerca la cantidad de actividades sedentarias (ej. Ver televisión)
c) Hace preguntas específicas acerca de la duración, intensidad y tipo de actividad física
d) Utiliza un cuestionario estandarizado

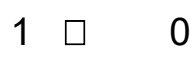
e) Otro, por favor especifique

\section{6 ¿Si usted evalúa el consumo de tabaco de sus pacientes, Cómo pregunta?}

$\square$ No aplica, Yo no pregunto acerca del tabaquismo a mis pacientes. (Pase a la pregunta 4.7 ) 
c) Hace preguntas generales de si su paciente fuma o no.

\begin{tabular}{lll}
$1 \quad 0 \quad 0$ \\
\hline
\end{tabular}

d) Hace preguntas generales acerca de los comportamientos $1 \square \quad 0 \quad \square$ asociados al tabaquismo. (ej. Fumador social)

e) Hace preguntas generales acerca de los intentos de dejar de $1 \square \quad 0 \quad \square$ fumar

f) Hace preguntas específicas acerca del numero de cigarrillos
diarios, cigarrillos fumados a los largo de la vida, intentos de dejar de fumar.

g) Utiliza un cuestionario estandarizado

h) Otro, por favor especifique

4.7 Qué tan seguido usted tomas las siguientes medidas en la consulta

\begin{tabular}{|c|c|c|c|c|c|c|c|}
\hline & & $\begin{array}{c}\text { En todo } \\
\text { paciente } \\
\text { en cada } \\
\text { visita }\end{array}$ & $\begin{array}{l}\text { Cada } \\
\text { visita }\end{array}$ & Anualmente & $\begin{array}{c}\text { Si es } \\
\text { necesario } \\
\text { clínicamente }\end{array}$ & Nunca & $\begin{array}{c}\text { Otro periodo } \\
\text { de tiempo } \\
\text { (favor } \\
\text { especificar) }\end{array}$ \\
\hline a) & $\begin{array}{l}\text { Peso medido en } \\
\text { una báscula }\end{array}$ & $\square$ & $\square$ & $\square$ & $\square$ & $\square$ & $\square_{-}$ \\
\hline b) & $\begin{array}{l}\text { Peso auto } \\
\text { reportado. }\end{array}$ & $\square$ & $\square$ & $\square$ & $\square$ & $\square$ & $\square_{2}$ \\
\hline c) & $\begin{array}{l}\text { Índice de masa } \\
\text { corporal (IMC). }\end{array}$ & $\square$ & $\square$ & $\square$ & $\square$ & $\square$ & $\square$ \\
\hline d) & $\begin{array}{l}\text { Circunferencia } \\
\text { abdominal. }\end{array}$ & $\square$ & $\square$ & $\square$ & $\square$ & $\bar{\square}$ & $\square$ \\
\hline e) & Talla. & $\square$ & $\square$ & $\square$ & $\square$ & $\square$ & $\square$ \\
\hline
\end{tabular}

4.8 Qué tan seguido usted solicita los siguientes exámenes a sus pacientes con sobrepeso y obesidad:

\begin{tabular}{|l|c|c|c|c|c|c|}
\hline No aplica/ & no lo utilizo & $\begin{array}{c}\text { Cada 2 } \\
\text { años }\end{array}$ & $\begin{array}{c}\text { Anualment } \\
\text { e }\end{array}$ & $\begin{array}{c}\text { Cada 6 } \\
\text { meses }\end{array}$ & $\begin{array}{c}\text { Más de 2 } \\
\text { veces al } \\
\text { año }\end{array}$ & $\begin{array}{c}\text { Otro periodo } \\
\text { de tiempo }\end{array}$ \\
\hline
\end{tabular}




\begin{tabular}{|l|l|l|l|l|l|l|}
\hline & & & & & & $\begin{array}{c}\text { (favor } \\
\text { especificar) }\end{array}$ \\
\hline $\begin{array}{l}\text { a) Pruebas de glucemia } \\
\text { aleatoria en... }\end{array}$ & & & & & & \\
\hline $\begin{array}{l}\text { Pacientes CON } \\
\text { otros factores de } \\
\text { riesgo adicional }\end{array}$ & $\square$ & $\square$ & $\square$ & $\square$ & $\square$ & $\square$ \\
\hline $\begin{array}{l}\text { Pacientes SIN otros } \\
\text { factores de riesgo } \\
\text { adicional }\end{array}$ & $\square$ & $\square$ & $\square$ & $\square$ & $\square$ & $\square$ \\
\hline \begin{tabular}{l} 
b) $\begin{array}{l}\text { Prueba de glicemia } \\
\text { en ayunas en... }\end{array}$ \\
\hline $\begin{array}{l}\text { Pacientes CON } \\
\text { otros factores de } \\
\text { riesgo adicional }\end{array}$
\end{tabular}$\quad \square$ & $\square$ & $\square$ & $\square$ & $\square$ & $\square$ \\
\hline $\begin{array}{l}\text { Pacientes SIN otros } \\
\text { factores de riesgo } \\
\text { adicional }\end{array}$ & $\square$ & $\square$ & $\square$ & $\square$ & $\square$ & $\square$ \\
\hline
\end{tabular}

4.9 ¿Usted ha prescrito alguna vez o actualmente...?

\begin{tabular}{|c|c|c|c|c|c|}
\hline \multirow[t]{2}{*}{ 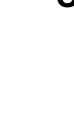 } & \multirow[t]{2}{*}{ 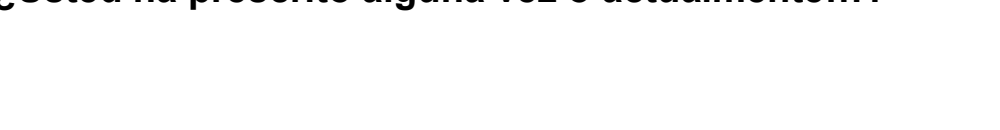 } & \multicolumn{2}{|c|}{ Alguna vez } & \multicolumn{2}{|c|}{ Actualmente } \\
\hline & & SI & NO & SI & NO \\
\hline i) & $\begin{array}{l}\text { ¿Tratamiento farmacológico para el control del peso en alguno de sus } \\
\text { pacientes? }\end{array}$ & $\square$ & $\square$ & $\square$ & $\square$ \\
\hline j) & $\begin{array}{l}\text { Referido a alguno de sus pacientes a tratamiento quirúrgico para la } \\
\text { obesidad }\end{array}$ & $\square$ & $\square$ & $\square$ & $\square$ \\
\hline k) & Tratamiento farmacológico para dejar de fumar & $\square$ & $\square$ & $\square$ & $\square$ \\
\hline l) & $\begin{array}{l}\text { Referido a alguno de sus pacientes a tratamiento } \\
\text { psiquiátricos/psicológico para dejar de fumar }\end{array}$ & $\square$ & $\bar{\square}$ & $\square$ & $\square$ \\
\hline
\end{tabular}

4.10 Cuando usted trata un paciente con alguna de las siguientes condiciones, usted pregunta por dieta/nutrición, actividad física o control del peso (por favor marque todas las que apliquen)

\begin{tabular}{|l|c|c|c|c|c|}
\hline & $\begin{array}{c}\text { No trato } \\
\text { estas } \\
\text { condiciones }\end{array}$ & Dieta & $\begin{array}{c}\text { Actividad } \\
\text { física }\end{array}$ & $\begin{array}{c}\text { Control } \\
\text { del } \\
\text { peso }\end{array}$ & Tabaquismo \\
\hline
\end{tabular}




\begin{tabular}{|c|c|c|c|c|c|c|}
\hline a) & $\begin{array}{l}\text { Peso inadecuado/ IMC } \\
\text { inadecuado }\end{array}$ & $\square$ & $\square$ & $\square$ & $\square$ & $\square$ \\
\hline b) & $\begin{array}{l}\text { Perfil lipídico anormal/ } \\
\text { Dislipidemias }\end{array}$ & $\square$ & $\square$ & $\square$ & $\square$ & $\square$ \\
\hline c) & Hipertensión & $\square$ & $\square$ & $\square$ & $\square$ & $\square$ \\
\hline d) & $\begin{array}{l}\text { Desordenes de la alimentación } \\
\text { como bulimia o anorexia }\end{array}$ & $\square$ & $\square$ & $\square$ & $\square$ & $\square$ \\
\hline e) & Asma & $\square$ & $\square$ & $\square$ & $\square$ & $\square$ \\
\hline f) & Diabetes Mellitus (Tipo II) & $\square$ & $\square$ & $\square$ & $\square$ & $\square$ \\
\hline g) & Enfermedad coronaria & $\square$ & $\square$ & $\square$ & $\square$ & $\square$ \\
\hline h) & Cáncer & $\square$ & $\square$ & $\square$ & $\square$ & $\square$ \\
\hline i) & Artritis & $\square$ & $\square$ & $\square$ & $\square$ & $\square$ \\
\hline j) & Apnea del sueño & $\square$ & $\square$ & $\square$ & $\square$ & $\square$ \\
\hline k) & Enfermedad obstructiva crónica & $\square$ & $\square$ & $\square$ & $\square$ & $\square$ \\
\hline l) & Problemas de espalda & $\square$ & $\square$ & $\square$ & $\square$ & $\square$ \\
\hline m) & $\begin{array}{l}\text { Historia familiar de Diabetes } \\
\text { mellitus }\end{array}$ & $\square$ & $\square$ & $\square$ & $\square$ & $\square$ \\
\hline n) & Historia familiar de infarto & $\square$ & $\square$ & $\square$ & $\square$ & $\square$ \\
\hline o) & Historia familiar de cáncer & $\square$ & $\square$ & $\square$ & $\square$ & $\square$ \\
\hline p) & Otro, por favor especificar: & $\square$ & $\square$ & $\square$ & $\square$ & $\square$ \\
\hline
\end{tabular}

\section{SECCIÓN 5: BARRERAS PARA LA EVALUACIÓN Y MANEJO DEL PACIENTE}

5.1 Por favor califique las siguientes afirmaciones en barreras para evaluar y/o manejar la dieta/nutrición, actividad física, peso y tabaquismo de los pacientes en su práctica clínica:

\begin{tabular}{|c|c|c|c|c|}
\hline & $\begin{array}{c}\text { Barrera } \\
\text { importante }\end{array}$ & $\begin{array}{c}\text { Barrera } \\
\text { moderada }\end{array}$ & $\begin{array}{c}\text { Barrera } \\
\text { menor }\end{array}$ & $\begin{array}{c}\text { No es } \\
\text { una } \\
\text { barrera }\end{array}$ \\
\hline h) No tengo suficiente tiempo & $\square$ & $\square$ & $\square$ & $\square$ \\
\hline i) No es parte de mi trabajo & $\square$ & $\square$ & $\square$ & $\square$ \\
\hline j) No estoy lo suficientemente entrenado en esta área & $\square$ & $\square$ & $\square$ & $\square$ \\
\hline k) Es muy difícil evaluar y manejar estos temas & $\square$ & $\square$ & $\square$ & $\square$ \\
\hline I) No hay un adecuado pago por este tipo de actividades & $\square$ & $\square$ & $\square$ & $\square$ \\
\hline
\end{tabular}




\begin{tabular}{|c|c|c|c|c|}
\hline $\begin{array}{l}\text { m) Falta de sistemas adecuados de referencia para estos } \\
\text { temas }\end{array}$ & $\square$ & $\square$ & $\square$ & $\square$ \\
\hline $\begin{array}{l}\text { n) Los pacientes no están interesaos en mejorar sus } \\
\text { hábitos }\end{array}$ & $\square$ & $\square$ & $\square$ & $\square$ \\
\hline o) Temor de ofender a un paciente & $\square$ & $\square$ & $\square$ & $\square$ \\
\hline p) Es muy difícil para los pacientes cambiar sus hábitos & $\square$ & $\square$ & $\square$ & $\square$ \\
\hline $\begin{array}{l}\text { q) Falta de herramientas adecuadas y de información } \\
\text { para darle a los pacientes }\end{array}$ & $\square$ & $\square$ & $\square$ & $\square$ \\
\hline Falta de opciones de tratamiento efectivas & $\square$ & $\square$ & $\square$ & $\square$ \\
\hline especificar & $\square$ & $\square$ & $\square$ & $\square$ \\
\hline
\end{tabular}

\section{SECCIÓN 6: HÁBITOS DE SALUD}

En esta sección Usted encontrará unas preguntas que harán referencia a hábitos como tabaquismo, actividad física y nutrición. Conteste cada pregunta tal como se le indica. Por favor conteste lo que le parezca más correcto.

\section{1 ¿Usualmente cuantas horas duerme por la noche?}

\begin{tabular}{|l|l|l|l|l|l|l|l|l|l|l|l|}
1 & 2 & 3 & 4 & 5 & 6 & 7 & 8 & 9 & 10 & 11 & 12 \\
\hline
\end{tabular}

\subsection{Durante los últimos 12 meses:}

a) ¿Por 2 semanas o más, alguna vez usted perdió el interés en la mayoría de las cosas como los hobbies, el trabajo u otras actividades? $1 \square$ SI $2 \square \mathrm{NO}$

b) ¿Por 2 semanas o más, alguna vez usted se sintió triste, apagado o deprimido? 1 $\square$ SI $2 \square \mathrm{NO}$

Si respondió que NO a las 2 preguntas anteriores pase a la pregunta 6.3

c) ¿Durante esas dos semanas o más, usted pensó mucho acerca de la muerte - la de usted mismo, la de alguien más o en la muerte en general? $1 \square \mathrm{SI} 2 \square \mathrm{NO}$

6.3 ¿Ha fumado usted al menos 100 cigarrillos en su vida? (Marque con una $x$ ) (Nota: 5 paquetes $=100$ cigarrillos)

$1 \square \mathrm{Si}$

$2 \square$ No

$14 \square$ No responde 
6.4 ¿Actualmente, fuma usted cigarrillos todos los días, algunos días o no fuma? (Marque con una $\mathrm{x}$ )

$1 \square$ Todos los días

$2 \square$ Algunos días

$3 \square \quad$ No fumo

$14 \square$ No responde

6.5 ¿Cuándo usted dejo de fumar?

$1 \square$ Hace $<$ de 1 año

$2 \square$ De 1 a 2 años atrás

$3 \square$ De 3 a 5 años atrás

$4 \square$ Hace más de 5 años

6.6 ¿En promedio, en el último mes en los días en que fumó, cuántos cigarrillos se fumó al día?

\begin{tabular}{|l|l|l|l|l|l|l|l|l|l|l|l|}
\hline 1 & 2 & 3 & 4 & 5 & 6 & 7 & 8 & 9 & 10 & 11 & $12+$ \\
\hline
\end{tabular}

Para las siguientes cuatro preguntas, tenga en cuenta únicamente los últimos

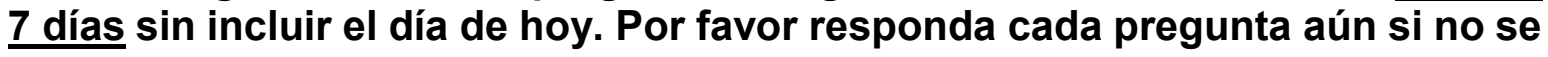
considera una persona activa. Piense en las actividades que realiza cuando se moviliza de un sitio a otro (a pie o en bicicleta), en su tiempo libre (ejercicio, deporte o recreación) o durante su trabajo:

Piense acerca de todas las actividades VIGOROSAS que realizó en los últimos 7 días. Actividades VIGOROSAS son las que requieren un esfuerzo físico FUERTE, le hacen respirar y latir el corazón mucho más fuerte de lo normal y pueden incluir: aeróbicos, jugar fútbol, pedalear rápido en bicicleta, trotar o correr vigorosamente, jugar baloncesto, entre otros. No incluya caminar. Solo cuente las actividades que usted hizo por lo menos 10 minutos continuos.

6.7 Durante los últimos 7 días sin incluir el día de hoy. ¿Cuántos días usted realizó actividades físicas VIGOROSAS?

Días por semana [Rango 0-7] Favor escribir únicamente números enteros 
6.8 Usualmente ¿Cuánto tiempo dedica usted en uno de esos días haciendo actividades físicas VIGOROSAS?

Minutos por día [Rango 0-960] Favor escribir únicamente números enteros

Piense acerca de todas las actividades MODERADAS que realizó en los últimos 7 días. Actividades MODERADAS son las que requieren un esfuerzo físico MODERADO, le hacen respirar algo más fuerte de lo normal y pueden incluir: bailar (no ritmos muy suaves), pedaleo regular, trotar suave, entre otros. No incluya caminar. Solo cuente las actividades que usted hizo por lo menos 10 minutos continuos.

6.9 Durante los últimos 7 días sin incluir el día de hoy. ¿Cuántos días usted realizó actividades físicas MODERADAS?

Días por semana [Rango 0-7] Favor escribir únicamente números enteros

6.10 Usualmente ¿Cuánto tiempo dedica usted en uno de esos días haciendo actividades físicas MODERADAS? Minutos por día [Rango 0-960] Favor escribir únicamente números enteros

Ahora piense en las actividades destinadas exclusivamente para el FORTALECIMIENTO muscular, tales como levantar pesas o hacer otros ejercicios para mantener la fuerza muscular. Por favor incluya todo este tipo de actividades sin importar si las ha incluido antes.

6.11 Durante los últimos 7 días sin incluir el día de hoy. ¿Cuántos días usted realizó actividades de FORTALECIMIENTO muscular?

Días por semana [Rango 0-7] Favor escribir únicamente números enteros

6.12 Usualmente ¿Cuánto tiempo dedica usted en uno de esos días haciendo actividades físicas MODERADAS?

Minutos por día [Rango 0-960] Favor escribir únicamente números enteros

6.13 Durante los últimos 7 días sin incluir el día de hoy, en promedio ¿Cuánto tiempo dedico a VER TELEVISIÓN?

Horas por día [Rango 0-12] Favor escribir únicamente números enteros

6.14 Para las siguientes dos preguntas, por favor marque con una $(x)$ el número de porciones que consume al día/semana. Para aquellos alimentos que nunca consume marque una $(x)$ en el 0 . Si usted consume menos de 1 porción al día, reporte el número de porciones por semana.

a. ¿En promedio, cuántas porciones de fruta consume al día o a la semana? 


\begin{tabular}{|c|c|c|c|c|c|c|c|c|}
\hline \multicolumn{7}{|c|}{ Número de porciones: } & \multicolumn{4}{|c|}{ Cada: } \\
\hline 0 & 1 & 2 & 3 & 4 & 5 & $6+$ & Día & Semana \\
\hline & & & & & & & & \\
\hline
\end{tabular}

Ejemplos equivalentes a 1 porción de fruta son:

- Medio pocillo de jugo $100 \%$ de frutas o vegetales

- Una fruta mediana (ej. manzana, naranja, banano)

- $1 / 2$ taza de fruta cortada, $1 / 4$ taza de fruta seca

b. ¿En promedio, cuántas porciones de verduras o vegetales consume al día o a la semana?

\begin{tabular}{|c|c|c|c|c|c|c|c|c|}
\hline \multicolumn{7}{|c|}{ Número de porciones: } & \multicolumn{2}{|c|}{ Cada: } \\
\hline 0 & 1 & 2 & 3 & 4 & 5 & $6+$ & Día & Semana \\
\hline & & & & & & & & \\
\hline & & & & & & & & \\
\hline
\end{tabular}

Ejemplos equivalentes a 1 porción de vegetales son:

- $1 / 2$ taza de arvejas o fríjoles cocidos o enlatados

- $1 / 2$ taza de vegetales crudos o cocidos

- 1 taza de vegetales de hoja (lechuga, repollo, espinaca)

\begin{tabular}{|c|c|c|c|c|c|c|c|c|c|c|c|}
\hline & \multicolumn{6}{c|}{ Número de porciones } & \multicolumn{3}{c|}{ Cada } \\
\cline { 3 - 10 } & $\mathbf{0}$ & $\mathbf{1}$ & $\mathbf{2}$ & $\mathbf{3}$ & $\mathbf{4}$ & $\mathbf{5}$ & $\mathbf{6}$ & DIA & SEMANA & MES \\
\hline C. & & & & & & & & & & \\
\hline $\begin{array}{l}\text { Gaseosas no Light (1 lata de 12 oz., 1 vaso } \\
\text { de 12 oz. (360 ml) 0 1 botella 350 ml } \\
\text { (retornable) }\end{array}$ & & & & & & & & & & \\
\hline $\begin{array}{l}\text { 1 paquete (papas fritas, platanitos, arepitas } \\
\text { entre otros) }\end{array}$ & & & & & & & & & & \\
\hline
\end{tabular}




\begin{tabular}{|c|c|c|c|c|c|c|c|c|c|c|}
\hline $\begin{array}{l}\text { Comidas rápidas (hamburguesa, pizza, perro } \\
\text { caliente, empanadas) }\end{array}$ & & & & & & & & & & \\
\hline d. & & & & & & & & & & \\
\hline Cafeína (1 soda, 1 taza de café, etc) & & & & & & & & & \\
\hline Multi vitaminas/suplementos minerales & & & & & & & & & & \\
\hline Suplementos de calcio & & & & & & & & & & \\
\hline
\end{tabular}

6.15 ¿Cuál de las siguientes afirmaciones describe mejor su situación actual? (Marque con una $x$ )

$1 \square$ Sí fumo y NO TENGO INTENCIÓN de dejar de fumar en los próximos 6 meses

$2 \square$ Sí fumo, PERO ESTOY CONSIDERANDO SERIAMENTE dejar de fumar en los próximos 6 meses

$3 \square$ Sí fumo, pero HE DECIDIDO DEJAR DE FUMAR en los próximos 30 días

$4 \quad \square$ Soy un ex fumador. Dejé de fumar hace MENOS DE 6 MESES

$5 \square$ Soy un ex fumador. Dejé de fumar hace MAS DE 6 MESES

$6 \square$ Nunca he fumado

$14 \square$ No responde

6.16 En relación con la cantidad de ACTIVIDAD FíSICA que ha realizado en su vida. ¿Cómo se clasificaría Usted? (Marque con una $x$ )

$1 \square$ He llevado una vida sedentaria

$2 \square$ Algunas veces camino, pero más bien poco

$3 \square$ He realizado ejercicio, aunque no con regularidad

$4 \square$ Practico ejercicio moderado regularmente

$5 \square$ Hago ejercicio vigoroso con frecuencia $\quad 14 \square$ No responde

6.17 En la actualidad considero que: (Marque con una $x$ )

$1 \square$ NO realizo NI TENGO LA INTENCIÓN de realizar actividad física 
$2 \square$ NO realizo, pero TENGO LA INTENCIÓN de realizar actividad física en los próximos 6 meses.

$3 \square$ NO realizo pero tengo la intención de realizar actividad física en los próximos 30 días.

$4 \square$ Realizo actividad física DE MANERA REGULAR desde hace MENOS DE UN MES

$5 \square$ Realizo actividad física DE MANERA REGULAR desde hace MÁS DE 6 MESES

$6 \square$ Realizo actividad FÍSICA REGULAR y estoy convencido de no abandonarla

$14 \square$ No responde

\subsection{En la actualidad considero que:}

$1 \square$ Como MENOS DE 5 porciones de frutas o verduras al día y NO TENGO LA INTENCIÓN de comer más en los próximos 6 meses

$2 \square$ Como MENOS DE 5 porciones de frutas o verduras al día y HE ESTADO PENSANDO en comer más en los próximos 6 meses

$3 \square$ ESTOY TRATANDO de comer 5 porciones de frutas o verdura al día, pero NO lo hago de manera CONSTANTE

$4 \square$ COMO 5 porciones de frutas o verdura al día de manera CONSTANTE

$14 \square$ No responde

\subsection{En la actualidad considero que:}

a) Estoy subiendo de peso o ya estoy pasado de peso y NO INTENTO reducir mi consumo de calorías de manera constante durante los próximos 6 meses.

b) Estoy subiendo de peso o ya estoy pasado de peso y HE ESTADO PENSANDO en reducir mi consumo de calorías de manera constante los próximos 6 meses.

c) Estoy subiendo de peso o ya estoy pasado de peso y ESTOY HACIENDO UN GRAN ESFUERZO para reducir mi consumo de calorías, pero NO lo puedo hacer de manera CONSTANTE

d) No estoy pasado de peso y no he subido de peso.

\section{SECCIÓN 7: ANTECEDENTES}

Esta sección consta de 5 preguntas referentes a antecedentes familiares y personales de patologías. Conteste cada pregunta tal como se le indica. Si no está seguro/a de cómo responder a una pregunta, por favor conteste lo que le parezca más correcto. 
7.1 Marque con una $(x)$ si sus padres y/o hermanos, tienen o han tenido alguna de las siguientes enfermedades antes de los 55 años en hombres y antes de los 65 años en mujeres:

Asegúrese de marcar en la casilla "ninguno" si nadie ha sufrido de estas condiciones.

\begin{tabular}{|r|r|l|l|}
\hline & $\begin{array}{c}\text { Padre y/o hermanos hombres } \\
\text { menores de 55 años }\end{array}$ & $\begin{array}{c}\text { Madre y/o hermanas mujeres } \\
\text { menores de } 65 \text { años }\end{array}$ & Ninguno \\
\hline $\begin{array}{r}\text { Infarto agudo de } \\
\text { miocardio }\end{array}$ & & & \\
\hline Muerte súbita & & & \\
\hline
\end{tabular}

No sabe

7.2 Marque con una $(x)$ si Usted, tiene o ha tenido alguna de las siguientes enfermedades:

Asegúrese de marcar en la casilla "No" si no ha sufrido de estas condiciones.

\begin{tabular}{|c|c|c|}
\hline & & \\
\hline & $\mathrm{Si}$ & No \\
\hline Diabetes mellitus & & \\
\hline Infarto agudo de miocardio & & \\
\hline Angina estable/inestable & & \\
\hline Accidente cerebrovascular & & \\
\hline Aneurisma de aorta abdominal & & \\
\hline Enfermedad arterial periférica & & \\
\hline Aterosclerosis carotídea & & \\
\hline
\end{tabular}

$14 \square$ No responde

\section{3 ¿Toma actualmente algún medicamento para controlar la diabetes?}
$1 \square$ Sí
$2 \square$ No
$14 \square$ No responde

7.4 ¿Toma actualmente algún medicamento para controlar la presión arterial alta?
$1 \square$ Sí
$2 \square$ No
$14 \square$ No responde 


\section{5 ¿Toma actualmente algún medicamento para controlar el colesterol elevado?}

$1 \square$ Sí

$2 \square$ No

$14 \square$ No responde

\section{SECCIÓN 8: CREENCIAS PERSONALES Y CONOCIMIENTOS}

8.1 Por favor indicar con su elección el grado de acuerdo o desacuerdo con los siguientes enunciados:

\begin{tabular}{|c|c|c|c|c|c|c|}
\hline & & $\begin{array}{l}\text { Fuertemente } \\
\text { en } \\
\text { desacuerdo }\end{array}$ & $\begin{array}{c}\text { En } \\
\text { desacuerd } \\
\text { o }\end{array}$ & $\begin{array}{c}\text { Ni de } \\
\text { acuerdo ni } \\
\text { en } \\
\text { desacuerdo }\end{array}$ & $\begin{array}{c}\text { De } \\
\text { acuerdo }\end{array}$ & $\begin{array}{c}\text { Fuertemente } \\
\text { de acuerdo }\end{array}$ \\
\hline & $\begin{array}{l}\text { Con el fin de promover } \\
\text { efectivamente la } \\
\text { adherencia del paciente a } \\
\text { un estilo de vida saludable, } \\
\text { el médico debe tener } \\
\text { también un estilo de vida } \\
\text { saludable. }\end{array}$ & $\square$ & $\square$ & $\square$ & $\square$ & $\square$ \\
\hline u) & $\begin{array}{l}\text { Tendré la capacidad de } \\
\text { aconsejar a mis pacientes } \\
\text { de una forma más } \\
\text { coherente y efectiva si yo: } \\
\text { a. Tengo una dieta } \\
\text { saludable }\end{array}$ & $\square$ & $\square$ & $\square$ & $\square$ & $\square$ \\
\hline & $\begin{array}{l}\text { b. Mantengo un } \\
\text { peso corporal } \\
\text { adecuado }\end{array}$ & $\square$ & $\square$ & $\square$ & $\square$ & $\square$ \\
\hline & $\begin{array}{l}\text { C. Realizo ejercicio y } \\
\text { estoy en buenas } \\
\text { condiciones } \\
\text { físicas }\end{array}$ & $\square$ & $\square$ & $\square$ & $\square$ & $\square$ \\
\hline & d. No fumo & $\square$ & $\square$ & $\square$ & $\square$ & $\square$ \\
\hline & $\begin{array}{l}\text { Los pacientes tienen una } \\
\text { mayor probabilidad de } \\
\text { adoptar estilos de vida } \\
\text { saludable si sus médicos } \\
\text { les aconsejan hacerlo. }\end{array}$ & $\square$ & $\square$ & $\square$ & $\square$ & $\square$ \\
\hline w) & $\begin{array}{l}\text { Los médicos tienen la } \\
\text { responsabilidad de lograr } \\
\text { que los individuos adopten } \\
\text { estilos de vida saludables }\end{array}$ & $\square$ & $\square$ & $\square$ & $\square$ & $\square$ \\
\hline $\mathrm{x})$ & $\begin{array}{l}\text { Existen estrategias y/o } \\
\text { herramientas efectivas } \\
\text { para ayudar a los } \\
\text { pacientes a: } \\
\begin{array}{l}\text { a. Alimentarse con } \\
\text { una } \\
\quad \text { adecuada dieta }\end{array} \\
\end{array}$ & $\square$ & $\square$ & $\square$ & $\square$ & $\square$ \\
\hline
\end{tabular}




\begin{tabular}{|c|c|c|c|c|c|}
\hline $\begin{array}{ll}\text { b. } & \begin{array}{l}\text { Ser físicamente } \\
\text { activos }\end{array}\end{array}$ & $\square$ & $\square$ & $\square$ & $\square$ & $\square$ \\
\hline $\begin{array}{ll}\text { c. } & \text { Mantener un peso } \\
\text { adecuado } & \text { o } \\
\text { perder peso }\end{array}$ & $\square$ & $\square$ & $\square$ & $\square$ & $\square$ \\
\hline d. Dejar de fumar & $\square$ & $\square$ & $\square$ & $\square$ & $\square$ \\
\hline $\begin{array}{l}\text { y) Tengo confianza en mi } \\
\text { habilidad para aconsejar a } \\
\text { mis pacientes con el fin de: } \\
\text { a. Mantener una } \\
\text { dieta adecuada }\end{array}$ & $\square$ & $\square$ & $\square$ & $\square$ & $\square$ \\
\hline $\begin{array}{l}\text { b. Ser físicamente } \\
\text { activos }\end{array}$ & $\square$ & $\square$ & $\square$ & $\square$ & $\square$ \\
\hline $\begin{array}{l}\text { c. Mantener un peso } \\
\text { adecuado }\end{array}$ & $\square$ & $\square$ & $\square$ & $\square$ & $\square$ \\
\hline d. Tabaquismo & $\square$ & $\square$ & $\square$ & $\square$ & $\square$ \\
\hline $\begin{array}{l}\text { z) Soy efectivo en ayudar a } \\
\text { mis pacientes a: } \\
\text { a. Mantener una } \\
\text { dieta adecuada }\end{array}$ & $\square$ & $\square$ & $\square$ & $\square$ & $\square$ \\
\hline $\begin{array}{l}\text { b. Ser físicamente } \\
\text { activos }\end{array}$ & $\square$ & $\square$ & $\square$ & $\square$ & $\square$ \\
\hline $\begin{array}{l}\text { c. Mantener un peso } \\
\text { adecuado }\end{array}$ & $\square$ & $\square$ & $\square$ & $\square$ & $\square$ \\
\hline $\begin{array}{l}\text { d. La cesación del } \\
\text { Tabaquismo }\end{array}$ & $\square$ & $\square$ & $\square$ & $\square$ & $\square$ \\
\hline $\begin{array}{l}\text { aa) Doctores necesitan más } \\
\text { entrenamiento } \\
\text { bb) en prevención }\end{array}$ & $\square$ & $\square$ & $\square$ & $\square$ & $\square$ \\
\hline $\begin{array}{l}\text { cc) La prevención es menos } \\
\text { interesante } \\
\text { tratamiento }\end{array}$ & $\square$ & $\square$ & $\square$ & $\square$ & $\square$ \\
\hline $\begin{array}{llr}\text { dd) } \begin{array}{l}\text { Pacientes } \\
\text { interesados } \\
\text { prevención }\end{array} & \text { en } & \text { la } \\
\end{array}$ & $\square$ & $\square$ & $\square$ & $\square$ & $\square$ \\
\hline $\begin{array}{l}\text { ee) Acceso al sistema de salud } \\
\text { básico es un derecho } \\
\text { humano fundamental }\end{array}$ & $\square$ & $\square$ & $\square$ & $\square$ & $\square$ \\
\hline $\begin{array}{l}\text { ff) Tengo el tiempo adecuado } \\
\text { para dedicar a mi paciente } \\
\text { durante la consulta }\end{array}$ & $\square$ & $\square$ & $\square$ & $\square$ & $\square$ \\
\hline $\begin{array}{l}\text { gg) Tengo la libertar de tomar } \\
\text { las decisiones para cumplir } \\
\text { las necesidades de mis } \\
\text { pacientes }\end{array}$ & $\square$ & $\square$ & $\square$ & $\square$ & $\square$ \\
\hline $\begin{array}{l}\text { hh) Es posible brindarles } \\
\text { atención de alta calidad a } \\
\text { todos mis pacientes }\end{array}$ & $\square$ & $\square$ & $\square$ & $\square$ & $\square$ \\
\hline
\end{tabular}

\section{CONOCIMIENTOS MÍNIMOS}

Seleccione la respuesta correcta, si no está seguro marque la opción NO SE: Evite adivinar. 


\section{Nutrición}

8.2 El consumo diario de porciones de frutas y verduras que se debe recomendar a un adulto que consuma es:
a) Mínimo 1 frutas y/o verduras
b) Mínimo 2 frutas y/o verduras
c) Mínimo 3 frutas y o verduras
d) Mínimo 4 frutas y/o verduras
e) Mínimo 5 frutas y/o verduras
f) Mínimo 6 frutas y/o verduras
g) No sé

\subsection{Los tipos de grasas que se deben reducir en la dieta son:}
a) Ácidos grasos monoinsaturados, Ácidos grasos saturados, Colesterol
b) Ácidos grasos saturados, Ácidos Grasos trans, Colesterol
c) Ácidos grasos monoinsaturados, Ácidos Grasos cis, colesterol
d) Ácidos grasos saturados, Ácidos grasos poliinsaturados, Ácidos Grasos trans
e) No sé

8.4 El requerimiento calórico diario para un varón sedentario de $\mathbf{7 0} \mathbf{k g}$ (que realice mínima actividad física) es:
a) $20 \mathrm{Kcal} / \mathrm{kg} / \mathrm{día}(1400 \mathrm{Kcal} / \mathrm{día})$
b) $25 \mathrm{Kcal} / \mathrm{kg} / \mathrm{día}(1750 \mathrm{Kcal} / \mathrm{día})$
c) $30 \mathrm{Kcal} / \mathrm{kg} / \mathrm{día}(2100 \mathrm{Kcal} / \mathrm{día})$
d) $35 \mathrm{Kcal} / \mathrm{kg} / \mathrm{día}(2450 \mathrm{Kcal} / \mathrm{día})$
e) $40 \mathrm{Kcal} / \mathrm{kg} / \mathrm{día}(2800 \mathrm{Kcal} / \mathrm{día})$
f) No sé

8.5 El requerimiento calórico diario para una mujer sedentaria de $60 \mathrm{~kg}$ (que realice mínima actividad física) es:
a) $20 \mathrm{Kcal} / \mathrm{kg} / \mathrm{día}(1200 \mathrm{Kcal} / \mathrm{día})$
a) $25 \mathrm{Kcal} / \mathrm{kg} / \mathrm{día}(1500 \mathrm{Kcal} / \mathrm{día})$
b) $30 \mathrm{Kcal} / \mathrm{kg} / \mathrm{día}(1800 \mathrm{Kcal} / \mathrm{día})$
c) $35 \mathrm{Kcal} / \mathrm{kg} / \mathrm{día}(2100 \mathrm{Kcal} / \mathrm{día})$
d) $40 \mathrm{Kcal} / \mathrm{kg} / \mathrm{día}(2400 \mathrm{Kcal} / \mathrm{día})$
e) No sé

8.6 El perímetro abdominal (cintura) recomendado en latino América para mantener un riesgo bajo de enfermedad cardiovascular y diabetes tipo 2 es:

a) $<120 \mathrm{~cm}$ para hombres y de $<110 \mathrm{~cm}$ para mujeres 
b) $<110 \mathrm{~cm}$ para hombres y de $<100 \mathrm{~cm}$ para mujeres

c) $<100 \mathrm{~cm}$ para hombres $\mathrm{y}<$ de $90 \mathrm{~cm}$ para mujeres

d) $<90 \mathrm{~cm}$ para hombres y $<80 \mathrm{~cm}$ para mujeres

e) $<85 \mathrm{~cm}$ para hombres y $<75 \mathrm{~cm}$ para mujeres

f) No sé

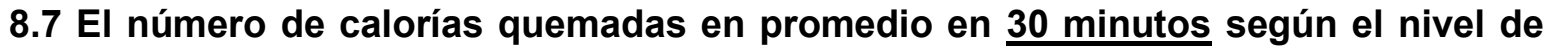
actividad física:

a) Leve ( $\leq 100 \mathrm{Kcal})$, Moderada (100-200 Kcal), vigorosa $(>200)$

b) Leve (<200 Kcal), Moderada (200-300 Kcal), vigorosa $(>300)$

c) Leve $(\leq 300 \mathrm{Kcal})$, Moderada $(300-400 \mathrm{Kcal})$, vigorosa $(>400)$

d) Leve $(\leq 400 \mathrm{Kcal})$, Moderada $(400-500 \mathrm{Kcal})$, vigorosa $(>600)$

e) No sé

8.8 ¿Cómo se define sobrepeso y obesidad en adultos, según el IMC (índice de masa corporal)?
a) Un IMC >20 (sobrepeso) y $>25$ (obesidad)
b) Un IMC >25 (sobrepeso) y > 35 (obesidad)
c) Un IMC > 18.5 (sobrepeso) y > 25 (obesidad)
d) Un IMC >25 (sobrepeso) y > 30 (obesidad)
e) No sé

8.9 De acuerdo con las guías actuales, en qué rango de percentiles del IMC se considera el peso de un niño o adolescente como adecuado/sano:
a) Del percentil 5 al 65
b) Del percentil 5 al 75
c) Del percentil 5 al 85
d) Del percentil 5 al 95
e) No sé

\section{Actividad Física}

8.10 Basado en las recomendaciones actuales de salud pública: ¿Con qué frecuencia semanal se debe realizar actividad física?
a) Mínimo 7 días por semana
b) Mínimo 6 días por semana
c) Mínimo 5 días por semana
d) Mínimo 4 días por semana
e) Mínimo 3 días por semana
f) Mínimo 2 días por semana
g) Mínimo 1 días por semana
h) No sé 
8.11 Basado en las recomendaciones actuales de salud pública: ¿cuál es la intensidad recomendada para realizar actividad física en un adulto?
a) Intensidad suave o leve
b) Intensidad moderada o intermedia
c) Intensidad vigorosa o fuerte
d) No sé

8.12 Basado en las recomendaciones actuales de salud pública: ¿cuánto tiempo al día se recomienda de actividad física para los adultos en general?
a) Mínimo 5 minutos al día
b) Mínimo 10 minutos al día
c) Mínimo 15 minutos al día
d) Mínimo 20 minutos al día
e) Mínimo 30 minutos al día
f) Mínimo 45 minutos al día
g) Mínimo 1 hora al día
h) No sé

8.13 ¿Cómo se calcula la frecuencia cardiaca máxima de un adulto que no está en embarazo?
a) 160 - edad
b) 180 - edad
c) 200 - edad
d) 220 - edad
e) No sé

\section{Tabaquismo}

8.14 Conteste falso (F) o verdadero (V). El cigarrillo es una causa contributoria importante en la patogénesis de las siguientes enfermedades.
a) Cáncer de vejiga
b) Bronquitis crónica
c) Cáncer de piel
d) Cáncer de la cavidad oral
e) Enfermedad de Alzheimer
f) Enfisema pulmonar 
g) Enfermedad coronaria

h) Cáncer de laringe

8.15 Para que una persona que deja de fumar alcance la cifra de mortalidad de los no fumadores se requiere:
a) 1-5 años
b) $5-10$ años
c) $20-30$ años
d) Tiempo proporcional al que fumo
e) No sé

8.16 ¿Qué porcentaje se aproxima más a la prevalencia de tabaquismo en la población Argentina?
a) $10 \%$
b) $20 \%$
c) $30 \%$
d) $40 \%$
e) $50 \%$
f) No sé

8.17 Con respecto a los fumadores pasivos conteste si cada una de las siguientes afirmaciones es falsa o verdadera:

\begin{tabular}{|c|c|c|c|}
\hline & Verdadero & Falso & No sé \\
\hline Los niños que son fumadores pasivos tienen mayor riesgo de morir & $\mathrm{O}$ & $\mathrm{O}$ & $\mathrm{O}$ \\
\hline $\begin{array}{l}\text { Los niños que son fumadores pasivos tienen mayor riesgo de } \\
\text { desarrollar infecciones de oído }\end{array}$ & $\mathrm{O}$ & $\mathrm{O}$ & $\mathrm{O}$ \\
\hline $\begin{array}{l}\text { Los fumadores pasivos tienen } 20 \% \text { más de riesgo de sufrir cáncer de } \\
\text { pulmón que los no fumadores }\end{array}$ & $\mathrm{O}$ & $\mathrm{O}$ & $\mathrm{O}$ \\
\hline $\begin{array}{l}\text { Los fumadores pasivos tienen } 30 \% \text { más de riesgo de sufrir de } \\
\text { enfermedad cardiaca que los no fumadores }\end{array}$ & $\mathrm{O}$ & $\mathrm{O}$ & $\mathrm{O}$ \\
\hline
\end{tabular}

\section{SECCIÓN 9: DATOS DE CONTACTO}

9.1. ¿Si esta encuesta estuviera disponible en internet, usted preferiría llenarla por internet o en papel y lápiz? (seleccione una respuesta)

$1 \square$ Yo preferiría en papel y lápiz 
$2 \square$ Yo preferiría un cuestionario por la internet

$3 \square$ Yo no tengo preferencia

$4 \quad \square$ Otro (por favor especificar):

9.2 Autorizo que esta información aquí consolidada, sea usada en investigaciones de la FAMG. Si $\square$ - No $\square$

Autorizo a que me sea contactado eventualmente en un futuro $\quad$ Si $\quad \square-$ No $\square$

En caso que autorice un posible futuro contacto, indique los siguientes datos:

9.3 Nombre

9.4 Dirección de correo electrónico

9.5 Teléfono de oficina

9.6 Teléfono de residencia

9.7 Dirección de correspondencia (Por favor indique ciudad) 


\section{ANEXO No 2}

Universidad Nacional de La Plata

Facultad de Ciencias Médicas

\section{BUENAS PRÁCTICAS CLÍNICAS DE LA DECLARACIÓN DE HELSINKI.}

Recomendaciones para guiar a los médicos en la investigación biomédica en seres humanos adoptada por la Asamblea Médica Mundial, Helsinki, Finlandia, Junio 1964. Modificada por la 29a Asamblea Médica Mundial, Tokio, Japón, Octubre 1975, por la 35a Asamblea Médica Mundial, Venecia, Italia, Octubre 1983, y la 41a Asamblea Médica Mundial, Hong Kong, Septiembre de 1989.

\section{Introducción}

La misión del médico consiste en velar por la salud de la humanidad. Cumple esta misión cuando desarrolla al máximo sus conocimientos y su conciencia.

La Declaración de Ginebra de la Asociación Médica Mundial señala este deber del médico con estas palabras: "Velar solícitamente y ante todo por la salud de mi paciente". Y el Código Internacional de tica médica declara que "el médico, cuando administre cuidados profesionales que puedan debilitar la condición física o mental de su paciente, sólo lo hará para beneficio del enfermo."

El propósito de la investigación biomédica en seres humanos debe ser el mejoramiento de los procedimientos diagnósticos, terapéuticos y profilácticos y el esclarecimiento de la etiología y patogenia de la enfermedad.

En la práctica real de la Medicina, la mayor parte de los procedimientos diagnósticos, terapéuticos y profilácticos conllevan riesgos. Esto es también cierto de la investigación biomédica.

El progreso de la Medicina se basa en la investigación que, en último término, tiene que apoyarse en la experimentación sobre seres humanos. 
En el campo de la investigación biomédica debe hacerse una distinción fundamental entre aquella cuyo fin es en esencia diagnosticar y tratar al enfermo, y aquella otra que persigue un fin puramente científico y que no supone ningún beneficio directo, diagnóstico o terapéutico, para la persona sometida a esa investigación.

Debe ponerse particular cautela en la realización de investigaciones que puedan afectar al ambiente. Deberá atenderse también al bienestar de los animales usados en investigación. Ya que es esencial, para el avance de los conocimientos científicos y el alivio del sufrimiento humano, que los resultados de los experimentos de laboratorio se apliquen a los seres humanos, la Asociación Médica Mundial ha preparado las siguientes recomendaciones para guía de los médicos en sus investigaciones biomédicas en seres humanos, recomendaciones que habrán de someterse a revisiones futuras. Hay que hacer hincapié en que los criterios aquí señalados son una simple guía para los médicos de todo el mundo. Los médicos no quedan por ello descargados, ante las leyes de su propio país, de sus responsabilidades, penal, civil o ética.

\section{Principios básicos}

1. La investigación biomédica en seres humanos debe concordar con las normas científicas comúnmente aceptadas y se basará en experimentos previos, correctamente realizados en el laboratorio y sobre animales, y en un conocimiento profundo de la bibliografía científica pertinente.

2. El diseño y el método de cada procedimiento experimental sobre seres humanos deberá estar claramente formulado en un protocolo que será entregado para estudio, observaciones y consejo a un comité especialmente nombrado al efecto. Ese comité, independiente del investigador y del patrocinador de la investigación, deberá conformarse a las leyes y normas del país en el que se lleve a cabo la investigación experimental.

3. La investigación biomédica en seres humanos sólo podrá ser realizada por personas cualificadas científicamente, y bajo la supervisión de un médico responsable competente en clínica. La responsabilidad por el sujeto de experimentación recaerá siempre en un médico debidamente titulado; nunca sobre el propio sujeto de investigación, aunque éste haya otorgado su consentimiento.

4. No puede realizarse legítimamente investigación biomédica en seres humanos a menos que la importancia de sus objetivos sea proporcionada al riesgo que por ella corran los sujetos. 
5. Todo proyecto de investigación biomédica en seres humanos debe estar precedido de un cuidadoso cálculo de los riesgos previsibles y de su comparación con los beneficios que puedan derivarse para el sujeto de la investigación y para otros individuos. La preocupación por los intereses del sujeto de la investigación deberá prevalecer siempre sobre los intereses de la ciencia y de la sociedad.

6. Debe respetarse siempre el derecho del sujeto de investigación a proteger su integridad. Deberán tomarse todas las precauciones para preservar su intimidad y para reducir al mínimo el efecto del estudio sobre su integridad física y mental y sobre su personalidad.

7. Los médicos se abstendrán de participar en proyectos de investigación en seres humanos, a menos que se hayan convencido de que los riesgos inherentes son predecibles. Suspenderán cualquier investigación si encuentran que los riesgos son superiores a los beneficios calculados.

8. Al publicar los resultados de su investigación, el médico está obligado a asegurarse de la exactitud de los resultados. No deben ser aceptados para publicación los artículos de investigación que no se ciñan a los principios de esta Declaración.

9. En cualquier investigación sobre seres humanos, todo sujeto potencial debe ser informado adecuadamente de los objetivos, los métodos, los beneficios calculados y los riesgos posibles del estudio y de las incomodidades que pueda implicar. Deberá también informársele de que es libre para participar o no en el experimento y para retirar su consentimiento en cualquier momento. El médico obtendrá entonces, preferiblemente por escrito, el consentimiento informado y libremente prestado del sujeto.

10. Al obtener el consentimiento informado para el proyecto de investigación, el médico actuará con particular cautela si ocupara ante el sujeto una posición de autoridad, a fin de evitar la intervención de cualquier tipo de coacción. En tal caso, el consentimiento deberá ser obtenido por otro médico que no participe en la investigación y que sea totalmente independiente de esa relación de autoridad.

11. En caso de falta de competencia legal, el consentimiento informado se solicitará de quien sea el tutor legal de acuerdo con la legislación del país. Cuando la incapacidad física o mental haga imposible la obtención del consentimiento informado, o cuando el sujeto sea menor de edad, el permiso del familiar responsable sustituye al del sujeto, de acuerdo con la legislación del país.

Siempre que, de hecho, el menor de edad sea capaz de prestar su consentimiento, se obtendrá éste, aparte del concedido por el tutor legal del menor. 
12. El protocolo de investigación deberá contener siempre una mención de las consideraciones éticas dadas al caso e indicará que se adapta a los principios enunciados en esta Declaración.

\section{Investigación médica combinada con la atención profesional (investigación clínica)}

1. Al tratar a su paciente, el médico debe gozar de libertad para aplicar procedimientos diagnósticos y terapéuticos nuevos, si a su juicio ofrecen esperanzas de salvar la vida, restablecer la salud o aliviar el sufrimiento.

2. Los beneficios, riesgos y molestias potenciales de un método nuevo deberán evaluarse comparándolos con las ventajas de los mejores métodos diagnósticos y terapéuticos disponibles en ese momento.

3. En toda investigación médica, a todos los pacientes -incluidos los del grupo control, si lo hubiera- debe garantizárseles que recibirán los mejores métodos diagnósticos y terapéuticos disponibles.

4. La negativa de un paciente a participar en una investigación no podrá menoscabar la relación médico enfermo.

5. Si el médico considera que es esencial no obtener el consentimiento informado, deberá hacer constar en el protocolo del experimento las razones específicas de esa decisión, para que las conozca el comité independiente a que se refiere el párrafo I-2.

6. El médico podrá combinar la investigación médica con la atención profesional a fin de obtener nuevos conocimientos médicos, sólo en la medida en que la investigación médica está justificada por su valor potencial, diagnóstico o terapéutico, para el enfermo.

\section{Investigación biomédica no terapéutica en seres humanos (investigación biomédica no clínica)}

1. Cuando la investigación médica sobre sujetos humanos se aplica con finalidad puramente científica, el médico tiene la obligación de seguir siendo el protector de la vida y de la salud de la persona sobre la cual se lleva a cabo la investigación.

2. Los sujetos, ya sean individuos sanos, ya pacientes en los que el experimento no tiene relación con la enfermedad que padecen, serán siempre voluntarios.

3. El investigador o el equipo de investigación deberán suspender la experiencia si, a su juicio, en caso de continuarla, se podría provocar algún daño al sujeto. 
4. En la investigación sobre el hombre, los intereses de la ciencia y de la sociedad nunca podrán prevalecer sobre el bienestar del sujeto. 